\title{
DYNAMIC IMAGING AND MODELLING OF GOLD PASTE TAILINGS FLOWS
}

\author{
by \\ Julio Antonio Henríquez, B.Eng.
}

\begin{abstract}
A thesis submitted to the Faculty of Graduate Studies and Research in partial fulfillment of the requirements for the degree of

Masters of Applied Science
\end{abstract}

Ottawa-Carleton Institute for Environmental Engineering

\author{
Department of Civil and Environmental Engineering \\ Carleton University \\ Ottawa, Ontario \\ Canada
}

으 Julio Henríquez, May 2008 
Library and

Archives Canada

Published Heritage

Branch

395 Wellington Street

Ottawa ON K1A 0N4

Canada
Bibliothèque et

Archives Canada

Direction du

Patrimoine de l'édition

395 , rue Wellington

Ottawa ON K1A ON4

Canada

Your file Votre référence

ISBN: 978-0-494-40665-6

Our file Notre référence

ISBN: 978-0-494-40665-6

NOTICE:

The author has granted a nonexclusive license allowing Library and Archives Canada to reproduce, publish, archive, preserve, conserve, communicate to the public by telecommunication or on the Internet, loan, distribute and sell theses worldwide, for commercial or noncommercial purposes, in microform, paper, electronic and/or any other formats.

The author retains copyright ownership and moral rights in this thesis. Neither the thesis nor substantial extracts from it may be printed or otherwise reproduced without the author's permission.
AVIS:

L'auteur a accordé une licence non exclusive permettant à la Bibliothèque et Archives Canada de reproduire, publier, archiver, sauvegarder, conserver, transmettre au public par télécommunication ou par l'Internet, prêter, distribuer et vendre des thèses partout dans le monde, à des fins commerciales ou autres, sur support microforme, papier, électronique et/ou autres formats.

L'auteur conserve la propriété du droit d'auteur et des droits moraux qui protège cette thèse. $\mathrm{Ni}$ la thèse ni des extraits substantiels de celle-ci ne doivent être imprimés ou autrement reproduits sans son autorisation.
In compliance with the Canadian

Privacy Act some supporting forms may have been removed from this thesis.

While these forms may be included in the document page count, their removal does not represent any loss of content from the thesis.
Conformément à la loi canadienne sur la protection de la vie privée, quelques formulaires secondaires ont été enlevés de cette thèse.

Bien que ces formulaires aient inclus dans la pagination, il n'y aura aucun contenu manquant.

\section{Canada}


An important challenge associated with surface disposal of paste tailings is to predict the evolution of the stack geometry, as this will facilitate the management of the tailings storage facility.

This research investigates the flow and depositional behaviour of gold paste tailings at a laboratory scale. To this end, several flow tests were recorded using a high-speed camera and the visualizations of the flows were compared with steady-state and transient solutions based on lubrication theory. The yield stress and viscosity of the tailings were obtained from flow curves fitted by the Bingham model.

The predicted flow profiles showed good agreement with the experimental data. The overall angle of the deposit was found to be a function of the scale of the flow, which may explain the observed discrepancy between former laboratory studies and field results. Finally, the results revealed that the theory applied in this study has potential for field scale applications. 


\section{ACKNOWLEDGMENTS}

I would like to thank all the people that contributed to the development of this study, in special to my supervisor Dr. Paul Simms for his support and guidance along these two years.

Sincere acknowledgments are also extended to the Ontario Centre of Excellence and Golder Associates for funding this project, Barrick Gold for providing the tailings, and Golder Paste Tec for their technical support.

Finally, I would like to express sincere appreciation to my family for the constant encouragement and support. Special gratitude is extended to my brother José Henríquez and Linda Finn. 
Success doesn't come to you...

You go to it.

- Marva Collins 


\section{TABLE OF CONTENTS}

ABSTRACT iii

ACKNOWLEDGMENTS ……………………………......................................... iv

TABLE OF CONTENTS............................................................................... vi

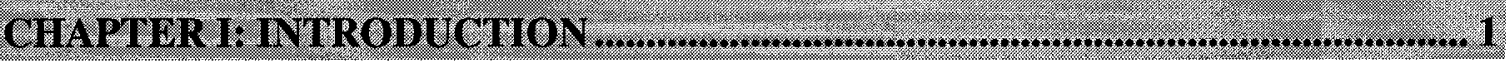

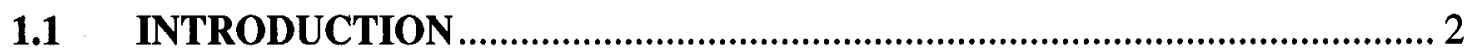

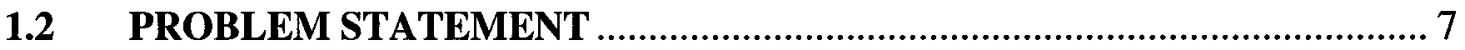

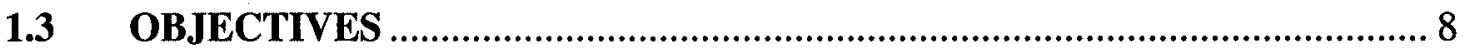

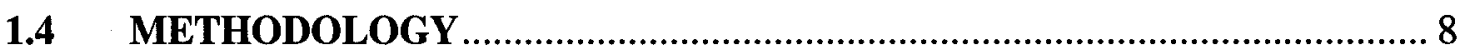

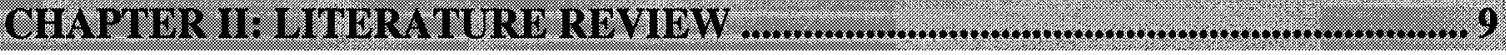

2.1 TAILINGS CHARACTERISTICS.......................................................... 10

2.2 TAILINGS STORAGE AND DISPOSAL METHODS .................................... 11

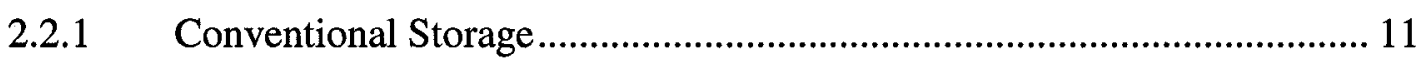

2.2.2 Conventional Mechanism of Tailings Disposal ..................................... 13

2.2.3 Paste Tailings Disposal ....................................................................... 15

2.3 GOVERNING RHEOLOGICAL PROPERTIES ......................................... 20

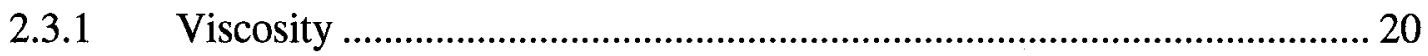

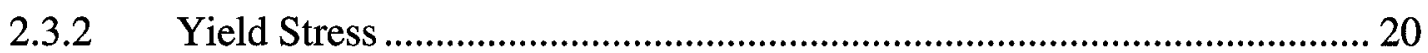

2.4 RHEOLOGICAL CLASSIFICATION ..................................................... 22

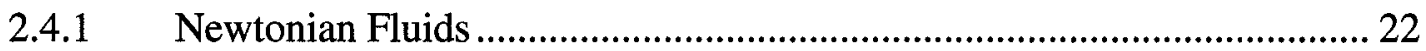

2.4.2 Non-Newtonian Fluids.................................................................. 22

2.4.2.1 Bingham Plastic Fluids ..................................................................... 23

2.4.2.2 Pseudo-plastic fluids .................................................................. 24

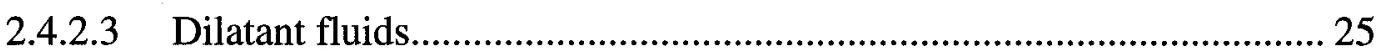

2.5 YIELD STRESS MEASUREMENT .................................................... 27

2.6 IMPORTANT FACTORS AFFECTING RHEOLOGICAL PROPERTIES 29

2.6.1 Physical properties ............................................................................ 29

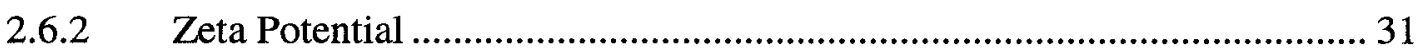

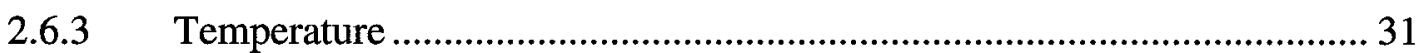

2.7 PREDICTION OF THE DEPOSITION GEOMETRY OF TAILINGS …...... 32

2.7.1 Steady state slow spreading of a thin layer of a Bingham fluid................. 34

2.7.2 Transient slow spreading of a thin layer of a Bingham fluid..................... 36 
3.1 GENERAL CHARACTERISTICS OF THE MATERIAL ......................... 38

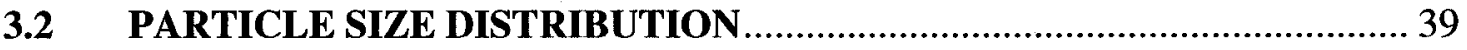

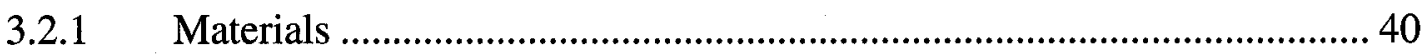

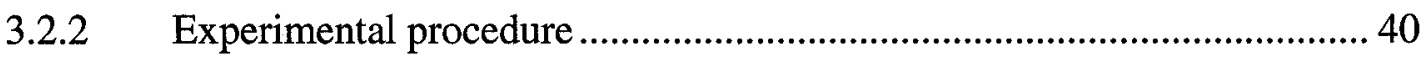

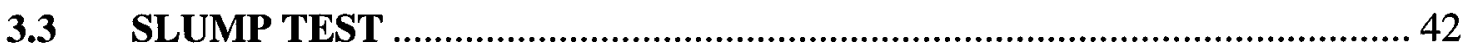

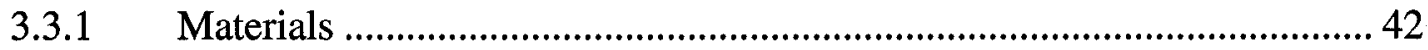

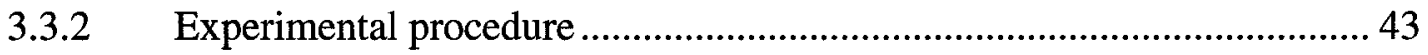

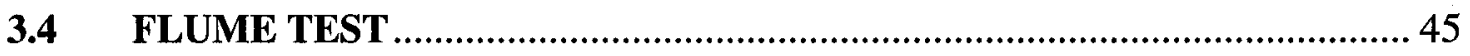

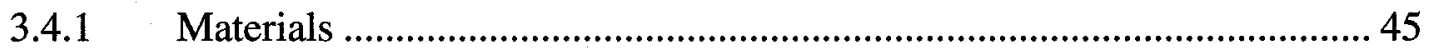

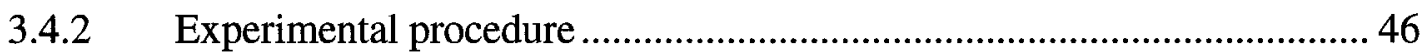

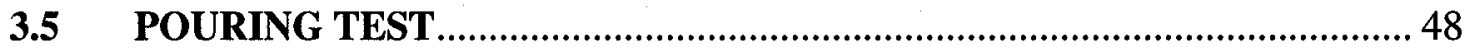

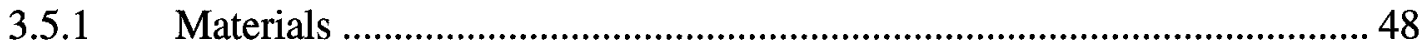

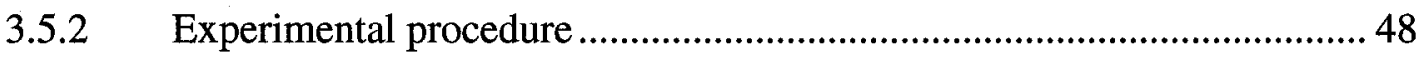

3.6 MODELLING THE SLOW SPREADING OF A BINGHAM FLUID .......... 50

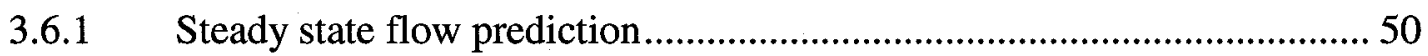

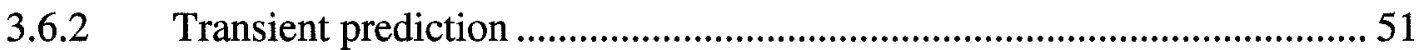

\section{CHA PIER IV: RESULTS AND DISCUSSION ........................................... 54}

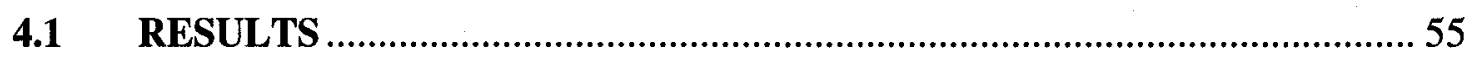

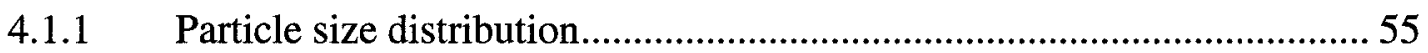

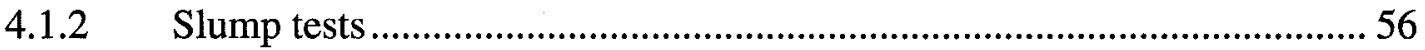

4.1.3 Rheological Characterization................................................................ 58

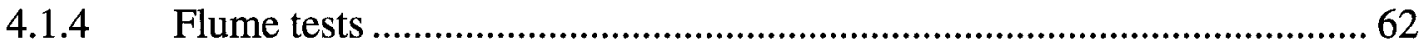

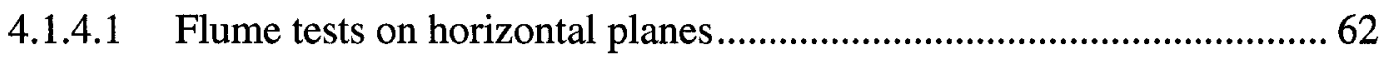

4.1.4.2 Flume tests on successive layers...................................................6. 67

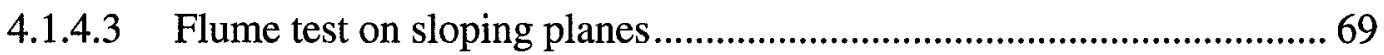

4.1.4.4 An example of a flume test recorded with the high speed camera ....... 70

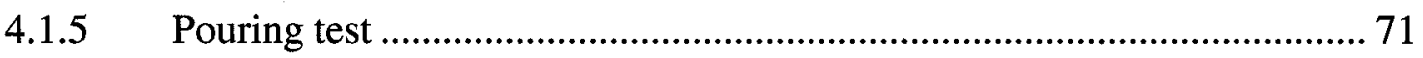

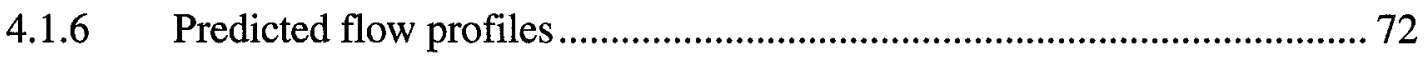

4.1.6.1 Steady state flow prediction on a flat bed.......................................... 72

4.1.6.2 Steady state flow prediction on an inclined bed ............................... 73

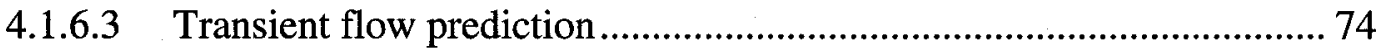

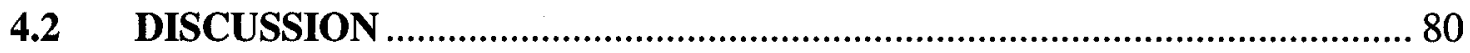

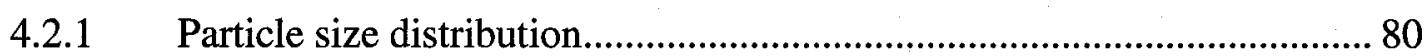

4.2.2 Rheological Characterization (yield stress) .......................................... 81 


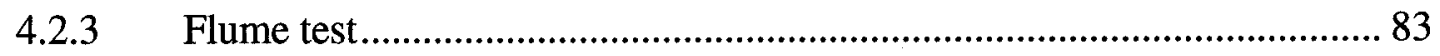

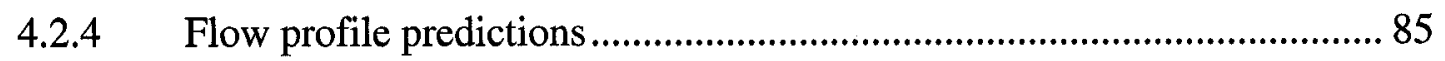

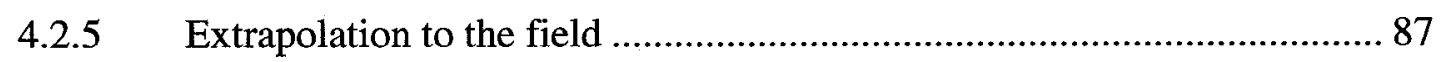

CHAPTER V: CONCLUSIONS ............................................................

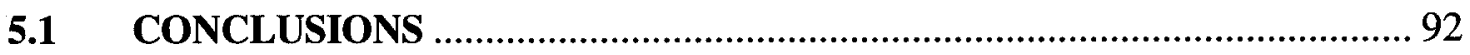

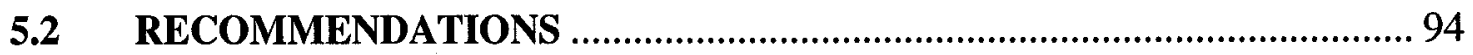

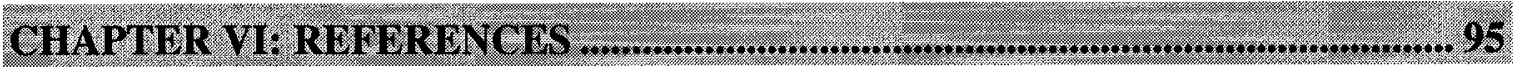

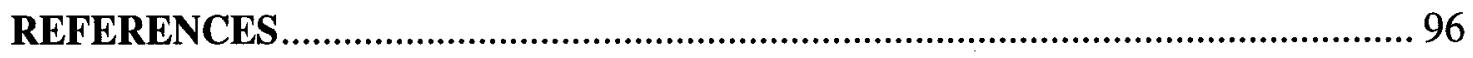

APPENDIX A: CHEMICAL COMPOSITION OF THE TAILINGS .......................... 103

APPENDIX B: PAPER SUBMITTED TO MINERALS ENGINEERING.................... 106

APPENDIX C: VISUALIZATION OF THE FLOW TESTS (enclosed DVD) ............ 136

\section{LIST OF FIGURES}

Figure II. 1: Tailings dam geometry using the upstream method............................................ 12

Figure II. 2: Tailings dam geometry using the downstream method...................................... 12

Figure II. 3: Tailings dam geometry using the centerline method............................................. 13

Figure II. 4: Los Frailes tailings dam, with a failure in one of its walls................................... 14

Figure II. 5: Tailing disposal facility at Bulyanhulu site.......................................................... 17

Figure II. 6: Graphical representation of a Newtonian flow curve............................................22

Figure II. 7: Graphical representation of a Bingham plastic fluid..............................................24

Figure II. 8: Graphical representation of a Pseudoplastic fluid..................................................25

Figure II. 9: Graphical representation of a Dilatant fluid...........................................................25

Figure II. 10: Illustration of a typical flow curve fitted by the Bingham model. .........................27

Figure II. 11: Stress-time profile obtained using the stress growth technique ..........................28

Figure II. 12: Yield stress values as a function of solids concentration of a gold paste tailing.... 30 


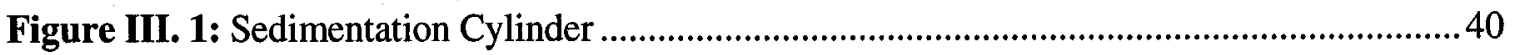

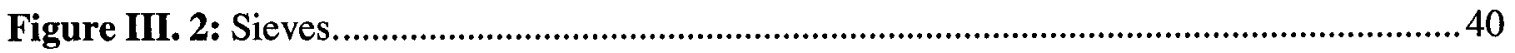

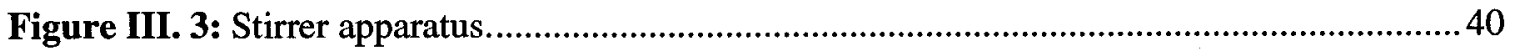

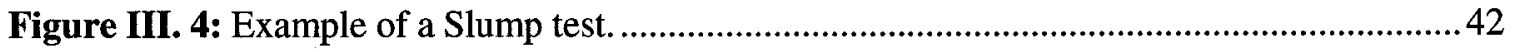

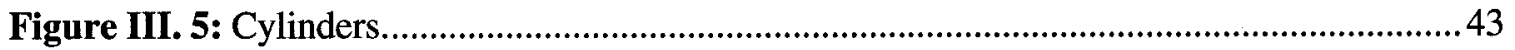

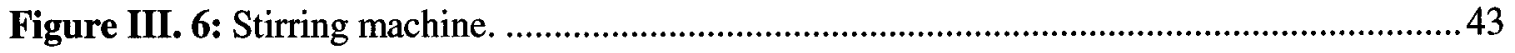

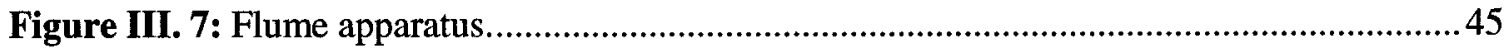

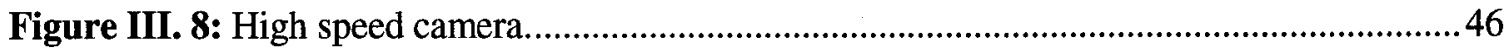

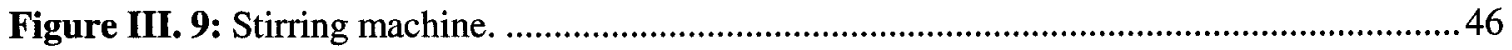

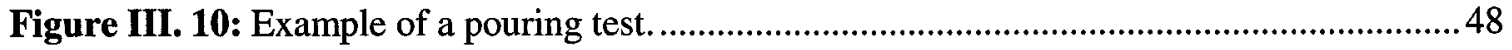

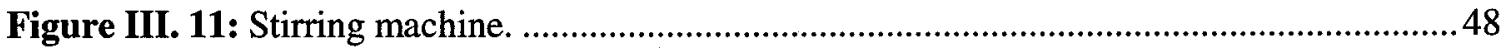

Figure III. 12: Example of spread sheet used to determine the free surface height values..........52

Figure III. 13: Microsoft Visual Basic code to loop calculation...............................................53

Figure IV. 1: Particle size distribution curve .........................................................................55

Figure IV. 2: Slump test results in the form of dimensionless slump vs. water content...............56

Figure IV. 3: Yield stress results for four different cylinders...................................................57

Figure IV. 4: Yield stress values determined using a rheometer................................................58

Figure IV. 5: Rheogram for a $72 \mathrm{wt} \%$ solids tailings sample without the low shear rate range...59

Figure IV. 6: Rheogram for a $71.7 \mathrm{wt} \%$ solids tailings sample with the entire data ....................59

Figure IV. 7: Flow curve for a $71.7 \mathrm{wt} \%$ solids tailings sample. Shear rate from 0 to $90 \mathrm{sec}^{-1}$...60

Figure IV. 8: Flume tests results performed on a horizontal plane and using the gate..................62

Figure IV. 9: Flume tests results performed on a horizontal plane and using the funnel.............63

Figure IV. 10: Comparison between flume tests performed with funnel and gate ......................64

Figure IV. 11: Flume tests result performed with funnel and gate for smaller volume................65

Figure IV. 12: Flume tests result for different volumes of material.......................................65

Figure IV. 13: Profiles obtained by using a narrow flume with lubrication................................66

Figure IV. 14: Flume tests results of five successive layers...............................................67

Figure IV. 15: Flume tests results of three successive layers. ....................................................6 68

Figure IV. 16: Flume tests performed on an inclined plane...................................................69

Figure IV. 17: Example of visualization of a flume test at $t=3-6-9$ sec. ............................. 70

Figure IV. 18: Graphical representation of a pouring test on a horizontal plane...........................71

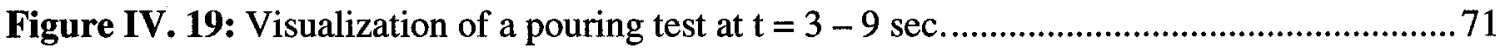


Figure IV. 20: Measured and predicted flow profiles for different volumes of material. .72

Figure IV. 21: Measured and predicted flow profiles of a pouring test...................................... 73

Figure IV. 22: Measured and predicted flow profiles at a slope of 0.57 degree...........................73

Figure IV. 23: Measured and predicted flow profiles at a slope of 1.14 degree............................ 74

Figure IV. 24: Measured and predicted flow profiles using the transient solution....................... 75

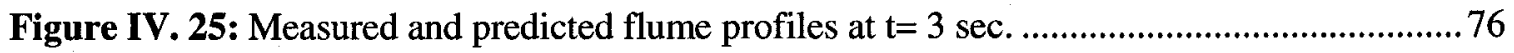

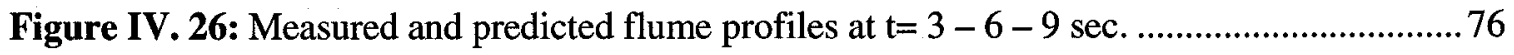

Figure IV. 27: Measured and predicted flow profile for a second layer...................................... 77

Figure IV. 28: Measured and predicted flow profile at 3 and $6 \mathrm{sec}$ for a second layer ................ 78

Figure IV. 29: Flow profiles predicted using the steady state and transient solution................... 79

Figure IV. 30: Yield stress results obtained from slump and rheometry .....................................81

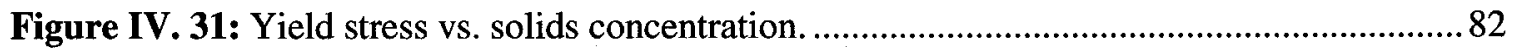

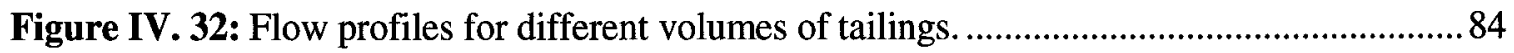

Figure IV. 33: Flow profiles prediction for a single layer using the steady state solution........... 86

Figure IV. 34: Flow profiles prediction for a single layer using the transient solution................. 87

Figure IV. 35: Flow profiles prediction of a second layer using the transient equation...............87

Figure IV. 36: Graphical representation of two case scenarios ................................................ 88

Figure IV. 37: Graphical representation of the two scenarios................................................... 89

Figure IV. 38: Representation of deposition of five different layers.......................................90 


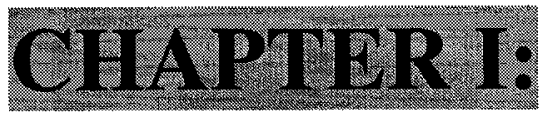

INTRODUCTION 


\subsection{INTRODUCTION}

Mining plays an important role in the economy of many nations, contributing significantly to their labour force and Gross Domestic Product (GDP). In Chile, for example, the mining sector has contributed around $8 \%$ to the GDP during the last 10 years (COCHILCO, 2006). Similar situation evidences Canada, where 4\% of its GDP is provided by the mining industry (MAC, 2005).

Mining processes involve the removal of tons of rock and soil, which are then crushed, grinded, and processed to recover the economic product. These processes necessarily generate large amount of waste materials that are commonly refer as to Waste Rock and Mine Tailings. The waste rock is the debris generated from the blasting that has no financial gain, whereas mine tailings are the waste products that are generated during the milling process, in which the valuable minerals are extracted from the ore. Mine tailings basically consist of a mixture of ground rock (fine sand and silt size particles) and process water (Vick, 1990).

Waste rocks are often stored in unconfined areas, forming large piles that in the short and long term represent a significant threat to the environment if they are not managed properly. Mine tailings, on the other hand, are traditionally deposited into engineered surface impoundments in the form of a slurry material. This material usually contains a solids concentration (mass of solids/total mass) ranging from 25 to $50 \%$, which allows the coarser particles to settle closer to the discharge point and the finer ones further away, where they sediment creating a large pond (Vick, 1990). This conventional 
deposition and storage system poses a high risk of a catastrophic event due to the likelihood of a failure of the tailings dam as a result of several factors, which includes: poor construction techniques, low density of the tailings, high pore pressure, and poor water control in the pond, among others (Davies, 2002; Martin et al., 2002; Davies and Martin, 2000). A tailings dam failure can result in a significant and irreparable environmental damage and in some cases in loss of life.

A common environmental problem associated with waste rock and mine tailings is the generation of acid rock drainage as a result of the exposure of sulphide minerals contained in the rocks to water and oxygen, which causes natural oxidation and, therefore, the generation of acids and dissolved metals (Garcia et al., 2005). The stabilization of these sites, for example, represents a multi-billion dollar liability to the mining industry (Feasby et al., 1991).

These problems and deficiencies have generated increasing attention from private and regulatory organizations, which is not surprising when considering that tailings impoundments can cover hundreds of hectares with millions of tones of waste materials. Therefore, the need to find solutions to mine waste management issues that radically reduce environmental catastrophes and, simultaneously, minimize operational costs have motivated the mining industry to study and implement new alternatives for the deposition of mine tailings. 
A relatively new disposal system involves the surface deposition of the tailings in a thickened or paste form. This technology consists of dewatering the tailings before they are transported to the surface containment facility, obtaining a non-segregating material with a consistency similar to wet concrete and with sufficient strength to resist deformation, which permits to eliminate the need for conventional dams and, therefore, reduce the risk of catastrophic events (Cincilla et al., 1997). In addition, a considerable amount of water can be recovered during the dewatering process and recycled back to the plant, reducing operational costs for water sources, especially in dry areas where lack of water can result in significant investments (Scola and Landriault, 2007).

Thickened and Paste tailings are normally difficult to differentiate, since both have been considerably dewatered. A simple and practical distinction is that paste tailings do not have a critical flow velocity when pumped, do not segregate when deposited, and present negligible bleed water when they are left idle (Newman and Landriault, 1997; Theriault et al., 2003). It should be noted that this study will focus specifically on paste deposition.

Surface paste disposal has been operated successfully in many places around the world. A typical well-known example is the Bulyanhulu Gold Mine, located in Northern Tanzania, Africa, which was the first mine in adopting a full-scale surface paste disposal (Shuttleworth et al., 2005).

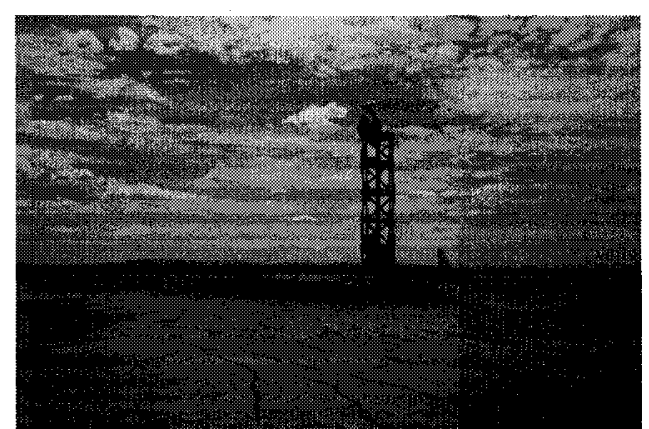

Figure I. 1: View of the tailings storage facility at Bulyanhulu site. 
The Bulyanhulu tailings storage facility covers approximately an area of 65 hectares. Figure I.1 on the previous page shows part of this facility with one of the vertical towers used to discharge the tailings.

Paste tailings are usually discharged from central disposal points or from topographical high points to form a self supporting conical stack with sufficient stability and strength, which minimize the requirement for conventional dams. Once discharged, the tailings will flow over long distances without exhibiting segregation of particles; therefore, presenting a constant particle size distribution across the facility. The flow will then stop at a gentle slope, normally ranging from 3 to 10 degree, providing the underlying material has stabilized (Theriault et al., 2003).

Tailings can gain sufficient strength through self-weight consolidation and/or desiccation (Theriault et al., 2003). In moderate and dry climates, for example, the stability of tailings is mostly influenced by desiccation. High evaporation rates allow the tailings to dry quickly and, therefore, enhance strength gain. In this context, layer thickness becomes a fundamental parameter affecting the rate of desiccation and, consequently, the strength of the deposit. Deposition of thicker layers will take longer to dry, whereas thinner layers will facilitate evaporation, allowing the tailings to dry faster. However, a high degree of drying will promote surface oxidation of the tailings and, consequently, the potential for acid generation (Simms et al., 2007). 
In terms of fluid flow, paste tailings are known to exhibit non-Newtonian flow behaviour, that is, the relationship between the shear stress and shear rate in not constant, contrary to Newtonian fluids (e.g. water) where this relationship becomes linear. The most common type of non-Newtonian fluid generally used to describe the flow behaviour of dewatered mine tailings is the Bingham fluid (Coussot and Proust, 1996). This type of fluid behaves as a solid when it is left at rest, requiring a minimum stress to initiate flow. This stress is known as "yield stress" and is, together with the viscosity, a fundamental parameter when predicting all aspects of the behaviour of paste tailings (Kwak et al., 2005). A material with a high yield stress will exhibit a significant resistance to flow, accumulating close to the discharge point instead of flowing further to provide an adequate distribution across the storage facility. On the other hand, if the material has a low yield stress it will spread over a large surface, making it difficult to form the desired self-supporting conical stack. In this context, the study of the governing rheological properties of mineral suspensions (e.g. viscosity and yield stress) becomes essential when trying to understand and control their flow behaviour during deposition. 


\subsection{PROBLEM STATEMENT}

At present, operators of tailings facilities experience some operational issues when trying to control the flow of tailings during deposition and when attempting to anticipate the resulted geometry (Shuttleworth et al., 2005). These problems pose several challenges, especially at the design phase. The storage capacity of the tailings facility, for example, will be directly dictated by the height and extent of the stack. Similarly, the average thickness to which each fresh layer is deposited will determine the likelihood of surface oxidation, with the potential of acid generation (Simms et al., 2007). Base on these factors, the prediction of the deposition geometry formed by the tailings at the design state would represent a great advance to mining operators, providing a more effective and controlled management of such facilities.

Several investigations have attempted to predict the deposition geometry of highdensity tailings base on a single angle obtained from laboratory flume tests (Kwak et al., 2005; Sofra and Boger, 2001). It has been observed in practice that angles measured at a laboratory scale may considerably overpredict the angles that are achieved in the field (Oxenford and Lord, 2006; Engman et al., 2004). This study will demonstrate that the average slope formed by the deposition of tailings is a function of the scale of the deposit and it can not be represented by single angles measured in the laboratory. 


\subsection{OBJECTIVES}

The overall objective of this research is to provide better correlation between laboratory flow tests and the deposition geometry in the field of paste tailings. To achieve this goal, several flume tests will be performed at a laboratory scale and the flows will be recorded using a high-speed camera. The visualization of the flows will be then compared with predictions of steady-state and transient equilibrium profiles obtained using a static and dynamic computer code written by the author.

\subsection{METHODOLOGY}

The experimental work contemplated in this study will adopt the following methodology:

- Basic characterization of the tailings, which will consider the determination of the specific gravity and the particle size distribution of the tailings;

- Rheological characterization of the tailings that will include yield stress measurements at different initial water contents, as well as characterization of the shear stress-shear rate relationship (flow curve);

- Flume tests on horizontal planes, on successive layers, at different initial slopes, and for different volumes of material;

- $\quad$ Pouring tests, where a certain volume of material is poured through a funnel;

- Dynamic imaging of both flume and pouring tests using a high speed camera;

- Static and dynamic modelling of the flows by using a numerical computer code.

HENRIQUEZ, J.A. 2008. DYNAMIC IMAGING AND MODELLING OF GOLD PASTE TAILINGS FLOWS 


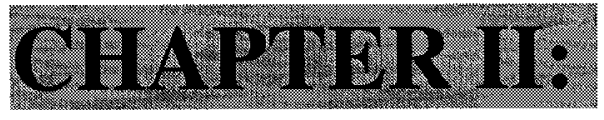

\section{LITERATURE REVIEW}




\subsection{TAILINGS CHARACTERISTICS}

Tailings are the waste products generated during the milling process, in which the valuable minerals are extracted from the ore. They consist of a mixture of ground rock (fine sand or silt size particles) and water used in the process.

The characteristics of tailings depend on the original mineralogy of the ore and the physical and chemical processes that are used to extract the desired metal (Wills, 1988). In consequence, tailings present different physical and chemical characteristics (even tailings of the same type) that determine the design requirements for a suitable storage facility.

The presence of reagents and chemicals (used to extract the mineral) in the tailings, as well as uneconomic minerals and metals, represent short and long term tailings management challenges. A common example is the generation of acid drainage, which is one of the major environmental problems facing the mining industry.

Acid Mine Drainage results from the exposure of metal sulphides (mainly pyrite, $\mathrm{FeS}_{2}$, which is iron-sulphide) contained in the material to water and oxygen, which causes natural oxidation and the consequent generation of acids (due to the dissolution of iron-sulphides) as well as the release of metals, such as: Cobalt, Copper, Iron, Nickel, Lead, etc. (Garcia et al., 2005; Ritcey, 2005; Norman and Raforth, 1998) for several years after the closure of the operation, constituting a significant environmental problem due to potential seepage and run-off to a source of water. 


\subsection{TAILINGS STORAGE AND DISPOSAL METHODS}

A well known traditional method of disposing mine tailings is in the form of a slurry material, which is transported directly to a dammed impoundment that is generally built using the upstream, downstream, or centerline method.

A relatively new surface disposal method involves the deposition of the tailing in a dewatered form, which results in numerous environmental benefits. Descriptions of conventional storage techniques as well as conventional and dewatered disposal methods are presented as follows.

\subsubsection{Conventional Storage}

As mentioned previously, the three basic dam methods of storage are upstream, downstream, and centerline.

The upstream method initially involves the construction of a starter dam (see Figure II.1 on the next page). The tailings are discharged from the top of the dam to create a beach, which becomes the foundation for a second and subsequent dams (Vick, 1990). The upstream method is the least expensive as it requires less fill material for initial construction, which makes it be the most popular to build. However, this method is considered to be the least stable; therefore, the one that poses the highest risk of failure as a result of several factors, such as: low density of the tailings, which makes them susceptible to liquefaction under seismic events; low strength of the embankment due to the high pore pressure caused by excessive rate of rise; the increase in height of the 
phreatic surface due to a poor water control in the pond; and poor construction techniques (Davies, 2002; Martin et al., 2002; Davies and Martin, 2000).
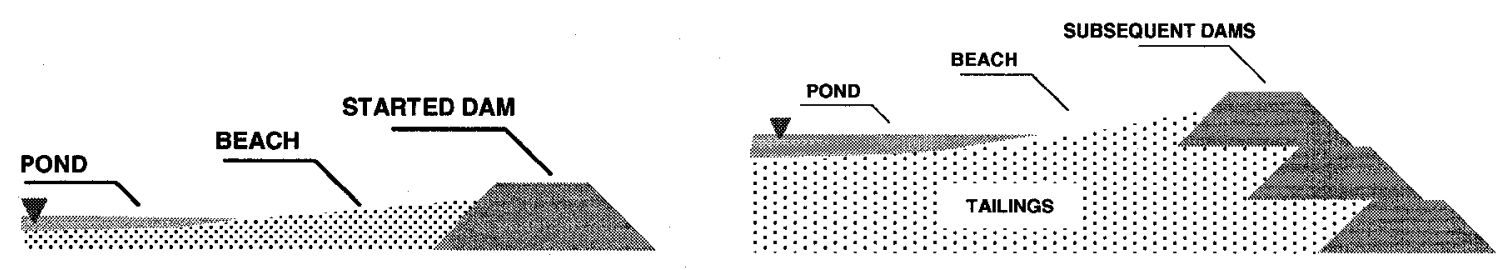

Figure II. 1: Illustrative representation of tailings dam geometry using the upstream method.

Unlike the upstream method, the downstream requires the most amount of fill material for dam construction, which makes it be the most expensive to build (Norman and Raforth, 1998). It initially involves the construction of an impervious starter dam. The tailings are then discharged behind this dam and, when required, a new dam is built on the downstream slope of the existing one (see Figure II. 2 below). This method is more stable than the upstream method due to the dams are not structurally dependent on the tailings (Mainali, 2006).
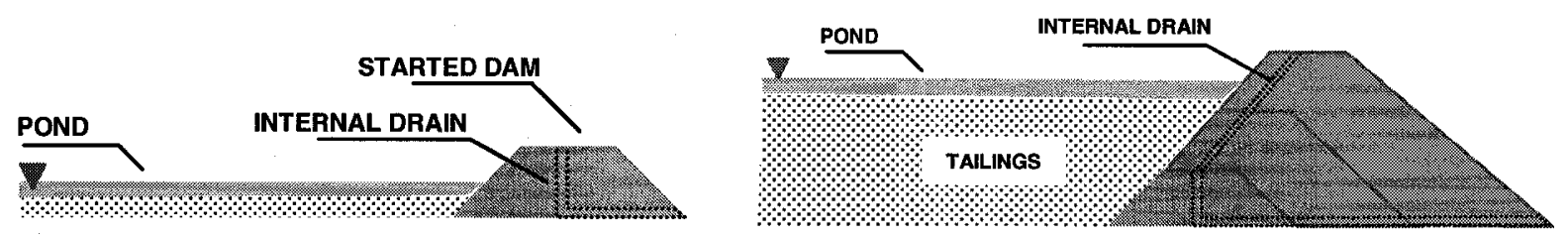

Figure II. 2: Illustrative representation of tailings dam geometry using the downstream method.

The centerline design includes the advantages and disadvantages of both the upstream and downstream method (Norman and Raforth, 1998). It requires more fill material than the upstream design but less than the downstream, which makes its cost be intermediate between both methods. Like the upstream design, the centerline method initially requires the construction of a started dam. The tailings are then discharged from 
the top of the dam to form a beach behind it (see Figure II.3 below). When required, the subsequent raises are place on both the beach and the downstream slope of the existing dam (Mainali, 2006). Like the downstream design, this method incorporates an internal drainage zone, which permits to maintain an acceptable level of the phreatic surface, reducing the risk of a failure and being more stable than the upstream method.
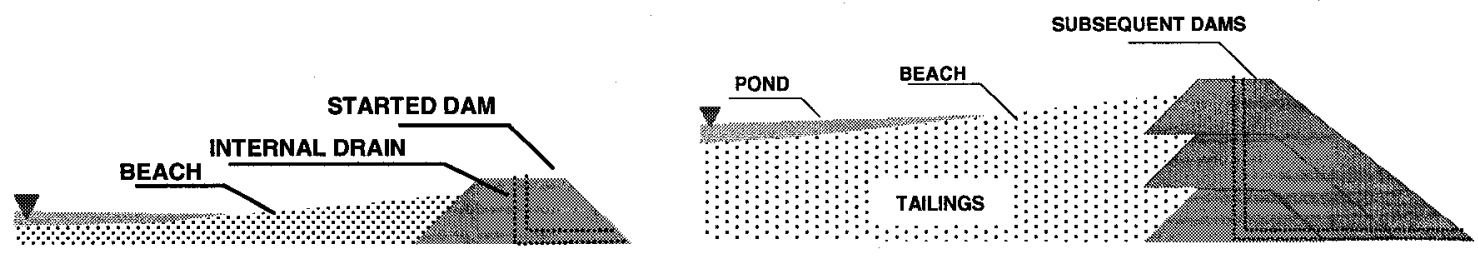

Figure II. 3: Illustrative representation of tailings dam geometry using the centerline method

\subsubsection{Conventional Mechanism of Tailings Disposal}

The conventional disposal method involves the deposition of the tailings in the form of a slurry material, which is transported from the ore processing plant to the engineered surface impoundment (dam) through a pipeline by pumping or simply gravity.

The solid content of the slurry varies from approximately 25 to $50 \%$ depending on the type of the tailings, and they initially contain a high water content. As a result, when the tailings are discharged out of the pipeline natural segregation occurs. The coarse solids settle close to the discharge point and the fine particles move further away. The particle size and the density of the tailings are considered to have significant effect on the degree of segregation (Vick, 1990).

HENRIQUEZ, J.A. 2008. DYNAMIC IMAGING AND MODELLING OF GOLD PASTE TAILINGS FLOWS 
As presented previously, the main negative characteristic associated with conventional disposal methods is the likelihood of a failure of the tailing dam, with the consequence of a catastrophic environmental damage. According to the International Commission On Large Dams (ICOLD and UNEP, 2001) there has been 221 tailings dam incidents (particularly associated to the upstream method) between the years 1968 and 2000. It is also mentioned that the main causes of the incidents were slope instability and earthquakes.

A common example of a catastrophic tailings dam failure is presented in Figure II.4 below. It corresponds to "Los Frailes" tailings impoundment of Minas de Aznalcollar, located in Aznalcollar, south-western Spain. On April 25, 1998, the eastern side of the impoundment failed, releasing around of 2 million of cubic meter of tailings solids and 4 million cubic meter of acid water to the surrounding environments, covering hectares of vegetation and crops and overflowing the Agrio and Guadiamar River for approximately 40 kilometres (Grimalt et al., 1999).
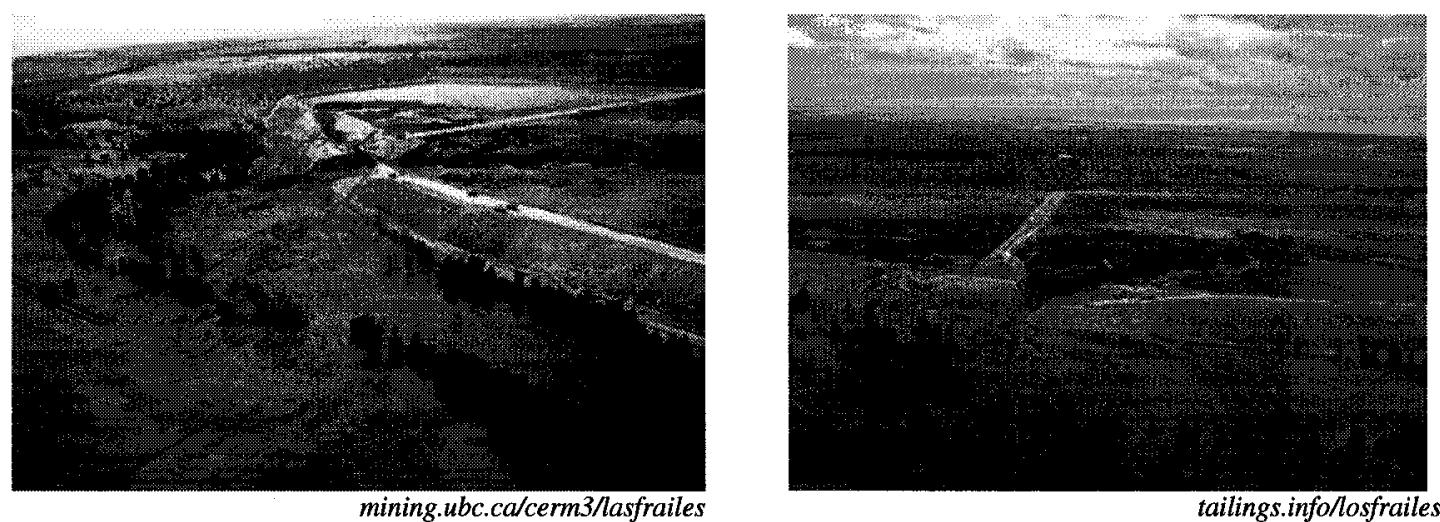

Figure II. 4: Los Frailes tailings dam, with a failure in one of its walls. 
Even though conventional disposal are still considered as an economically convenient alternative to deposit mine tailings, new systems consisting of depositing the tailings in a dewatered form is gaining increasing interest.

\subsubsection{Paste Tailings Disposal}

This method basically consists of removing most of the process water of the tailings before they are transported to the surface containment facility. The dewatering process must be sufficient to form a non-segregating material, with a consistency similar to wet concrete. To achieve this goal, the use of high density thickeners and/or filters becomes necessary (Meggyes and Debreczeni, 2006).

Paste tailings can be defined as a high-density mixture of solid and water that does not segregate when deposited. In addition, paste tailings do not have a critical flow velocity when pumped and they present negligible bleed water when left idle (Newman and Landriault, 1997; Theriault et al., 2003).

These types of tailings contain sufficient fine particles to avoid particle segregation during transportation and deposition. It has been reported that they should contain at least $15 \%$ by mass of particles less than 20 micron in diameter (Meggyes and Debreczeni, 2006; Cincilla et al., 1997).

Paste tailings are usually discharged from central disposal points or from topographical high points to form a self supporting conical stack with sufficient stability 
and strength, which minimize the requirement for conventional dams and eliminate the pond that is usually observed on top of conventional deposits (ICOLD and UNEP, 2001). Once discharged, the tailings will flow over long distances without exhibiting segregation of particles; therefore, presenting a constant particle size distribution across the facility. The flow will then stop at a gentle slope, normally ranging from 3 to 10 degree, providing the underlying material has stabilized (Theriault et al., 2003).

Tailings can gain sufficient strength through self-weight consolidation and/or desiccation. In moderate and dry climates, for example, the stability of tailings will be mostly influenced by desiccation (Simms et al., 2007). High evaporation rates allow the tailings to dry quickly and, therefore, enhance the strength gain. In this context, layer thickness becomes a fundamental parameter affecting the rate of desiccation and, consequently, the strength of the deposit. Deposition of thicker layers will take longer to dry, whereas thinner layers will facilitate evaporation, allowing the tailings to dry and gain strength faster. However, a high degree of drying will promote surface oxidation of the tailings and, consequently, the potential for acid generation. Experience at Bulyanhulu site indicates a deposited layer thickness of about $30 \mathrm{~cm}$ to facilitate desiccation (Shuttleworth et al., 2005).

As mentioned earlier, a well known example of surface paste tailings disposal correspond to the Bulyanhulu Gold Mine, located in Tanzania, Africa, which was the first mine to adopt the surface paste technology for all of its tailings (Shuttleworth et al., 
2005). Figure II.5 below, for example, presents some pictures of the tailings disposal facility at Bulyanhulu site, with some of the vertical towers used to discharge the tailings.
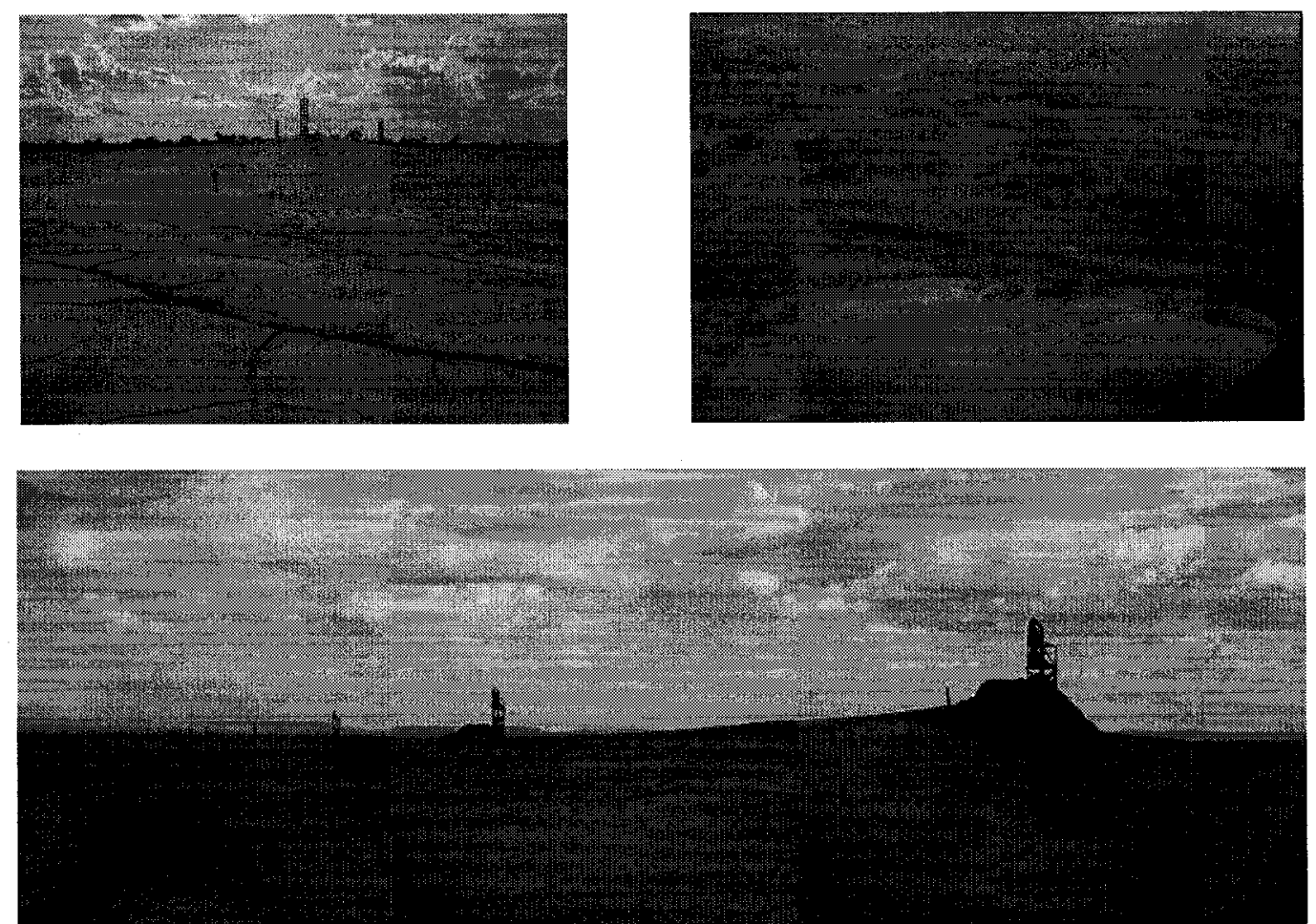

Figure II. 5: Tailing disposal facility at Bulyanhulu site (from Simms and Bryan, 2007 and Shuttleworth et al., 2005). 
The advantages associated with paste disposal system over conventional disposal are many. Some of those include (Meggyes and Debreczeni, 2006):

- minimal or no dam construction, which reduces the capital cost for the storage facility;

- water conservation. The considerable amount of water recovered during the dewatering process of the tailings can be recycled back to the plant processes for use, which is very attractive in arid areas;

- leachate reduction. The little free water available in the tailings reduces the potential for leachate generation;

- reduction of mine acid drainage. High degree of saturation of the tailings reduces the infiltration of oxygen and, therefore, minimizes the rate of sulphide oxidation. It should be noted, however, that some authors have affirmed that initial saturation of the tailings does not inhibit ingress of oxygen (Simms et al., 2007) and, therefore, the generation of acid drainage;

- reduce the risk of a catastrophic event as the tailings are stable after deposition;

- extend the life of the deposit because of the increase in the storage capacity. 
On the other hand, there are some concerns associated with this technology. The main disadvantage refers to the high operational costs. This is in part due to the need of transportation systems (pump) that provide sufficient driving forces to transport a very viscous material from the paste thickener facility to the disposal area, as well as the need for high rate/paste type thickeners required to produce a paste consistency (Grant-Stuart, 2004) adequate to achieve steep slope angles. According to Lindvall and Drielsma (2006) the cost to manage the tailings in a paste form for many low grade mines is equivalent to the value of all the metals content in the ore, which makes the entire operation unfeasible. In contrast, the economic evaluation presented by Scola and Landriault (2007) of two case studies for two large scale mining operations in Chile's Atacama Desert demonstrated that the change from conventional to highly dewatered disposal method will result in important cost savings.

As presented previously, paste technology certainly offers several environmental advantages. However, in terms of potential cost saving, these will need to be evaluated on a case-by-case basis analysis.

HENRIQUEZ, J.A. 2008. DYNAMIC IMAGING AND MODELLING OF GOLD PASTE TAILINGS FLOWS 


\subsection{GOVERNING RHEOLOGICAL PROPERTIES}

Rheology has been defined as the study of how materials deform and flow under the influence of an applied stress. All materials possess rheological properties that can strongly influence their flow behaviour. Viscosity and yield stress are known to be the rheological parameters that have the most significant effect.

\subsection{Viscosity}

Viscosity refers to the property of a material to resist deformation under shear stress and it is expressed in Pascal-second (Pas). It can be represented as the ratio of the shear stress $(\tau)$ to the shear rate $(\gamma)$, as presented in the following equation:

$$
\eta=v i s \cos i t y=\frac{\tau}{\gamma}
$$

Shear stress $(\tau)$ refers to the force per unit area required to generate shearing, that is, the movement of a layer of fluid in relation to another layer. The unit of measurement corresponds to Newton per square meters $\left(\mathrm{N} / \mathrm{m}^{2}\right)$ or Pascal $(\mathrm{Pa})$. On the other hand, shear rate $(y)$ refers to the velocity gradient of the flow and its unit is reciprocal second $\left(\mathrm{sec}^{-1}\right)$.

\subsubsection{Yield Stress}

The yield stress is defined as the minimum stress required to initiate flow of a fluid (Harris, 1977) and it represents a fundamental parameter when studying the flow behaviour of materials. 
Materials that exhibit a yield stress (e.g. pastes, paints, cements, toothpaste, tomato catsup, etc) behave like a solid at low stresses and like a liquid at high stress values. For example, when the applied stress is less that the yield stress these type of fluids do not flow but deform elastically, with a complete strain recovery upon removal of the stress. On the other hand, when the applied stress is greater than the yield stress the fluid flows like a viscous material, without recovery upon removal of that stress (Liddell and Boger, 1996).

The importance of the yield stress is vital, especially for industrial processes that involve handling and transport of materials that exhibit yield stresses. In pipeline design, for example, the yield stress plays a fundamental role in determining the appropriate pump pressure required to transport a fluid.

Yield stress measurement includes direct and indirect techniques. Direct methods involve independent assessments of the yield stress, whereas indirect techniques basically consist of extrapolating shear stress - shear rate data (Nguyen and Boger, 1992). Further information on yield stress measurements is presented in Section 2.5.

HENRIQUEZ, J.A. 2008. DYNAMIC IMAGING AND MODELLING OF GOLD PASTE TAILINGS FLOWS 


\subsection{RHEOLOGICAL CLASSIFICATION}

Fluids can be classified as either Newtonian or non-Newtonian, as presented as follows.

\subsubsection{Newtonian Fluids}

These fluids (e.g. water, solvents) exhibit a constant viscosity at different shear rates and at a given temperature, and the relationship between shear stress and shear rate becomes linear (Kreith, 1999), as shown in Figure II.6 below.
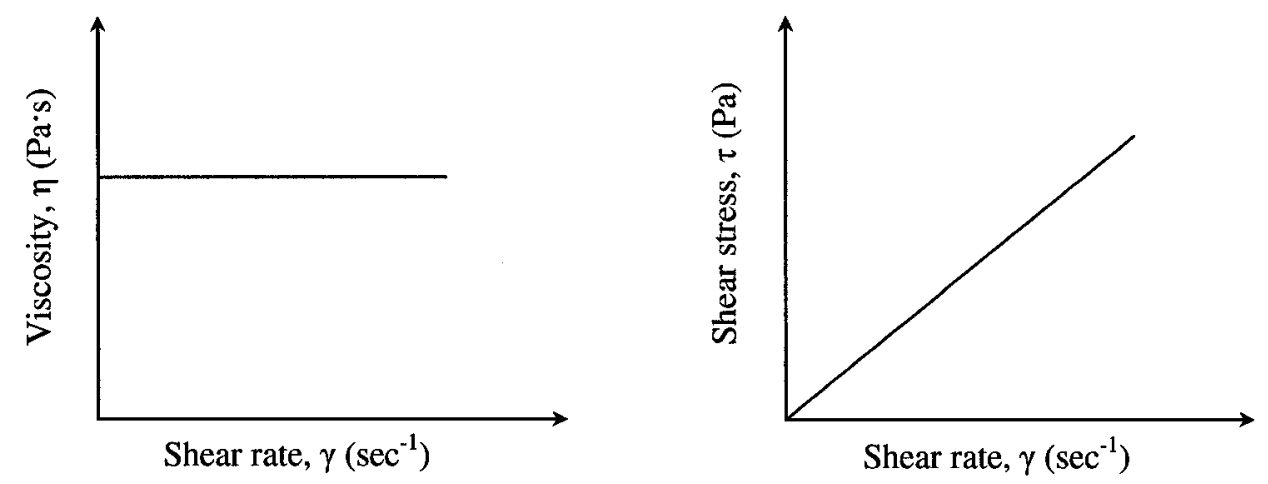

Figure II. 6: Graphical representation of a Newtonian flow curve.

\subsubsection{Non-Newtonian Fluids}

For non-Newtonian fluids (e.g. paste tailings) the relationship between shear stress and shear rate is not linear, which means that the shear stress does not change in the same proportion when the shear rate is varied. Similarly, the viscosity of this type of fluids is not constant as the shear rate is varied (Tanner, 2000).

HENRIQUEZ, J.A. 2008. DYNAMIC IMAGING AND MODELLING OF GOLD PASTE TAILINGS FLOWS 
Non-Newtonian fluids can be classified as (Kreith, 1999):

- purely viscous time independent fluids, whose viscosity changes as the shear rate is varied;

- purely viscous time dependent fluids, which exhibit a change in viscosity with time at constant shear rate; and

- viscoelastic fluids, which display viscous and elastic properties.

For the purposes of this study, the last two categories of non-Newtonian fluids are not of interest; therefore, further information will not be provided.

The most common types of time independent non-Newtonian fluids include Bingham plastic, Pseudoplastic or shear thinning, and Dilatant or shear thickening.

\subsubsection{Bingham Plastic Fluids}

This type of fluids behaves as a solid when they are left at rest, requiring a minimum stress to initiate flow. This stress is known as "yield stress". As shown in Figure II.7 on the next page, the Bingham plastic model is represented by a straight line that intercepts on the shear stress axis, which represents the magnitude of the yield stress (denoted as $\tau_{\mathrm{y}}$ ). For any stress below this magnitude, the structure deforms elastically and it is reformed when the stress is removed, whereas if the yield stress is exceeded the material flows like a liquid with a constant viscosity, behaving as a Newtonian fluid 
(Tanner, 2000). Figure II.7 below presents a graphical representation of a Bingham plastic fluid.

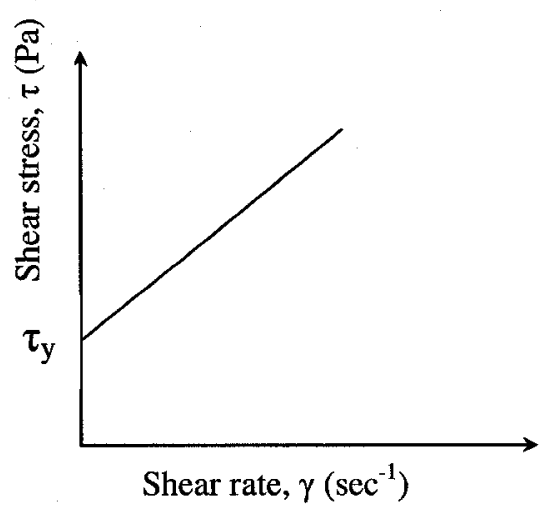

Figure II. 7: Graphical representation of a Bingham plastic fluid.

The constitutive equation for a Bingham plastic model is given by:

$$
\begin{array}{ll}
\gamma=0, & \tau<\tau_{\mathrm{y}} \\
\tau=\tau_{\mathrm{y}}+\eta_{\mathrm{p}} \cdot \gamma & \tau>=\tau_{\mathrm{y}},
\end{array}
$$

where $\tau$ is the shear stress, $\gamma$ is the shear rate, $\tau_{\mathrm{y}}$ is the yield stress, and $\eta_{\mathrm{p}}$ is the plastic viscosity which represents the slope of the curve.

The Bingham model represents an ideal case of plastic flow, where the structure of the material disintegrates as soon as the yield stress is exceeded (Nguyen and Boger, 1992).

\subsubsection{Pseudo-plastic fluids}

Pseudoplastic flow behaviour, also called "shear thinning" exhibit a decreasing viscosity when increasing the shear rate (see Figure II. 8 on the next page). This situation 
results from the alignment of the particles in the direction of shear when the shear rate increases, which provides a lower resistant to flow (Sofra and Boger, 2001). Some examples of this type of fluid include paints, emulsions, gel, among others.
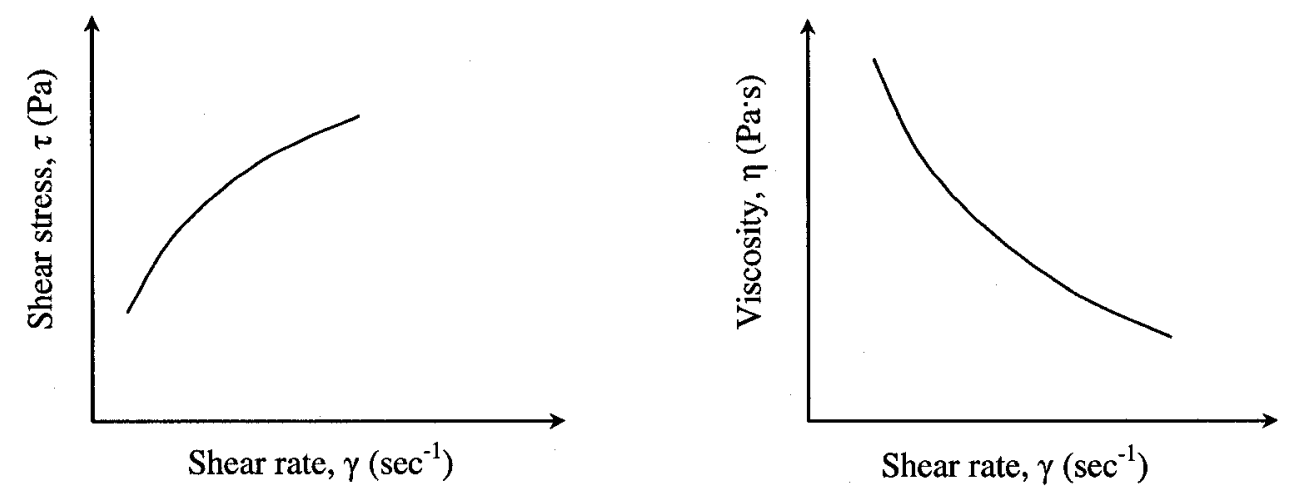

Figure II. 8: Graphical representation of a Pseudoplastic fluid.

\subsubsection{Dilatant fluids}

Dilatant behaviour, also referred to as a "shear thickening", display an increasing viscosity with an increase in the shear rate (see Figure II.9 below). Examples include fluids having elevated levels of deflocculated solids (e.g. clay slurries).
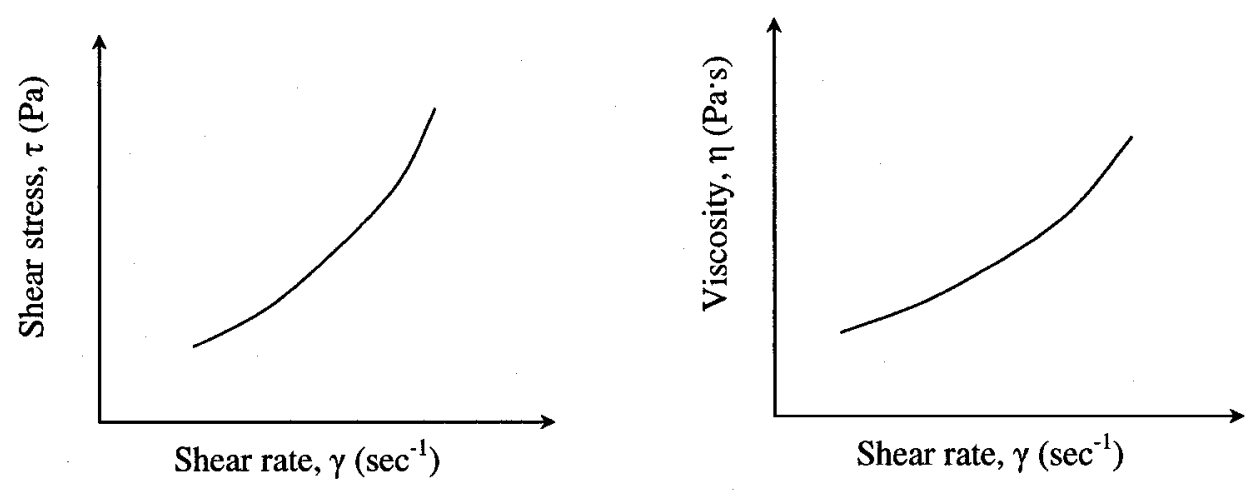

Figure II. 9: Graphical representation of a Dilatant fluid. 
As presented previously, viscoplastic fluids may exhibit linear flow behaviour once the yield stress is exceeded (e.g Bingham plastic fluid). It should be noted, however, that they may also display nonlinear flow behaviour, becoming pseudo-plastic or dilatant fluids (Nguyen and Boger, 1992).

A constitutive equation for nonlinear visco-plastic behaviour can be described by the Herschel Bulkley model, as presented below:

$$
\tau=\tau_{\mathrm{y}}+\mathrm{k} \cdot \gamma^{\mathrm{m}} \quad \tau>=\tau_{\mathrm{y}}
$$

where $\mathrm{m}$ and $\mathrm{k}$ are constant. Note that when $\mathrm{m}>1$ the fluid is dilatant, for $\mathrm{m}<1$ the fluid is pseudo-plastic, and for $\mathrm{m}=1$ eqn. II. 4 becomes the Bingham equation. 


\subsection{YIELD STRESS MEASUREMENT}

As mentioned earlier, yield stress measurement includes indirect and direct techniques (Nguyen and Boger, 1992). Indirect techniques consist of extrapolating experimental shear stress vs. shear rate data to zero shear rate, being the intercept on the shear stress axis the magnitude of the yield stress. The extrapolation can be done using a model (like the Bingham or Hershel-Bulkley model) or by a simple direct extrapolation. As an example, Figure II.10 below shows a typical flow curve (four tests are presented) fitted by the Bingham model.

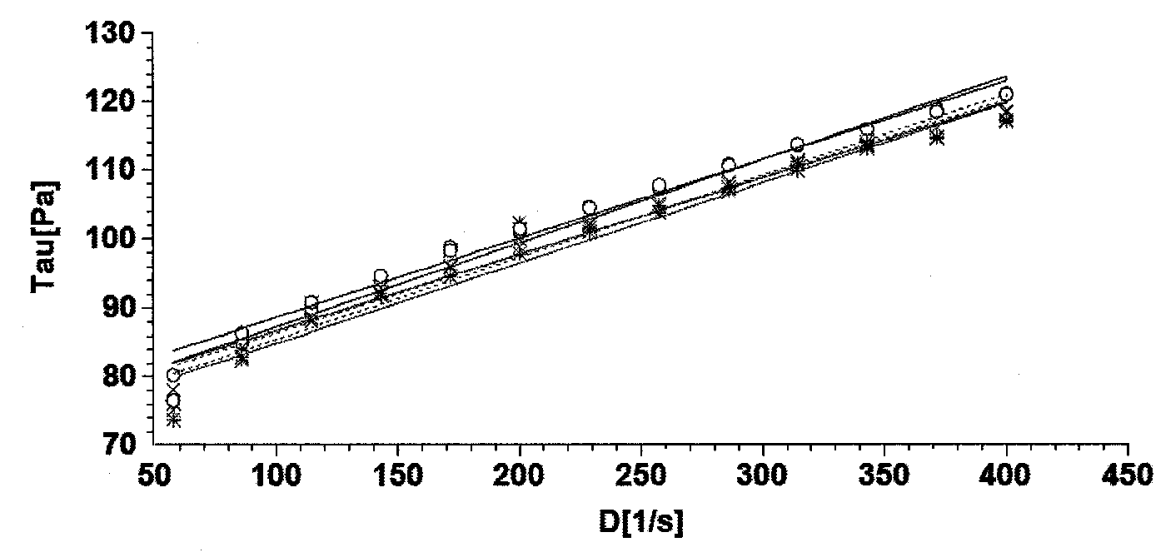

Figure II. 10: Illustration of a typical flow curve fitted by the Bingham model. Note that four tests are shown

On the other hand, direct methods involve independent assessments of the yield stress that involve, for example, the use of conventional rheometers (Liddell and Boger, 1996). A common example of a direct yield stress measurement using a rheometer includes the Stress Growth technique. This technique consists of shearing a fluid at a low and constant shear rate, and measuring the shear stress as a function of time, obtaining a stress vs. time profile like the one illustrated in Figure II.11 on the next page. 


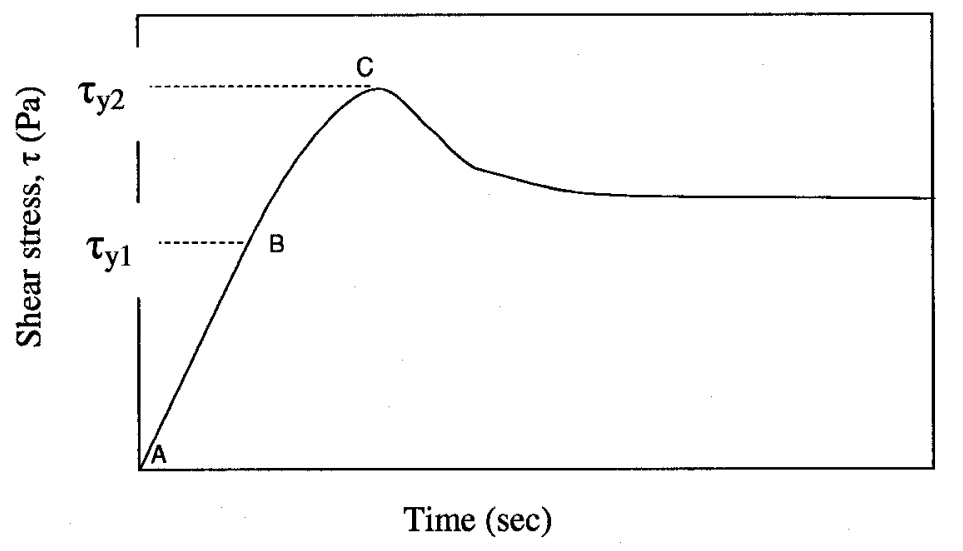

Figure II. 11: Illustration of a typical stress-time profile obtained using the stress growth technique for yield stress measurement.

From the previous figure, it can be observed that the fluid initially exhibits a linear increase in shear stress with time (section A-B), followed by a nonlinear behaviour (section B-C), a peak stress (C), and finally a stress decay. According to Liddell and Boger (1996), two yield stresses can be identified from the previous profile. A static yield stress $\left(\tau_{\mathrm{y} 1}\right)$, where the fluid ceases to display elastic behaviour and begins to exhibit viscoelastic behaviour (point B), and a dynamic yield stress $\left(\tau_{\mathrm{y} 2}\right)$, where the structure of the fluid disintegrates completely (point C) and flow starts. In practice, the stress at point $\mathrm{C}$ is much easier to detect and represents a good measure of the yield stress value (Nguyen and Boger, 1992).

In addition, another alternative technique for measuring yield stresses without the need of sophisticated equipments corresponds to the "slump" test. This test, initially originated to evaluate the workability of fresh concrete, was adopted by Pashias et al. (1996) as a means of measuring, in a quick and easy way, yield stresses of mineral suspensions. A detailed description of this technique is presented in Section 3.3. 


\subsection{IMPORTANT FACTORS AFFECTING RHEOLOGICAL PROPERTIES}

As presented in Section 2.3, yield stress and viscosity can strongly affect the flow behaviour of materials. Similarly, these rheological parameters can be influenced by other factors such as physical properties (particle size and solids concentration), zeta potential, and temperature, among others.

\subsubsection{Physical properties}

The physical properties of suspensions, such as particle size and solid concentration, are known to have a significant effect on the rheological properties of tailings (Hallbom and Norwood, 2007; Paterson, 2006; Sofra, 2006).

The particle size of tailings varies depending on the mineral being processed and the mineralogical composition of the ore body, which is different between mineral types and deposits (Sofra, 2006). A change in particle size distribution of a deposit can represent a significant variation in the yield stress of tailings at a given solids concentration. Sofra (2006), for example, confirmed the effect of particle size on yield stress of a bauxite sample. His results showed a yield stress of around $20 \mathrm{~Pa}$ for samples composed of particles of $212 \mu \mathrm{m}$ and approximately $110 \mathrm{~Pa}$ for samples with particles of $53 \mu \mathrm{m}$ for a given solids concentration ( $67 \%$ by weight). In this context, it is worth mentioning again that paste tailings must contain at least $15 \%$ by mass of particles smaller than 20 micron in order to allow the tailings to flow without segregation of the particles (Kwak et al., 2005).

HENRIQUEZ, J.A. 2008. DYNAMIC IMAGING AND MODELLING OF GOLD PASTE TAILINGS FLOWS 
Alike the particle size distribution, the solids concentration can also affect the flow properties of tailings. A material with high solids content, for example, will present a high yield stress and, therefore, a significant resistance to flow, accumulating close to the discharge point instead of flowing further to provide an adequate distribution across the storage facility. On the other hand, if the material has low solids content and, consequently, a low yield stress, it will spread over a large surface, making it difficult to form the desired self-supporting conical stack (Kwak et al., 2005). Figure II.12 below, for example, presents a graphical representation of yield stress values as a function of solids concentration for a gold paste tailing.

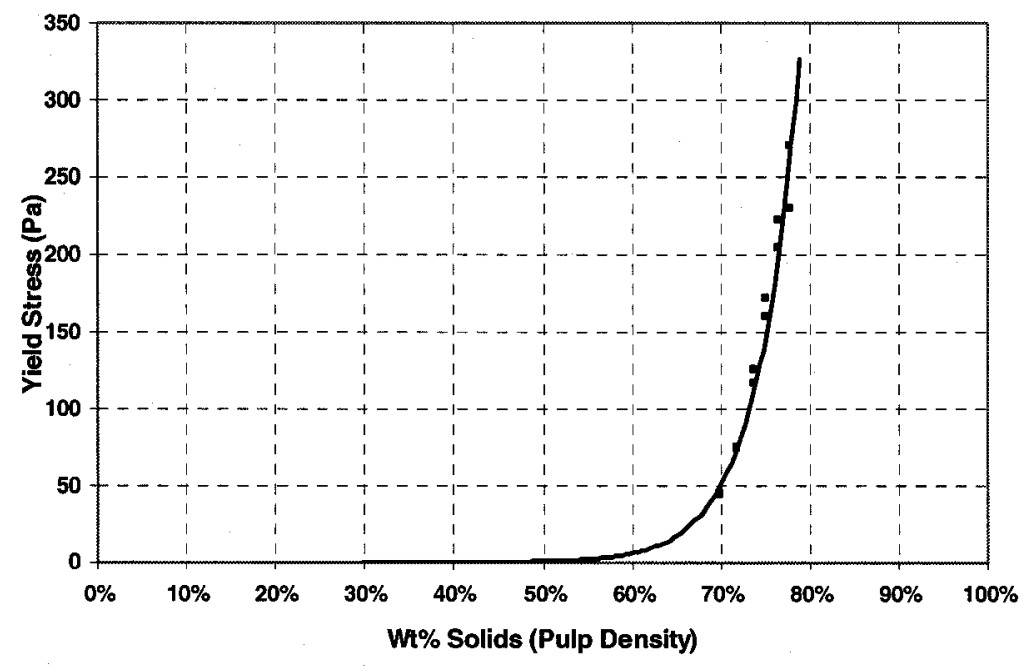

Figure II. 12: Graphical representation of yield stress values as a function of solids concentration of a gold paste tailing.

It should be noted that paste tailings usually exhibit solids content in the range of 70 $-80 \%$ by weight. Higher concentrations will result in higher yield stresses and, therefore, a considerable increase in pumping costs. As noted from the previous figure, there is an exponential relationship between the yield stress and solids concentration. This effect may be explained by the fact that as the solids concentration increases the distance 
between particles decreases, resulting in a stronger interaction between the particles and, therefore, in an increase of the yield stress. According to Shih et al. (1999), as cited by Zhu et al. (2002) there is no successful explanation for this exponential relation.

\subsubsection{Zeta Potential}

Zeta potential is an indicator of the electrical charge that exists on the surface of a particle dispersed in a specific medium (e.g. water). Its magnitude determines the potential stability of the colloidal suspension, that is, particles having a large negative or large positive zeta potential will repel each other, reducing the tendency for coagulation (Hunter, R.J. 1981). It has been reported that zeta potential is strongly correlated with yield stress for many non-Newtonian fluids (Mpofu et al., 2003). Kwak et al. (2005) performed zeta potential measurements on a gold paste tailing (obtained from the same mine as the tailings used in this study) to evaluate the effect of water content on the particles. Their results showed that the zeta potential did not vary with water content, and that the variation in yield stress was due to physical properties.

\subsubsection{Temperature}

Another factor affecting the rheological properties of a material is temperature. Some fluids are more sensitive to temperature than others, where a small variation can result in a significant change in viscosity (Wright, 1977). For the purposes of this study, temperature effects will not be evaluated. All the tests will be performed at room temperature. 


\subsection{PREDICTION OF THE DEPOSITION GEOMETRY OF TAILINGS}

As presented previously, high density tailings are usually discharged from central or topographical high points to form a self supporting conical stack. The discharge is normally cycled from different disposal points, which promotes faster desiccation and consolidation before another layer is deposited on top of the existing one. Once discharged, the tailings will flow over long distances to stop at a gentle slope, normally ranging from 3 to 10 degree, providing the underlying material has stabilized (Theriault et al., 2003).

Some Canadian examples in the application of thickening and paste tailing for surface disposal cited by Oxenford and Lord (2006) include the Kidd Zinc/Copper operation located in Ontario, whose tailing deposit presents a $2 \%$ slope; the Jonquière Alumina Refinery in Quebec, where its deposit has slopes between $3-4 \%$; The Cluff Lake Uranium Mine located in Saskatchewan, where the thickened tailing formed a slope of about 3\%; and the Ekati Mine situated in the North West Territories, with a deposit slope of around $1 \%$.

Numerous investigations have been conducted to predict the deposition geometry of paste tailings. Sofra and Boger (2001), for example, presented a model that relates the properties of a mineral suspension and the condition of operation to the depositional slope. Similarly, Pinto and Barrera (2002) proposed an empirical formula for slope predictions based on fitting equations to measurements taken from real tailings impoundments. Other models have been based on turbulent open channel flows (Fitton $e t$

HENRIQUEZ, J.A. 2008. DYNAMIC IMAGING AND MODELLING OF GOLD PASTE TAILINGS FLOWS 
al., 2006; Fitton et al., 2008), where it is assumed that flow stops when the average velocity drops below the "critical" velocity, demarking the onset of sedimentation. The overall beach slope is then determined by the slope of self-formed tailings channels (Pirouz and Williams, 2007).

Some models that have been used to simulate the slow spreading of non-Newtonian fluids that exhibit a yield stress include the Smooth Particle Hydrodynamics method (SPH), Marker and Cell technique (MAC), among others. The SPH, for example, is a Lagrangian method based on the conservation laws, where the fluid is divided into a set of particles, each of which with associated properties. The constitutive equations are built on the fact that the particles move with the material velocity of the continuum (Rodriguez-Paz and Bonet, 2003). Similarly, the MAC method is a finite difference solution technique that discretizes space into cubical cells, each of which with pressure and velocity. The fluid volume is represented by marker particles that are used to determine which cells contain fluid (Tome and McKee, 1994).

Alike the SPH and MAC techniques, there are other methods to simulate nonNewtonian flows that are much simpler. They basically solve reduced forms of the Navier-Stokes equations using various simplifying assumptions. An example corresponds to the Lubrication Theory, which simplifies the Navier-Sokes equations by assuming the slow spreading of a thin layer of fluid. It should be noted that this theory, which has been used by several researchers (Jeyapalan et al., 1983; Liu and Mei, 1990; Simms, 2007), will be applied in this study.

HENRIQUEZ, J.A. 2008. DYNAMIC IMAGING AND MODELLING OF GOLD PASTE TAILINGS FLOWS 


\subsubsection{Steady state slow spreading of a thin layer of a Bingham fluid}

Lui and Mei (1990) applied the Bingham model as a constitutive equation to study the slow spreading of a thing layer of fluid mud. Lubrication theory was used to deduce the approximate equations for the equilibrium profiles of fluids that yield. This theory, as mentioned previously, essentially assumes a homogeneous fluid, negligible inertia, and a very small thickness-to length ratio, thus, the pressure distribution of the fluid flowing down a plane inclined at an angle $\theta$ will be the one caused by the weight of the fluid (hydrostatic pressure), which is equal to:

$$
p=\rho g(h-z) \cos \theta
$$

where $\mathrm{p}$ is the pressure, $\rho$ is the density of the fluid, $\mathrm{g}$ is the acceleration due to gravity, $\mathrm{h}$ is the thickness of the flow measured perpendicular to the plane, $\mathrm{z}=\mathrm{h}(x, t)$, and $\theta$ is the angle of the surface. Thus, the balance of momentum in the $\mathrm{x}$ direction reduces to (Liu and Mei, 1990):

$$
\rho g \sin \theta-\frac{\partial p}{\partial x}+\frac{\partial \tau}{\partial z}=0
$$

being $\tau$ the shear stress. Then, solving for $\tau$ to get an expression that depends on $\mathrm{z}$,

$$
\tau=\rho g(h-z) \cos \theta\left(\tan \theta-\frac{\partial h}{\partial x}\right)
$$

For a flat bed $(\theta=0)$ and setting $z=0$, an expression for the steady state profile of a Bingham fluid can be obtained (given the condition $\tau<\tau_{\mathrm{y}}$ ):

$$
h^{2}-h_{0}^{2}=\frac{2 \tau_{y}}{\rho g}\left(x-x_{0}\right)
$$

being $h_{o}$ the height at $x_{o}$. 
Simms (2007) examined the applicability of the previous equation for predicting thickened tailings geometry. In his paper he compares profiles of flume tests performed on tailings at field scale. His results show a good agreement between the measured profiles (field scale) and the ones predicted by using equation II.8.

Following the investigations conducted by Lui and Mei (1990) for a twodimensional slow flow on a plane, Yuhi and Mei (2004) examined the slow spreading of fluid mud over a sloped conical surface. They presented the following equation for the steady state profile of flow from the top of a conical hill:

$$
h^{\prime}-h_{o}+\ln \left(1-h^{\prime}\right)=x^{\prime}-x_{o}^{\prime}
$$

where $h^{\prime}$ and $x^{\prime}$ are the normalized variables.

$$
h=h^{\prime}\left[\frac{\partial y}{\rho g \sin \theta}\right] \quad x=x^{\prime} \cot \theta\left[\frac{\tau y}{\rho g \sin \theta}\right]
$$

Simms (2007) also examined the applicability of equation II.9, this time for predicting deposited paste geometry in the field, assuming a conical hill with slopes of 0.5 and 2 degrees. Again, his results show a good agreement between the measured and predicted profiles. 


\subsubsection{Transient slow spreading of a thin layer of a Bingham fluid}

Mei and Yuhi (2000) presented a numerical calculation for predicting the transient spreading of a finite fluid volume. Like in the models presented in the previous section, they applied the lubrication theory, where the inertia is negligible and the pressure is hydrostatic.

The depth-integrated law of mass conservation for one-dimensional limit presented by these authors is:

$$
\frac{\partial h}{\partial t}+\frac{\rho g}{\mu} \frac{\partial}{\partial x}\left[\left(-\frac{\partial h}{\partial x}\right) F\right]=0
$$

where $\mathrm{F}$ and $\mathrm{h}_{0}$ are:

$$
\begin{aligned}
& F=\frac{1}{6}\left(3 h-h_{o}-2 H\right)\left(h_{o}-H\right)^{2} \\
& h_{0}=h-\frac{\tau_{y}}{\rho g}\left(\frac{\partial x}{\partial h}\right)
\end{aligned}
$$

being $h$ : the free surface height, $h_{0}$ : the yield surface height, and $H$ : the channel bottom height. 


\section{MATERIALS AND METHODS}




\subsection{GENERAL CHARACTERISTICS OF THE MATERIAL}

The material that will be used along this study was provided by Barrick Gold Corporation and corresponds to a gold mineral tailings paste that was produced at the Bulyanhulu Mine, located in the north west of Tanzania, Africa.

The tailings were collected from the Bulyanhulu paste plant at the pumping water content (40\%) and then shipped to Carleton University in $20 \mathrm{~L}$ plastic buckets. As received, the tailings had compacted due to vibrations during shipment, producing a layer of water. This water was used during mixing to bring the sample to the desired water content.

The general characteristics of the tailings are presented below. However, information on the chemical composition (solid and liquid phase) is provided in Appendix A.

- Specific gravity $: 2.9$

- Liquid Limit : $\quad 23 \%$

- Plastic Limit : $20 \%$

- Mineralogy

- Silicates $: 80 \%$

- Pyrite $: 6 \%$

- Calcite $\quad: 5 \%$

- Ankerite $: 4 \%$

HENRIQUEZ, J.A. 2008. DYNAMIC IMAGING AND MODELLING OF GOLD PASTE TAILINGS FLOWS 


\subsection{PARTICLE SIZE DISTRIBUTION}

The particle size distribution (PSD) classifies particle sizes in term of their proportions by weight. The results are expressed as the cumulative percentage of the whole sample plotted versus the particle size, on a logarithm scale.

Two methods are generally used to determine the distribution of particle sizes in soils: the sedimentation process by using a hydrometer, to determine particle sizes smaller than $75 \mu \mathrm{m}$; and the sieving method, for particle sizes larger than $75 \mu \mathrm{m}$.

The hydrometer is an instrument, which consists of a bulb (weighted with mercury) attached to a steam (with a paper scale inside it), used to measure the relative density of a suspension (solid-water). Hydrometer readings together with the knowledge of the specific gravity of the soil particles allow for the calculation of the percentage of soil remaining in suspension. The diameter of a particle associated to the percentage determined by a given hydrometer reading is then calculated based on Stokes' law, which relates the settling velocity of a spherical particle to its own weight (more details in ASTM standard D $422-63,1990)$.

For this particular study, the PSD of the gold tailings was determined according to ASTM standard D 422 - 63 (1990) "Standard Test Method for Particle-Size Analysis of Soils". The materials that were used, as well as the experimental procedure followed during this test are presented as follows.

HENRIQUEZ, J.A. 2008. DYNAMIC IMAGING AND MODELLING OF GOLD PASTE TAILINGS FLOWS 


\subsection{Materials}

- A mineral tailing paste sample, supplied by Barrick

Gold. The sample has a specific gravity of 2.9 ,

- A sedimentation cylinder marked for a volume of 1

$\mathrm{L}, 45.7 \mathrm{~cm}$ in height and $6.35 \mathrm{~cm}$ in diameter (Figure

III.1),

- A hydrometer $152 \mathrm{H}$,

- Sieves $\mathrm{N}^{\circ} 40,60,100$, and 200 (Figure III.2),

- A stirring apparatus (Figure III.3),

- A thermometer,

- Distilled water,

- A balance,

- Personal protective equipment (PPE).

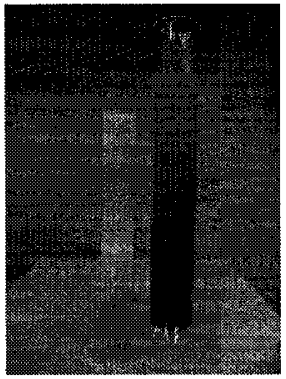

Figure III. 1: Sedimentation Cylinder

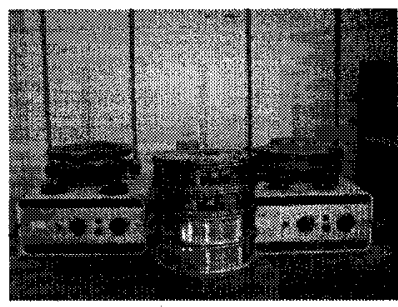

Figure III. 2: Sieves.

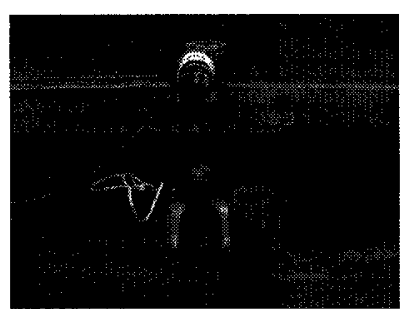

Figure III. 3: Stirrer apparatus.

\subsubsection{Experimental procedure}

\section{Dispersion of the sample}

An air-dry sample of $50 \mathrm{~g}$ was place in a beaker of $250 \mathrm{~mL}$ and then covered with $125 \mathrm{~mL}$ of sodium hexametaphosphate solution $(40 \mathrm{~g} / \mathrm{L})$. The mixture was stirred for 1 min with a glass rod and then allowed to soak for $24 \mathrm{hrs}$. At the end of this period, the sample was transferred to a mixer cup and dispersed for $1 \mathrm{~min}$ using a high-speed mechanical stirrer (see Figure III.3). Once thoroughly dispersed, the suspension was 
poured into a graduated sedimentation cylinder and distilled water was added until the level of $1000 \mathrm{~mL}$ was reached. The cylinder was covered with a rubber stopper and then agitated by turning it upside down and back for $1 \mathrm{~min}$.

\section{Hydrometer test}

After the agitation period, the cylinder was placed on a stable surface to start taking the hydrometer readings. To this end, the hydrometer was inserted into the suspension and the reading was taken at the top of the meniscus formed by the suspension on the stem. After each reading, the hydrometer was removed slowly from the cylinder and placed into another cylinder filled with distilled water with a spinning motion to remove any particles adhered on it. The readings were taken at $2,5,15,30,60$, 250 , and $1440 \mathrm{~min}$.

It should be noted that the temperature of the suspension was recorded after each reading.

\section{Sieving test}

Once the last hydrometer reading was taken, the suspension was poured into the sieve $\mathrm{N}^{\circ} 200(75 \mu \mathrm{m})$ and washed with distilled water for around $5 \mathrm{~min}$. The portion retained was oven dried at $110 \pm 5^{\circ} \mathrm{C}$ and then sieved using the sieves $\mathrm{N}^{\circ} 40,60,100$, and 200. Finally, the mass of the dry samples contained in each sieve was determined.

Several particle size analyses were conducted on the mineral tailing sample following the same procedure described above. 


\subsection{SLUMP TEST}

The slump test, originally used to evaluate the "workability" of fresh concrete (ASTM, 1998), was adopted by Pashias et al. (1996) as a means of measuring the yield stress (minimum shear stress required to cause a material to flow) of mineral suspensions.

Analytical slump test models have previously been developed for the cone and cylinder slump test. This study considered the cylinder model only due to its advantages over the cone model. Some of these advantages includes: more accurate determination of yield stress; simple geometry that makes the cylinder to be easy to fill; mathematically simpler; and generalized for any-sized cylinder (Clayton et al., 2003).

The test basically consists of filling an open-ended cylinder with the test material, removing the excess material at the top, and quickly lifting the cylinder allowing the material to collapse under its weight. The resulting change in height of the slumped material is measured (see Figure III.4).

\subsubsection{Materials}

- A mineral tailing paste sample, supplied by Barrick Gold. The sample has a specific gravity of 2.9 .

- Open-ended Polyvinyl Chloride (PVC) cylinders of various height and diameters, as shown in Table 1 and Figure III.5.

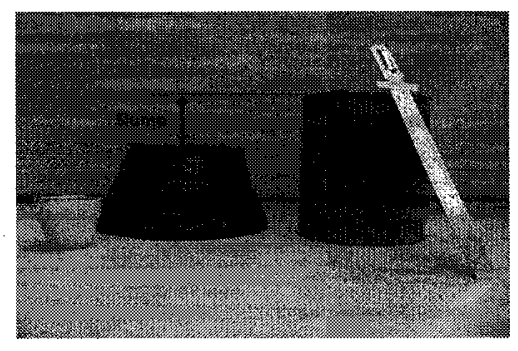

Figure III. 4: Example of a Slump test. 
Table 1: Dimensions of the cylinders used for the tests.

\begin{tabular}{lcc}
\hline & Height $(\mathrm{cm})$ & Diameter $(\mathrm{cm})$ \\
\hline $\mathrm{C} 1$ & 6.22 & 4.78 \\
$\mathrm{C} 2$ & 5.9 & 5.2 \\
$\mathrm{C} 3$ & 8.05 & 5.15 \\
$\mathrm{C} 4$ & 22.9 & 15.25 \\
\hline
\end{tabular}

- Distilled water,

- A smooth flat surface,

- Buckets for mixing,

- A mixing machine (Figure III.6),

- A measurement tape,

- Personal protective equipment (PPE).

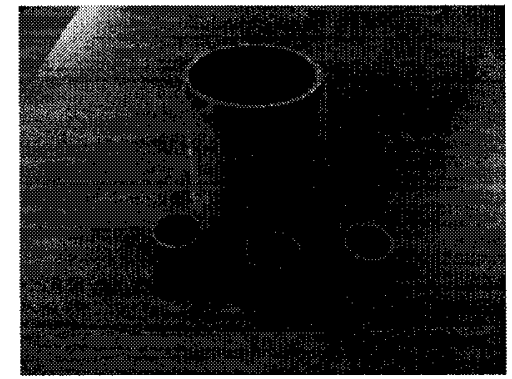

Figure III. 5: Cylinders.

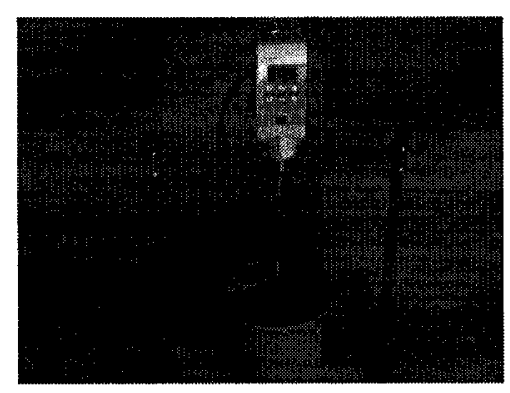

Figure III. 6: Stirring machine.

\subsubsection{Experimental procedure}

Prior to each test the mineral tailing paste sample was placed in a small beaker and mixed with a stirring machine for approximately 10 minutes (see machine in Figure III.6). Once the material was thoroughly mixed, the cylinder was placed on a smooth flat plate and then filled with the sample. After filling, the cylinder was carefully and evenly lifted (in less than 7 seconds) allowing the material to collapse under its own weight. The change in height between the cylinder and the deformed material (see example in Figure III.4) as well as the diameter of the outward flow of the sample were measured. Note that the middle point of the material was taken as the representative height. 
Several slump tests were conducted on the mineral tailing sample following the same procedure described previously and using four different cylinder sizes (see dimensions in Table 1). Additionally, for each test the water content of the material was varied between $25 \%-55 \%$ in order to obtain different consistencies.

It is worth noticing that the tests were performed on the sample in the "asreceived" stated (no defloculant was added) and at room temperature (around $22-24^{\circ} \mathrm{C}$ ). 


\subsection{FLUME TEST}

The flume test has been extensively used to study the depositional behaviour of dewatered mine tailings (Sofra and Boger, 2001; Kwak et al., 2004; Engman et al., 2004). It basically consists of a flow channel with a reservoir in one of the edge. With the gate down, the reservoir is filled with the material and then the gate is quickly lifted allowing the material to flow down the plane until it comes to rest. The resulting length and height at two different locations is measured, allowing the calculation of the angle of repose. Sofra and Boger (2001), for example, used a small scale incline plane flume $(0.2$ $\mathrm{m}$ wide and $2 \mathrm{~m}$ long) with base angles varying from 0 to 4 degrees to examine the effect that yield stress and viscosity have on the angle of deposition of dewatered tailings.

For this particular study, flume tests will be performed on horizontal planes, on successive layers, at different initial slopes, and for different volumes of material. The length of the flow and the depth at different locations will be measured in order to determine the resulted profile of each flow. In addition, a high speed camera will be used to record the tests.

\subsubsection{Materials}

- A mineral tailing paste sample, supplied by Barrick Gold. The sample has a specific gravity of 2.9 .

- Flume apparatus with acrylic side walls of high optical quality (Figure III.7). The dimensions of

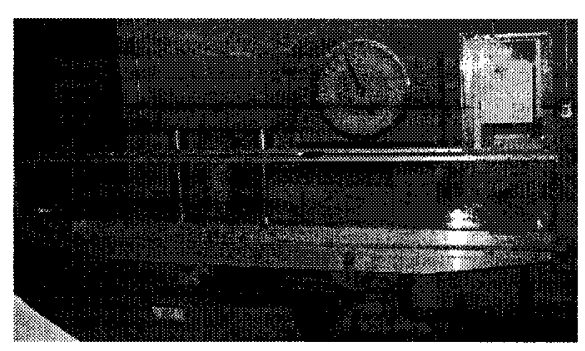

Figure III. 7: Flume apparatus. 
the flume (flow channel) are presented below.

\begin{tabular}{lc}
\hline & $\mathrm{cm}$ \\
\hline Length & 243 \\
Height & 30 \\
Width & 15.2 \\
\hline
\end{tabular}

- A high speed camera, model IN250 (Figure III.8), with a capture of 250 frames per second,

Figure III. 8: High speed camera.

- A laptop,

- Buckets for mixing,

- A mixing machine (Figure III.9),

- A measurement tape,

- A funnel,

- Personal protective equipment (PPE).
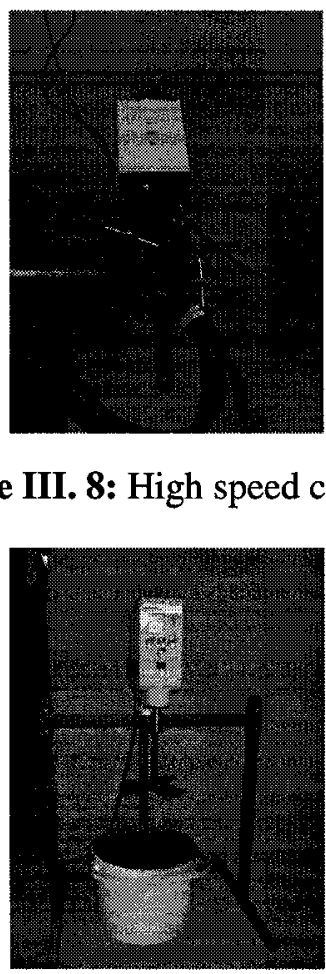

Figure III. 9: Stirring machine.

\subsubsection{Experimental procedure}

Several flume tests were performed by using two methods: 1. - by placing the material in the reservoir of the flume and 2. - by pouring it through a funnel. In both cases and prior to each test the mineral tailing paste sample was placed in a bucket and mixed with a stirring machine (see Figure III.9) for approximately 10 minutes.

Once the material was thoroughly mixed it was placed in the reservoir of the flume at a specified height $(20 \mathrm{~cm}$ and $10 \mathrm{~cm})$. Then the gate was quickly lifted allowing the material to flow down the plane until it came to rest. Once the material had visually stopped the length of the flow and the depth at different locations (every $5 \mathrm{~cm}$ ) were measured. 
The same procedure was followed for the second method, with the exception that the material was poured into the flume through a funnel with a diameter of $2.4 \mathrm{~cm}$.

Flume tests on successive layers were conducted using the funnel. Before pouring a new layer the previous one was left to dry and self-weight consolidate to a moisture content on the order of $30 \%$. This allowed avoiding remobilization of the old layer when placing a fresh one.

A few flume tests were performed to examine the effect of the width of the flume apparatus and the friction of the walls. To this end, the flume was narrowed from $15 \mathrm{~cm}$ to $10 \mathrm{~cm}$ and the walls were lubricated with hydrophobic grease.

It is worth noticing that the tests were performed on the sample in the "asreceived" stated (no defloculant was added) and at room temperature (around $22-24^{\circ} \mathrm{C}$ ). In addition, flume tests were performed over the course of the experimental program (May 2007 - March 2008). No variability in the flow profiles (for tests performed with the same amount of material and at the same gravimetric water content) was observed. 


\subsection{POURING TEST}

This test basically consists of pouring a certain volume of material through a funnel, forming a conical stack that will grow upwardly and radially (see Figure III.10).

The pouring tests will be performed on a horizontal surface and a high speed camera will be used to record the flows.

\subsection{Materials}

- A mineral tailing paste sample, supplied by Barrick Gold,

- A smooth flat surface,

- A high speed camera,

- A laptop,

- Buckets for mixing,

- A mixing machine (Figure III.11),

- A measurement tape,

- A funnel,

- Personal protective equipment (PPE).

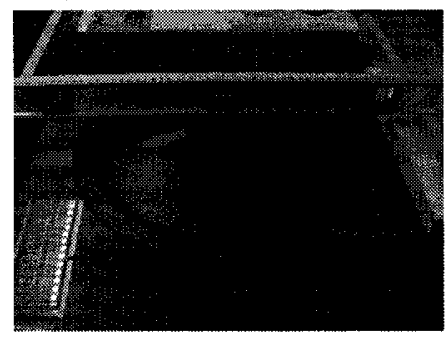

Figure III. 10: Example of a pouring test.

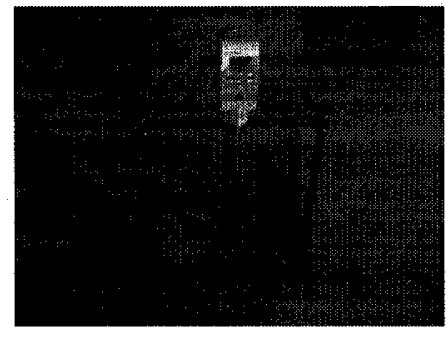

Figure III. 11: Stirring machine.

\subsubsection{Experimental procedure}

Prior to each test the mineral tailing paste sample was placed in a bucket and mixed with a stirring machine for approximately 10 minutes. 
Once the tailings were thoroughly mixed, a certain volume was poured through the funnel. Once the material had visually stopped, the extent of the flow and the height at different locations were measured in order to obtain the resulted profile.

Note that the tests were performed on the sample in the "as-received" stated (no defloculant was added) and at room temperature $\left(22-24^{\circ} \mathrm{C}\right)$. 


\subsection{MODELLING THE SLOW SPREADING OF A BINGHAM FLUID}

\subsubsection{Steady state flow prediction}

As presented in Section 2.7.1, a two-dimensional equilibrium profile of a slow spreading of a thin layer of a Bingham fluid on a flat bed can be described by the following equation (Lui and Mei, 1990):

$$
h^{2}-h_{0}^{2}=\frac{2 \tau_{y}}{\rho g}\left(x-x_{0}\right)
$$

where $\tau_{\mathrm{y}}$ is the yield stress, $\rho$ is the bulk density, $g$ is the acceleration due to gravity, $h$ is the thickness of the flow measured perpendicular to the plane at a particular $x$, and $h_{0}$ is the height at $x_{0}$.

Similarly, the steady state slow spreading of a fluid from the top of a conical hill can be described as follows (Yuhi and Mei, 2004):

$$
h^{\prime}-h_{o}+\ln \left(1-h^{\prime}\right)=x^{\prime}-x_{o}^{\prime}
$$

being $h$ ' and $x$ ' the normalized variables, which are defined as:

$$
h=h^{\prime}\left[\frac{\partial y}{\rho g \sin \theta}\right] \quad x=x^{\prime} \cot \theta\left[\frac{\partial y}{\rho g \sin \theta}\right]
$$

Flow profiles obtained from flume tests will be compared with those predicted using the previous equations. To this end, eqn. III.1 and III.2 will be fitted to laboratory flume tests by setting $X_{0}$ to be the run-out distance and, therefore, $h_{0}$ becomes zero. Then, by simple calculation using "Solver" of Microsoft excel the heights at different run-out can be obtained.

HENRIQUEZ, J.A. 2008. DYNAMIC IMAGING AND MODELLING OF GOLD PASTE TAILINGS FLOWS 


\subsubsection{Transient prediction}

As presented in section 2.7.2, a numerical calculation for predicting the onedimensional transient spreading of a finite fluid volume is given by (Mei and Yuhi, 2001):

$$
\frac{\partial h}{\partial t}=-\frac{\rho g}{\mu} \frac{\partial}{\partial x}\left[\left(-\frac{\partial h}{\partial x}\right) F\right]
$$

where $\mu$ is the dynamic viscosity and the terms $F$ and $h_{0}$ correspond to:

$$
\begin{aligned}
& F=\frac{1}{6}\left(3 h-h_{o}-2 H\right)\left(h_{o}-H\right)^{2} \\
& h_{0}=h-\frac{\tau_{y}}{\rho g}\left(\frac{\partial x}{\partial h}\right)
\end{aligned}
$$

being, $h_{0}$ : the yield surface height, $h$ : the free surface height and $H$ : the channel bottom height. Note that for a horizontal surface $\mathrm{H}$ becomes zero.

For this particular study, equation III. 4 was used to simulate the transient flow of gold paste tailings. To this end, a one-dimensional finite volume solution scheme of equation III.4 was applied using Microsoft Excel. Macros were employed to specify the input and output sequence and the Visual Basic application was used to run the macros.

A mesh of $2 \mathrm{~m}$ long was considered, with a spatial discretization of $0.02 \mathrm{~m}$ and a time step of $0.0001 \mathrm{~s}$ (see Figure III.12 on the next page). It should be noted that this time step $(0.0001 \mathrm{~s})$ was chosen based on several trials to determine the largest time step that did not affect the results.

HENRIQUEZ, J.A. 2008. DYNAMIC IMAGING AND MODELLING OF GOLD PASTE TAILINGS FLOWS 


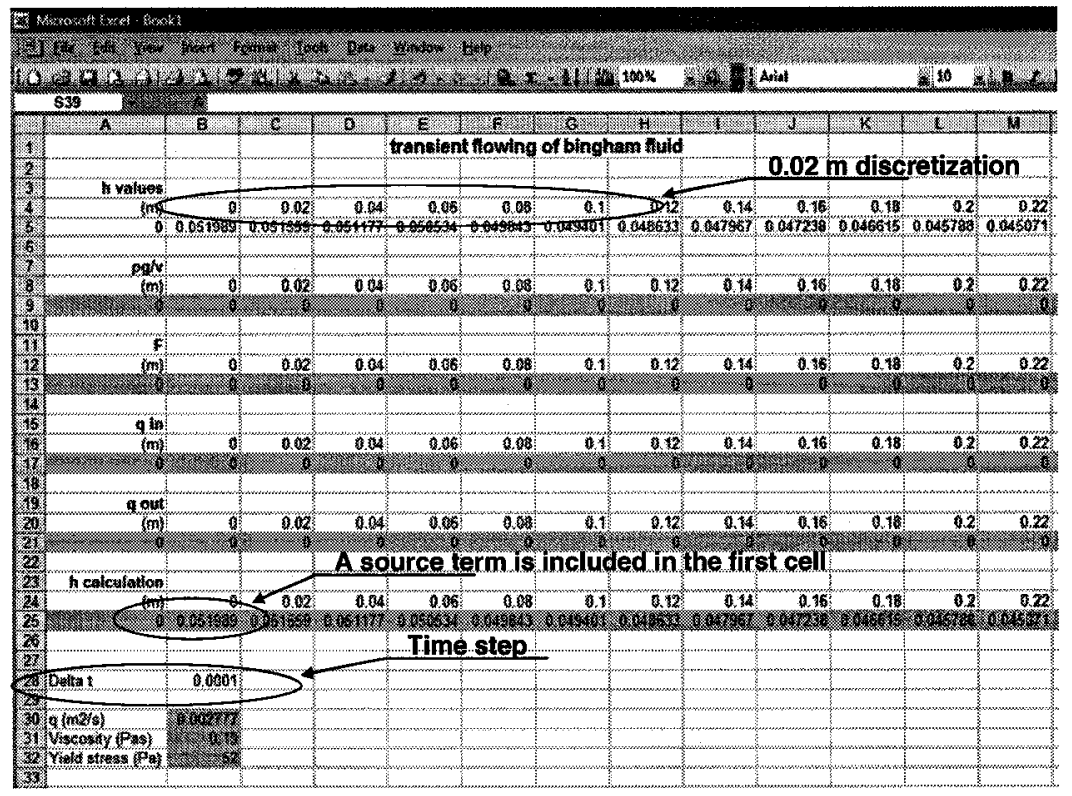

Figure III. 12: Example of spread sheet used to determine the free surface height $(h)$ values.

The calculation of the $h$ values was done as follows:

- A source term $\left(q^{*} \Delta t\right)$ was added onto equation III.4 and introduced into the first cell of the spatial mesh (cell B25 in Figure III.12) to allow for addition of mass. Note that the "q" was based on flow rates determined by observing the volume of tailings in the flume at any one time. The volume of tailings was deduced from the images recorded by the high speed camera.

- The terms $\rho g / \mu$ and $F$ were calculated separately in rows 9 and 13 of Figure III.12,

- The mass coming in and out ("q in" and "q out") of the individual cells was given by $q=\frac{\rho g}{\mu} \frac{\partial h}{\partial x} F$ from equation III.4. The spatial derivative $(\partial h / \partial x)$ was evaluated at each mesh element boundary. For example, in cell C25 of Figure III.12, $\partial h$ (for 
"q in") is calculated by subtracting the $h$ value contained in cell B5 minus the one contained in cell $\mathrm{C5}$, whereas when determining the mass coming out, $\partial h$ is calculated by subtracting D5 minus C5.

- The free surface height values $(h)$ are calculated in row 25 of Figure III.12, where each cell evaluates the condition for flow to occur, that is, the yield stress $\left(\tau_{\mathrm{y}}\right)$ of the fluid must be higher that the shear stress. As the $h$ values are being calculated, they are copied into the cells of row 5.

- The visual basic application was used to loop the calculation (an example of a session in Microsoft Visual Basic is presented in Figure III.13). The time considered in this calculation corresponded to the time for the tailings to stop flowing. This time was determined from the images recorded by the high speed camera.

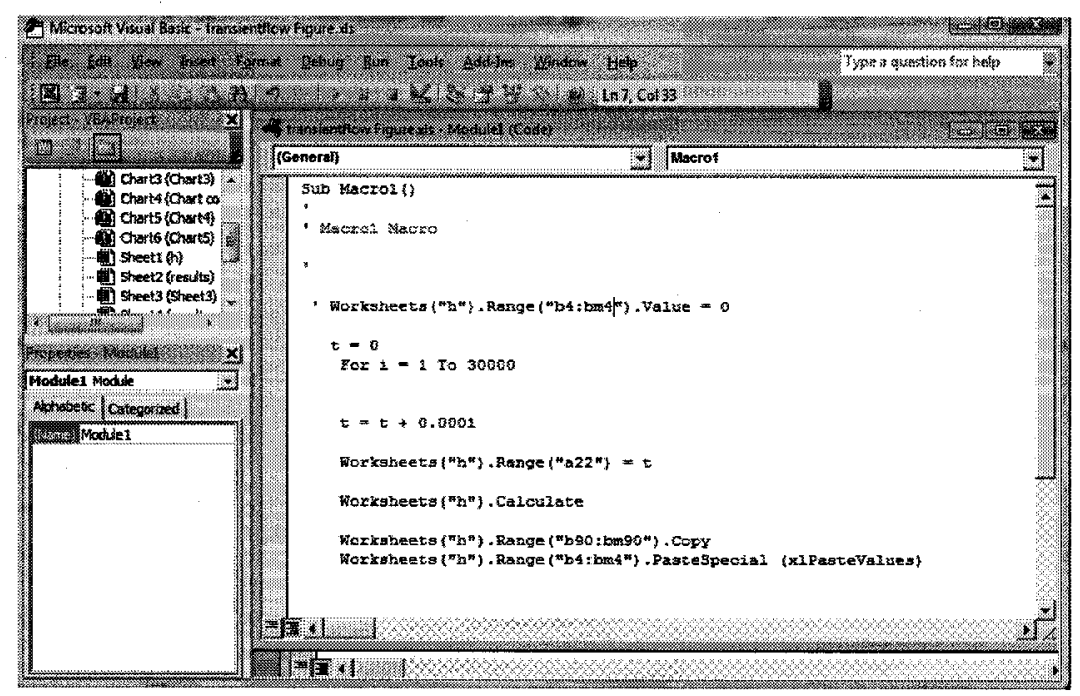

Figure III. 13: Microsoft Visual Basic code to loop calculation. 


\section{RESULTS AND DISCUSSION}




\subsection{RESULTS}

The following sections present the results obtained from the experimental work contemplated in this study, which consisted of particle size distribution analysis, slump tests, rheological characterization, flume experiments, and pouring tests.

\subsubsection{Particle size distribution}

Particle size distributions analyses were conducted on a gold mineral tailings paste sample provided by Barrick Gold. The results are illustrated in Figure IV.1 in terms of percentage of fines by weight versus diameter of particles.

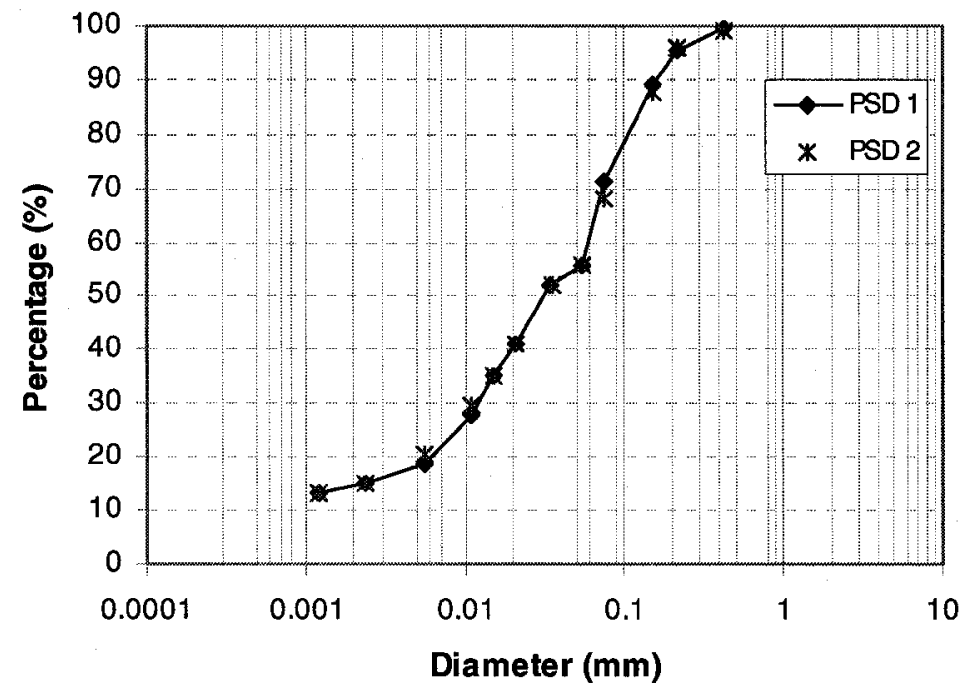

Figure IV. 1: Particle size distribution curve.

The particle size distribution curve presented above reveals that the grain size of the gold tailings sample ranges from $1 \mu \mathrm{m}$ to $0.5 \mathrm{~mm}$, having an average size $\left(\mathrm{d}_{50}\right)$ of approximately $35 \mu \mathrm{m}$. It should be also noted that around $40 \%$ by weight corresponds to particles finer that $20 \mu \mathrm{m}$.

HENRIQUEZ, J.A. 2008. DYNAMIC IMAGING AND MODELLING OF GOLD PASTE TAILINGS FLOWS 


\subsubsection{Slump tests}

A series of slump tests were conducted on the mineral tailing paste sample at a variety of water content and cylinders sizes. The results are presented in Figure IV.2 below in terms of dimensionless slump height as a function of water content.

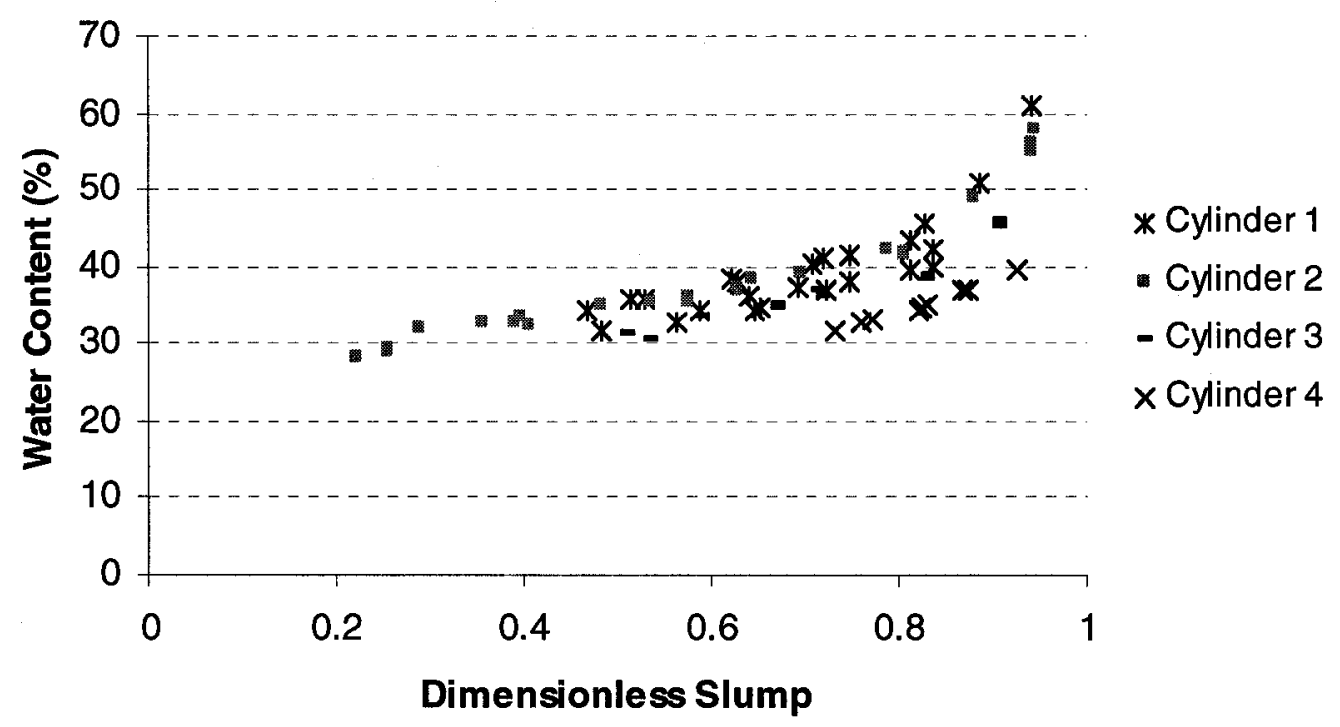

Figure IV. 2: Slump test results in the form of dimensionless slump vs. water content.

As can be observed from the previous figure, the height of the cylinder can slightly affect the slump results. For example, no significant difference is found when looking at the results obtained from the small cylinders (Cylinders 1, 2, and 3); however, the dimensionless slump heights for the largest cylinder (Cylinder 4 in the graph) deviates from the other ones, being higher at the same water content.

Several investigations have been performed to study the relationship between the slump height and the yield stress. Pashias et al. (1996), for example, demonstrated that 
the slump test provides a simple and effective method for measuring yield stresses. In their paper they provide an equation that relates the slump height to the yield stress. That equation corresponds to:

$$
\tau_{y}^{\prime}=\frac{1}{2}-\frac{1}{2} \sqrt{s^{\prime}}
$$

where $\tau_{\mathrm{y}}{ }^{\prime}$ and $S^{\prime}$ are the dimensionless yield stress and slump height. The yield stress is determined by multiplying the dimensionless yield stress by $\rho g h$; being $\rho$ the density of the material, $g$ the acceleration due to gravity, and $h$ the height of the cylinder.

Based on the previous equation the yield stress for each test was calculated. The results are presented in Figure IV.3 as follows.

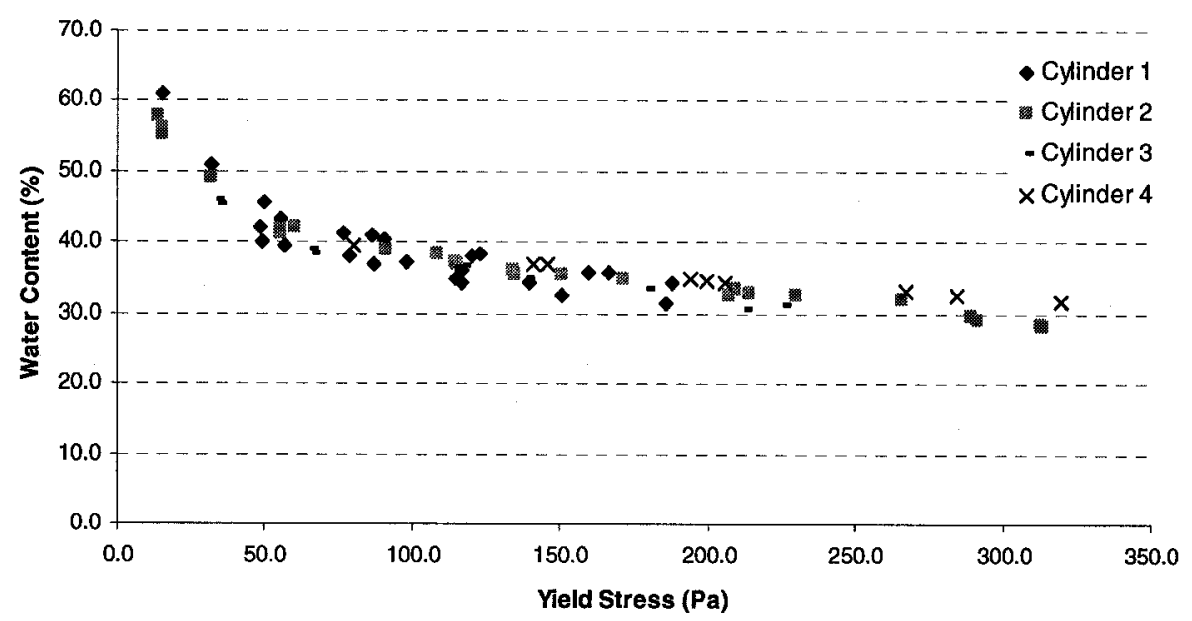

Figure IV. 3: Yield stress results for four different cylinders in the form of yield stress vs. gravimetric water content.

As observed from Figure IV.3 above, the yield stress of the sample becomes very sensitive to changes in water content at the range of 30 and $40 \%$. In this range a small change in water content leads to a high change in the yield stress of the sample. 


\subsubsection{Rheological Characterization}

A $1 \mathrm{~L}$ sample of tailings was sent to Golder Paste Technology for rheological testing. The characterization of the governing rheological properties of the sample (yield stress and viscosity) was undertaken using a Rheometer, model R/S-CPS.

Yield stress values determined using the Rheometer are presented in Figure IV.4 bellow. It should be noted that these values were obtained by fitting the Bingham model to shear stress- shear rate data corresponding to shear rates values greater than $50 \mathrm{sec}^{-1}$ (see Figure IV.5 on the next page), that is, the experimental data below $50 \sec ^{-1}$ was cut from the graph before fitting the model. This procedure is often done in practice due to measurement errors in the low shear rate range (DIN 53019).

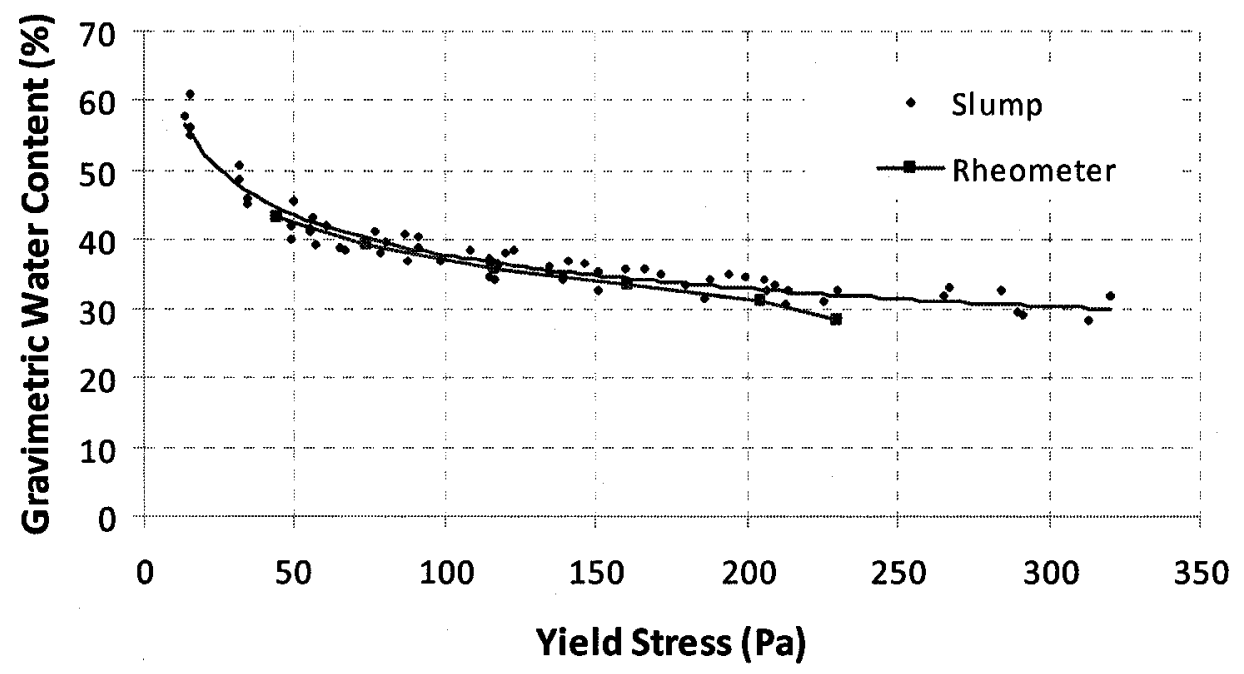

Figure IV. 4: Yield stress values as a function of gravimetric water content determined using a rheometer. Note that slump test results are also included in the graph. 
As noted from the previous figure, the results from the slump tests show good agreement with those obtained by the rheometer, especially for yield stress values lower than $150 \mathrm{~Pa}$.

The flow curve obtained for a sample with $71.7 \%$ solids content (around $40 \%$ gravimetric water content) is presented in the two following figures. Figure IV.5 shows the data without the low shear rate range, whereas Figure IV.6 presents the entire data.

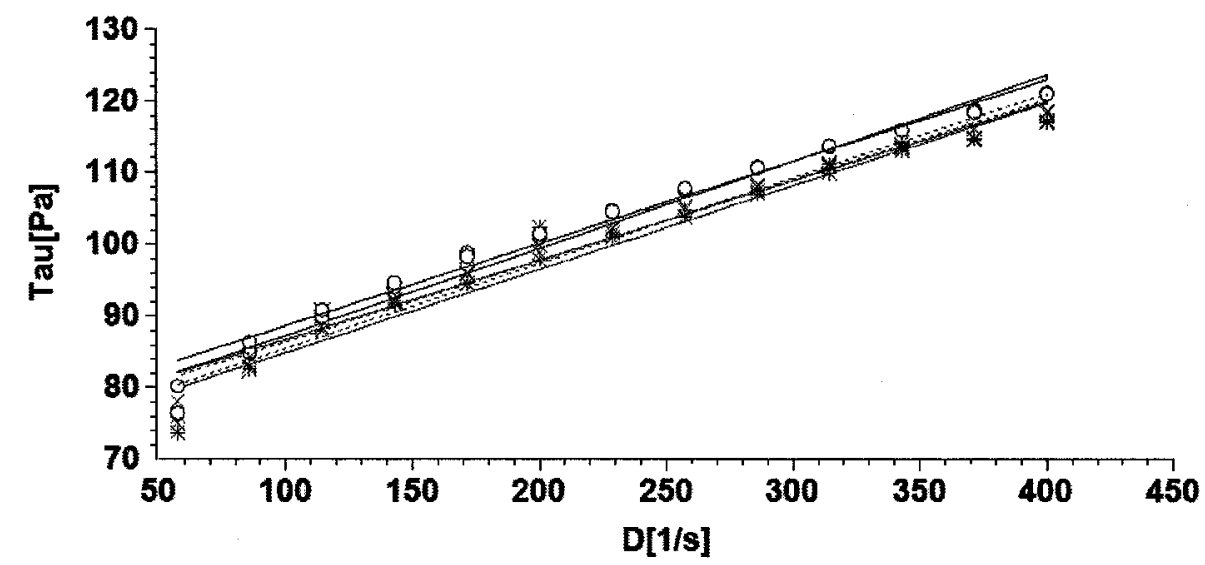

Figure IV. 5: Rheogram for a $71.7 \mathrm{wt} \%$ solids tailings sample without the low shear rate range. Note that several tests are shown.

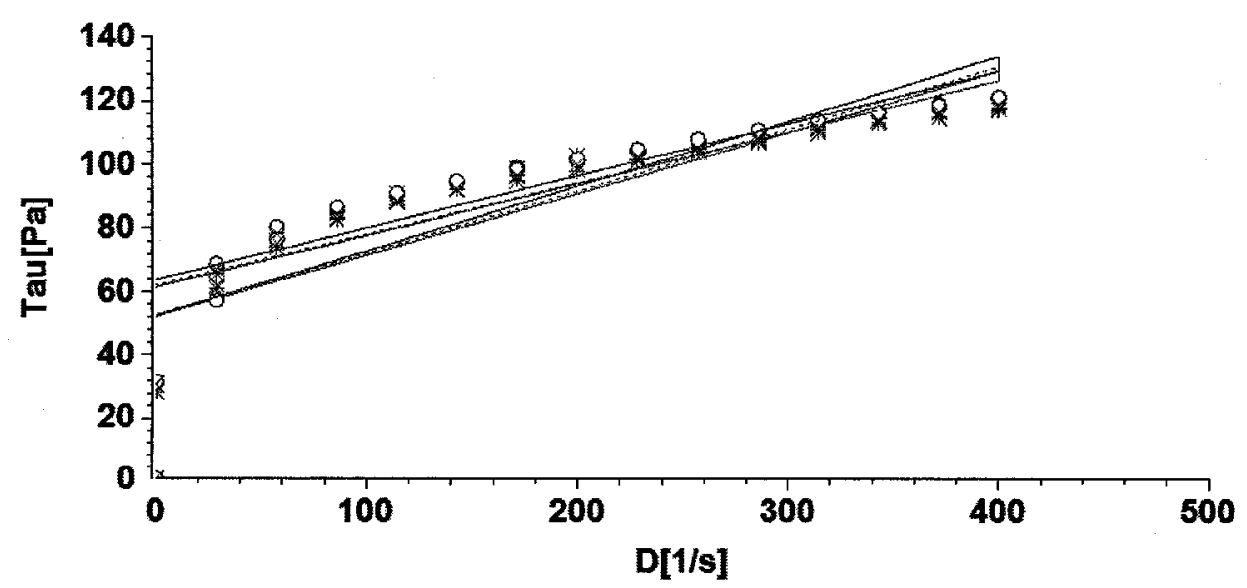

Figure IV. 6: Rheogram for a 71.7 wt\% solids tailings sample with the entire data. Note that several tests are shown. 
As observed from the previous figures, the shear rate was varied from 0 up to 400 $\sec ^{-1}$ approximately. This range of shear rate is normally used for pipeline design, when determining the flow properties to transport the tailings through a pipe. Therefore, yield stress values obtained at such high range of shear rate may not necessarily represent the yield stress that is related to the flow deposition of the tailings, that is, the yield stress at which the tailings will stop flowing.

As can be observed from Figure IV.6 on the previous page, the flow curve describes better a pseudo-plastic behaviour than a perfect Bingham fluid. However, when considering only the lower shear rate range $\left(<90 \mathrm{sec}^{-1}\right)$, a new curve is obtained that represents a more acceptable approximation to Bingham behaviour (see Figure IV.7 below).

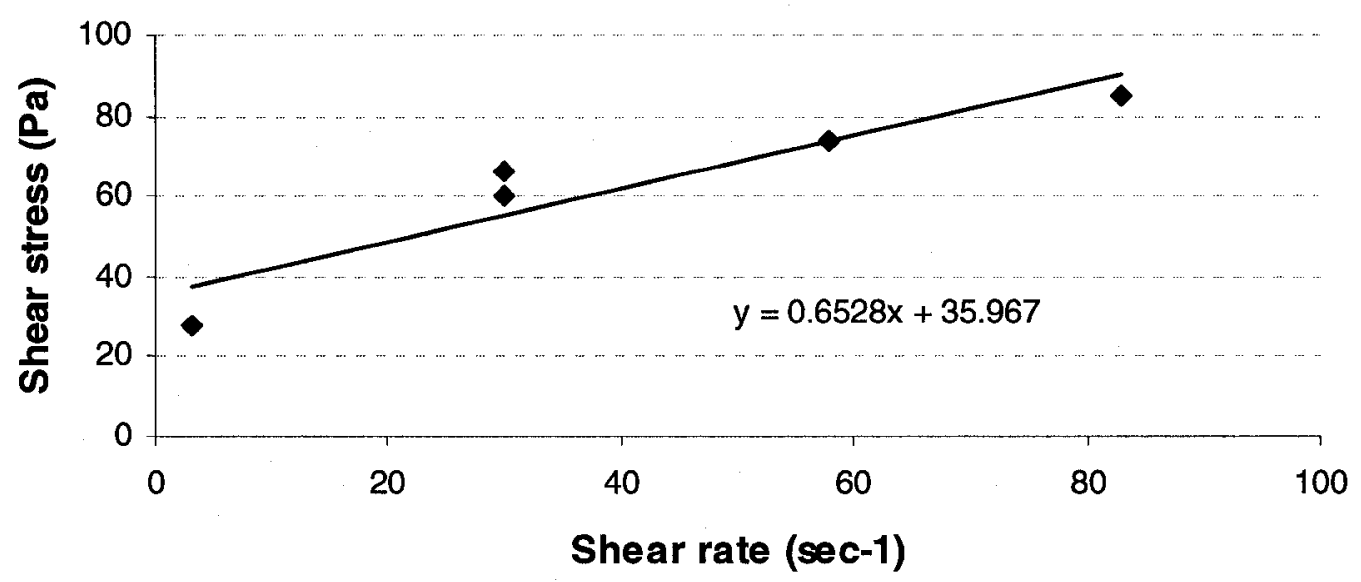

Figure IV. 7: Flow curve for a $71.7 \mathrm{wt} \%$ solids tailings sample. Shear rate ranging from 0 to 90 $\sec ^{-1}$. 
As mentioned earlier, the flow behaviour of paste tailings can be described by the Bingham model, which is characterized by a straight line with an intercept on the shear stress axis that represents the yield stress. The viscosity, in this case, corresponds to the slope of the line.

In this context, as observed from the three rheoggrams shown previously (Figures IV.5, IV.6, and IV.7), depending on the shear rate range that is considered, three different yield stress and viscosity values can be obtained for the same sample when fitting the Bingham model:

- Figure IV.5: Yield stress $=73 \mathrm{~Pa}$ and Viscosity $=0.12 \mathrm{~Pa} \cdot \mathrm{s}$,

- Figure IV.6: Yield stress $=52 \mathrm{~Pa}$ and Viscosity $=0.19 \mathrm{~Pa} \cdot \mathrm{s}$,

- Figure IV.7: Yield stress $=36 \mathrm{~Pa}$ and Viscosity $=0.65 \mathrm{~Pa} \cdot \mathrm{s}$.

It should be noted; however, that for the purposes of this study, yield stress values obtained by fitting the Bingham model to the high shear rate range will not be considered, since this will not adequately characterize the flow behaviour at the range of interest for deposition (low shear rates). Instead, an approximate yield stresses of $36 \mathrm{~Pa}$ and a viscosity of $0.65 \mathrm{~Pa}$ 's will be evaluated along this study. 


\subsubsection{Flume tests}

A flume apparatus was used to study the behaviour of the gold mine tailings during flow. Flume tests on horizontal planes, on successive layers, at different initial slopes, and for different volumes of material were considered in this investigation. The results are presented as follows.

\subsubsection{Flume tests on horizontal planes}

Initial flume tests were performed on horizontal planes to evaluate the effect of water content on the extent of the flow. The results are presented in Figure IV. 8 below.

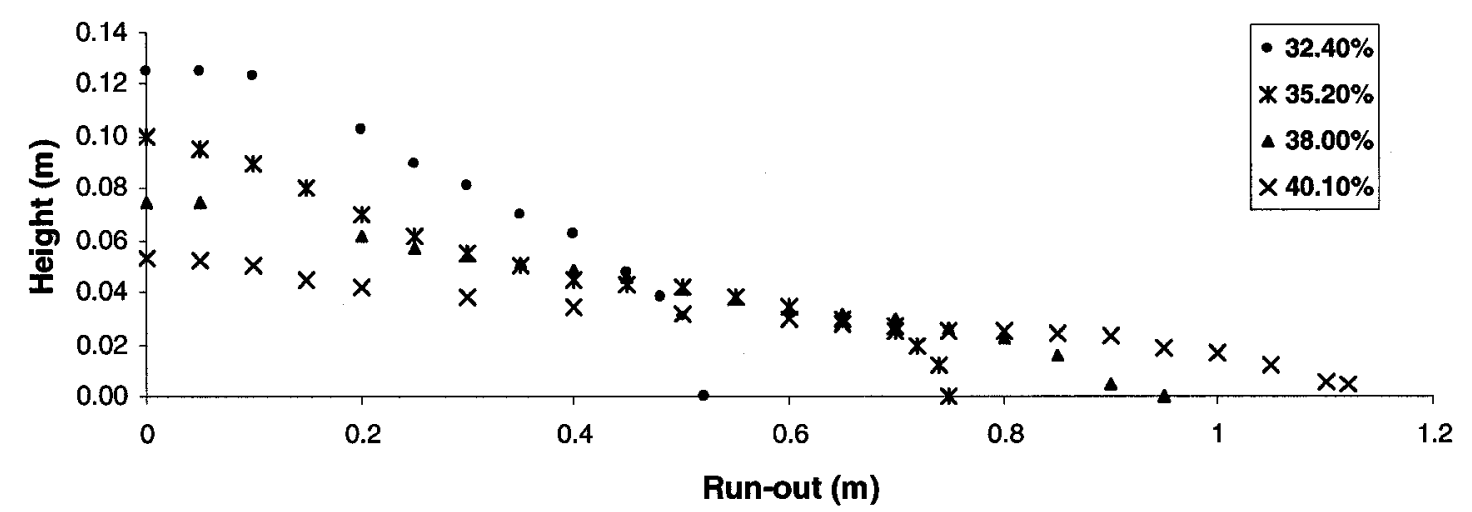

Figure IV. 8: Graphical representation of flume tests performed on a horizontal plane and using the gate. Gravimetric water content ranging from 32 to $40 \%$ respectively.

As expected, the run-out of the flows increases when increasing the water content of the sample. For example, the sample with a gravimetric water content of $40 \%$ resulted in a run-out of approximately $120 \%$ greater that the one with $30 \%$ of water content for the same volume of material. 
Subsequent flume tests were performed with tailings having a gravimetric water content and solids concentration of $40 \%$ and $71 \%$ respectively. These values represent the typical thickening level to economically pump the tailings to the surface containment facility. Higher values will result in higher yield stresses and, therefore, a considerable increase in pumping costs.

The results for the flume tests on a horizontal plane and at $40 \%$ of gravimetric water content are presented in Figure IV.9 as follows.

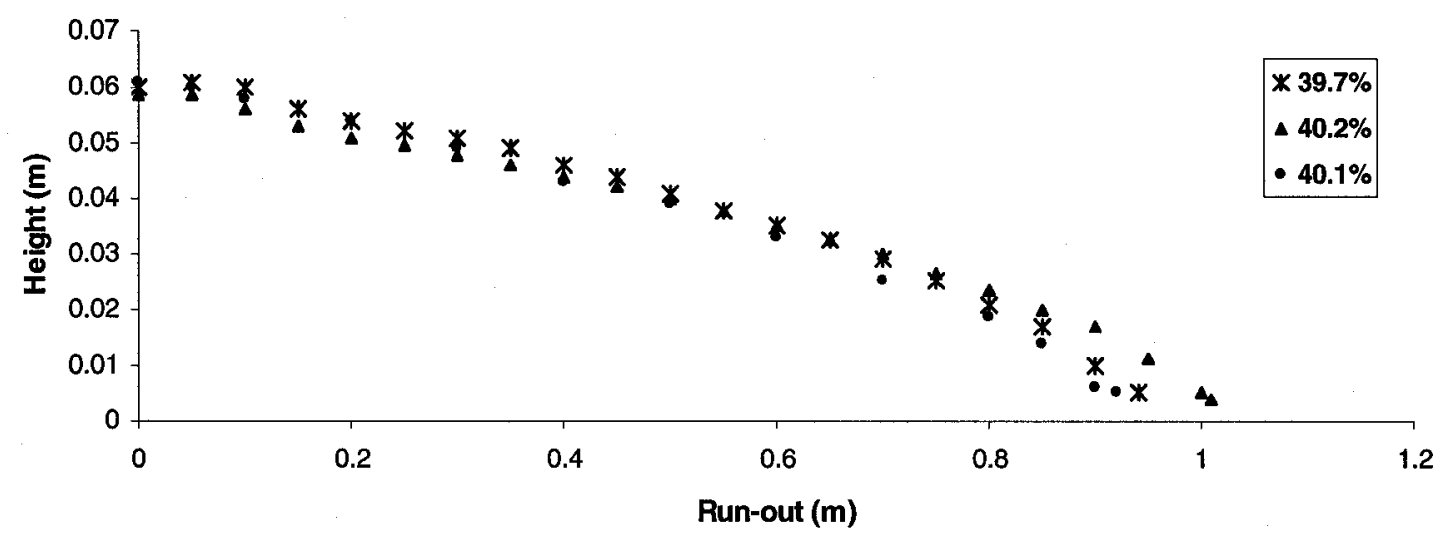

Figure IV. 9: Graphical representation of flume tests performed on a horizontal plane and using the funnel. Gravimetric water content ranging from 39 to $40 \%$ respectively.

An interesting observation arises when looking at the extent of the flow obtained when using the funnel and gate (see Section 3.4 for more information about these two methods). As can be observed from Figure IV.10 on the next page, tests performed with the gate resulted in a greater flow distance than the tests conducted with the funnel for a given water content $(40 \%)$ and volume $\left(\sim 5500 \mathrm{~cm}^{3}\right)$. 

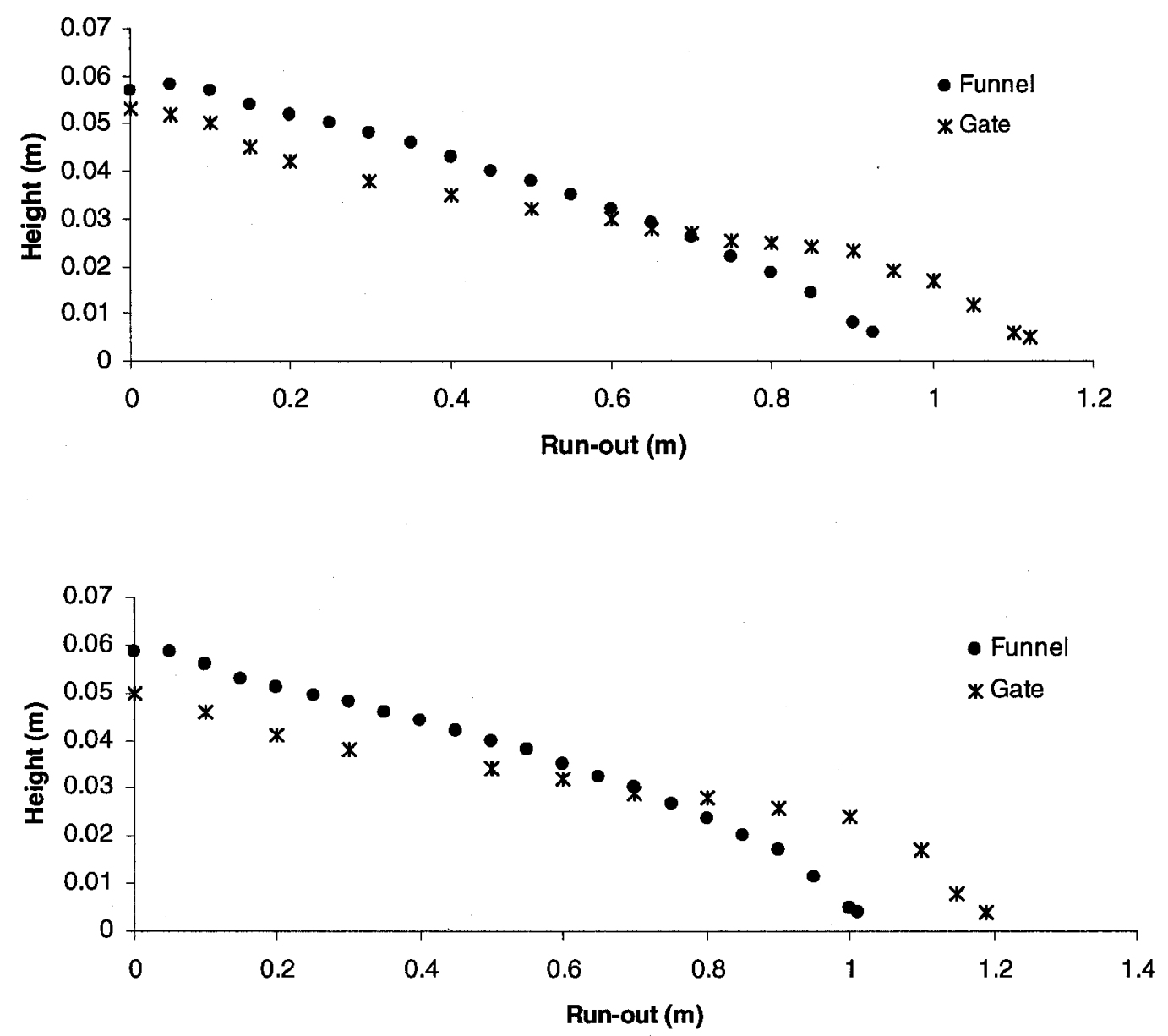

Figure IV. 10: Comparison between flume tests performed with funnel and gate. Both on a horizontal plane and with sample at $40 \%$ gravimetric water content.

However, when reducing the volume of material to half of the initial one, that is, reduce the volume being poured through the funnel, as well as reduce the height of the material in the reservoir (lower hydrostatic pressure), no considerable difference is observed (see Figure IV.11 on the next page). 


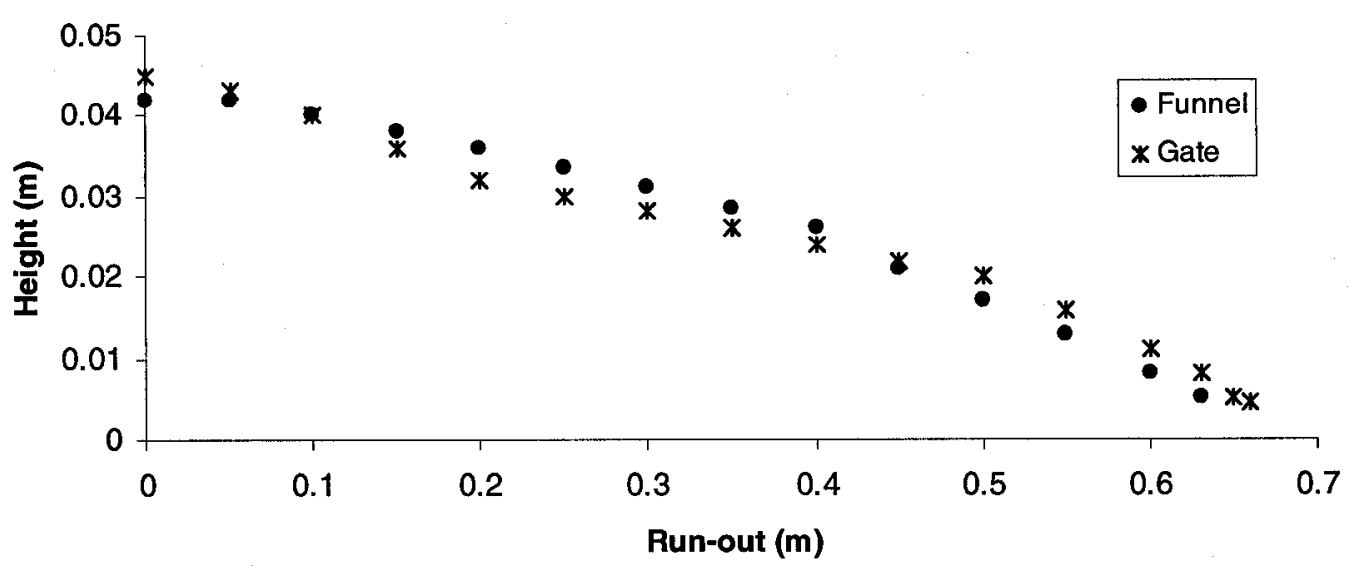

Figure IV. 11: Comparison between flume tests performed with funnel and gate using less volume of material. Both on a horizontal plane and with sample at $40 \%$ gravimetric water content.

It should be noted that no further tests employing method 1 (with gate) were performed, as it was believed that too much inertia was being imparted to the flow, violating the assumption of lubrication theory. In addition, in the reality the tailings are discharged through pipes and not by using gates.

As mentioned earlier, flume tests were also performed for different volumes of material. The results are presented in Figure IV.12 below.

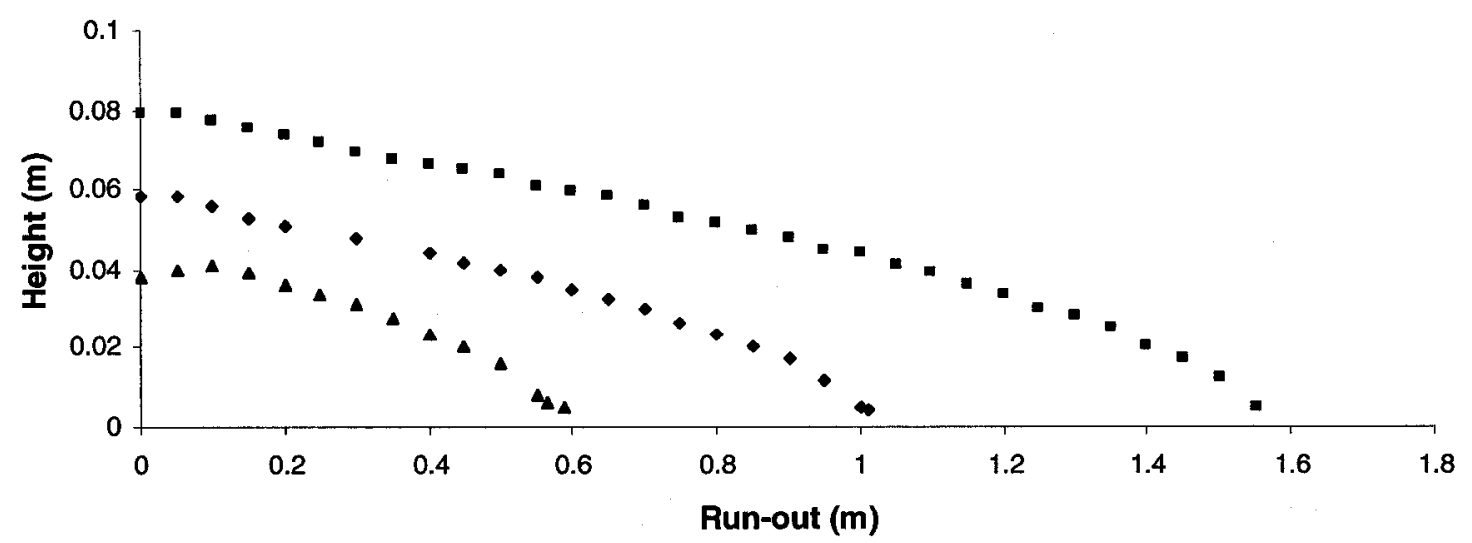

Figure IV. 12: Flume tests for different volumes of tailings. Sample at $40 \%$ gravimetric water content. 
A few flume tests were performed to examine the effect of both the width of the flume apparatus and the friction of the walls on the resulted flow profiles. To this end, the flume was narrowed from $15 \mathrm{~cm}$ to $10 \mathrm{~cm}$ and the walls were lubricated with hydrophobic grease. As presented in Figure IV.13 below, the changes did not affect the final equilibrium profile of the flows.
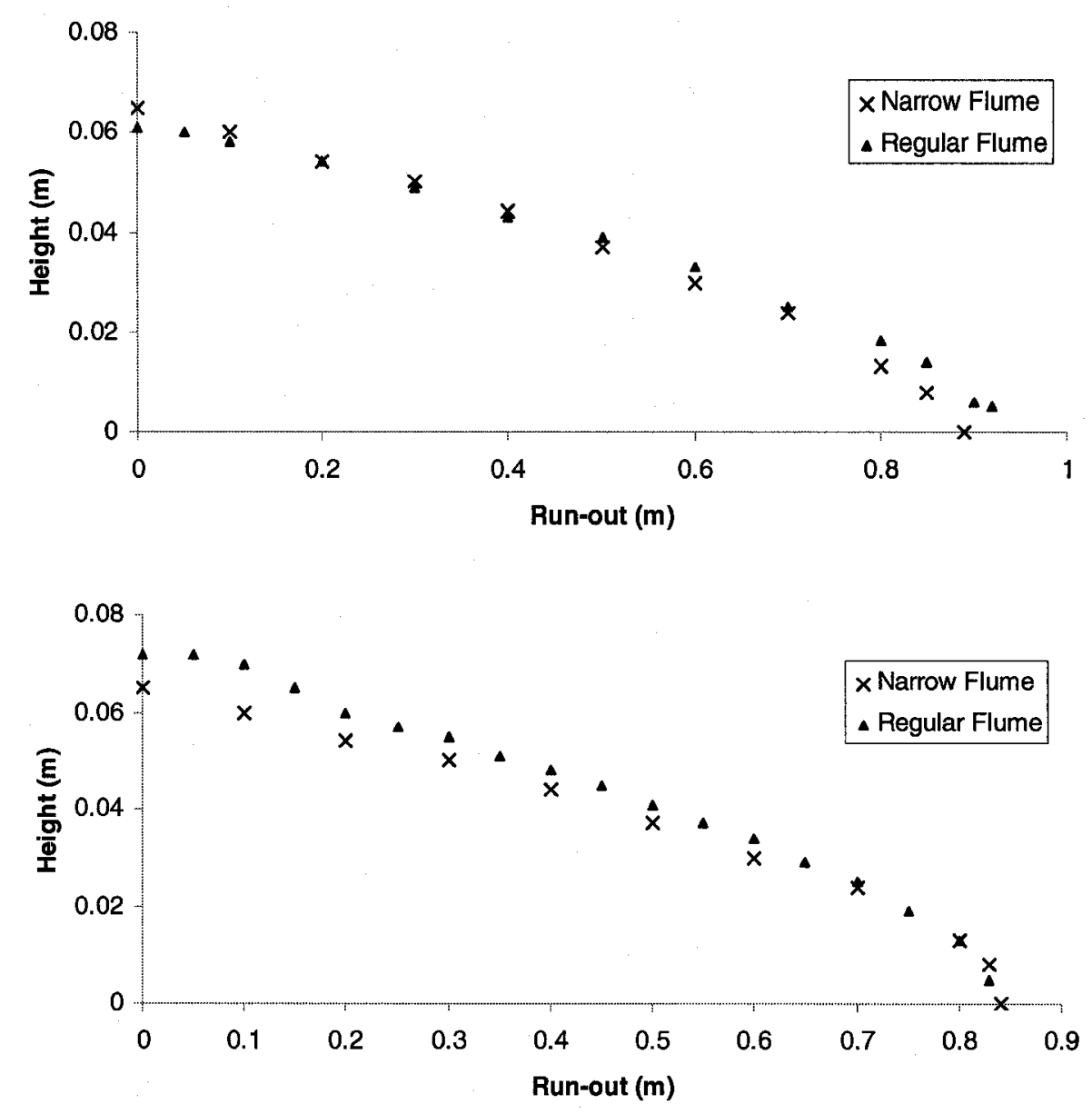

Figure IV. 13: Comparison between flow profiles obtained using a narrow flume with lubrication and the regular flume with no lubrication. Note that the same volume of material per unit width was used. Sample at $40 \%$ gravimetric water content. 


\subsubsection{Flume tests on successive layers}

Flume tests on successive layers and using a funnel to pour the material were conducted to evaluate the effect of topography on the angle of repose after the material come to rest. Three and five different layers were considered in the tests; each of one with an initial gravimetric water content of $40 \%$. It should be noted that before pouring a new layer the previous one was left to dry and self-weight consolidate to a moisture content on the order of $30 \%$. This allowed avoiding remobilization of the old layer when placing a fresh one.

Figures IV.14 and IV.15 as follows present the flow profiles obtained after pouring five and three different layers, one on top of each other. It is worth noticing that the height of the old layer decreased (between $0.1-0.4 \mathrm{~cm}$ ) once consolidated.

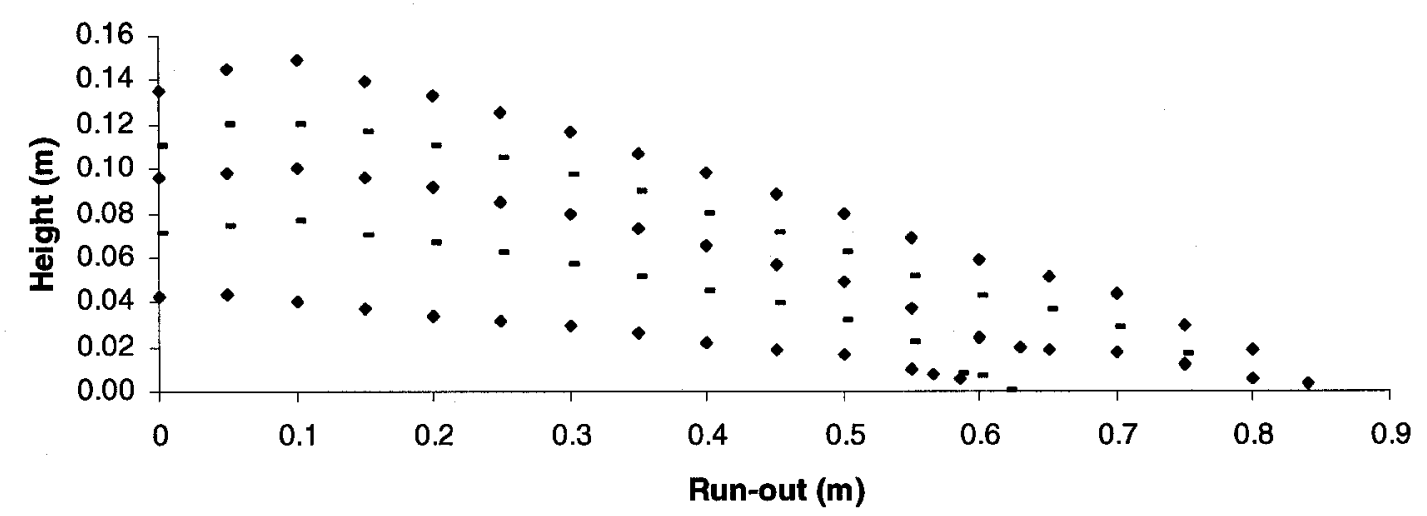

Figure IV. 14: Flume tests results of five successive layers. Samples at $40 \%$ gravimetric water content. 


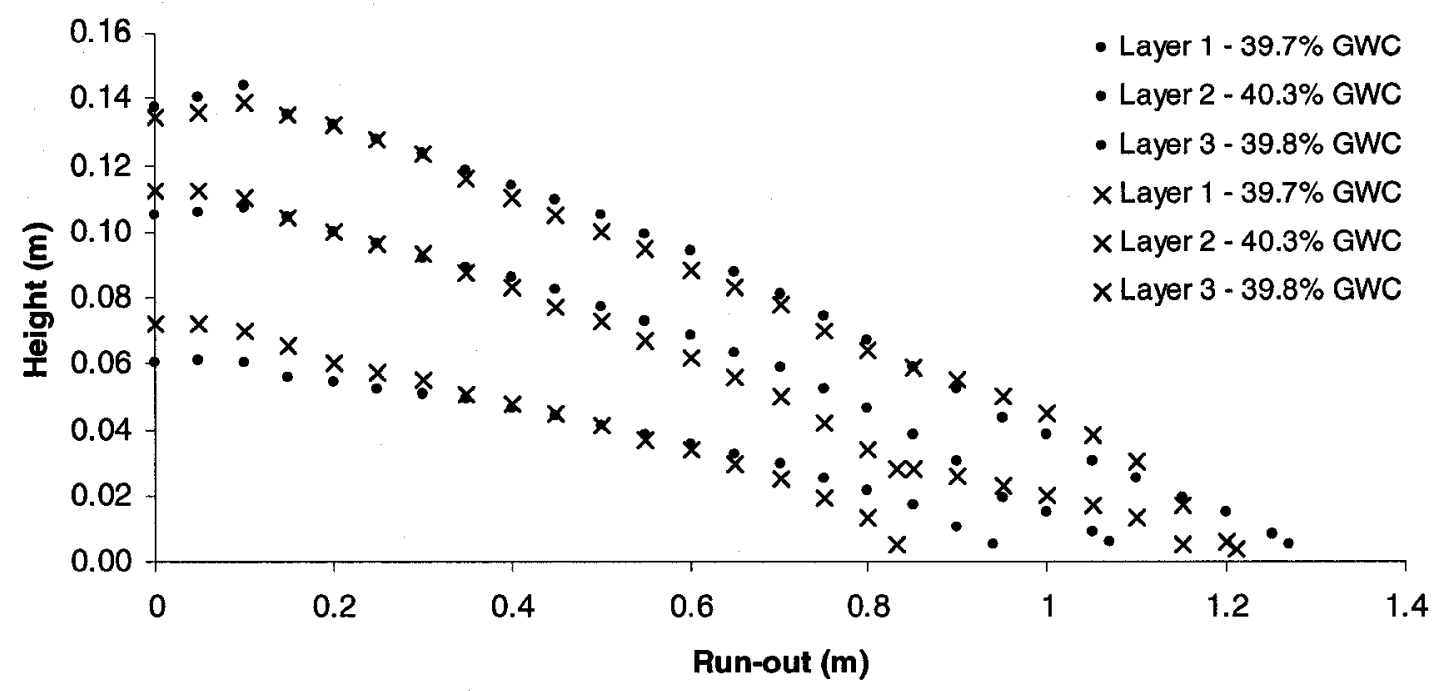

Figure IV. 15: Flume tests results of three successive layers. Note that two tests are included. GWC is gravimetric water content.

As can be visually observed from the previous figures the slope of each flow gets steeper as a new layer is poured. To confirm this, the angle of repose, $\theta_{r}$, for each layer was calculated using the following equation:

$$
\theta_{r}=\tan ^{-1}\left(\frac{H_{1}-H_{2}}{L}\right)
$$

where $\mathrm{H}_{1}$ and $\mathrm{H}_{2}$ are the depth at $0.10 \mathrm{~m}$ and $0.50 \mathrm{~m}$ of the flow (for these particular tests) and $\mathrm{L}$ is the distance between $\mathrm{H}_{1}$ and $\mathrm{H}_{2}$.

Base on the previous equation, the first and third layer (in both figures) exhibited an angle of repose equal to 3.4 and 7.3 degree respectively. 


\subsubsection{Flume test on sloping planes}

Flume tests on a single layer were performed at different initial slopes $(0,0.57$, and 1.14 degrees). The gravimetric water content of the sample considered for these tests was around $40 \%$. The results are presented in Figure IV.16 below.
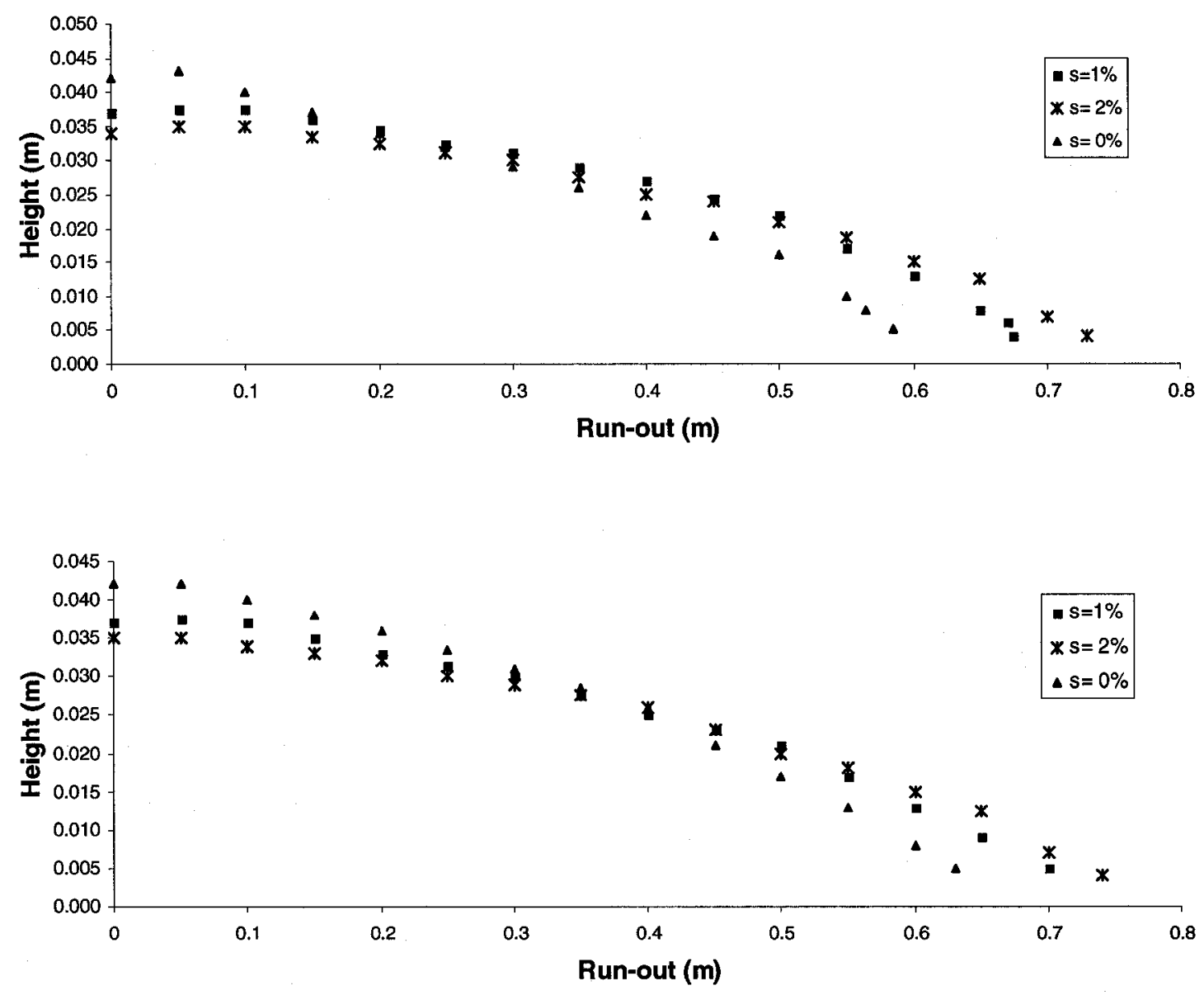

Figure IV. 16: Flume tests performed on an inclined plane. Note that " $\mathrm{s}$ " refers to slope.

As expected, when increasing the slope of the plane, the flow resulted in a greater extend and, therefore, a lower angle of repose. 


\subsubsection{An example of a flume test recorded with the high speed camera}

As mentioned earlier, flume tests were recorded using a high speed camera. The recorded flows are provided in Appendix C, on the attached DVD. Nevertheless, an example of the visualization is presented in Figure IV.17 as follows.
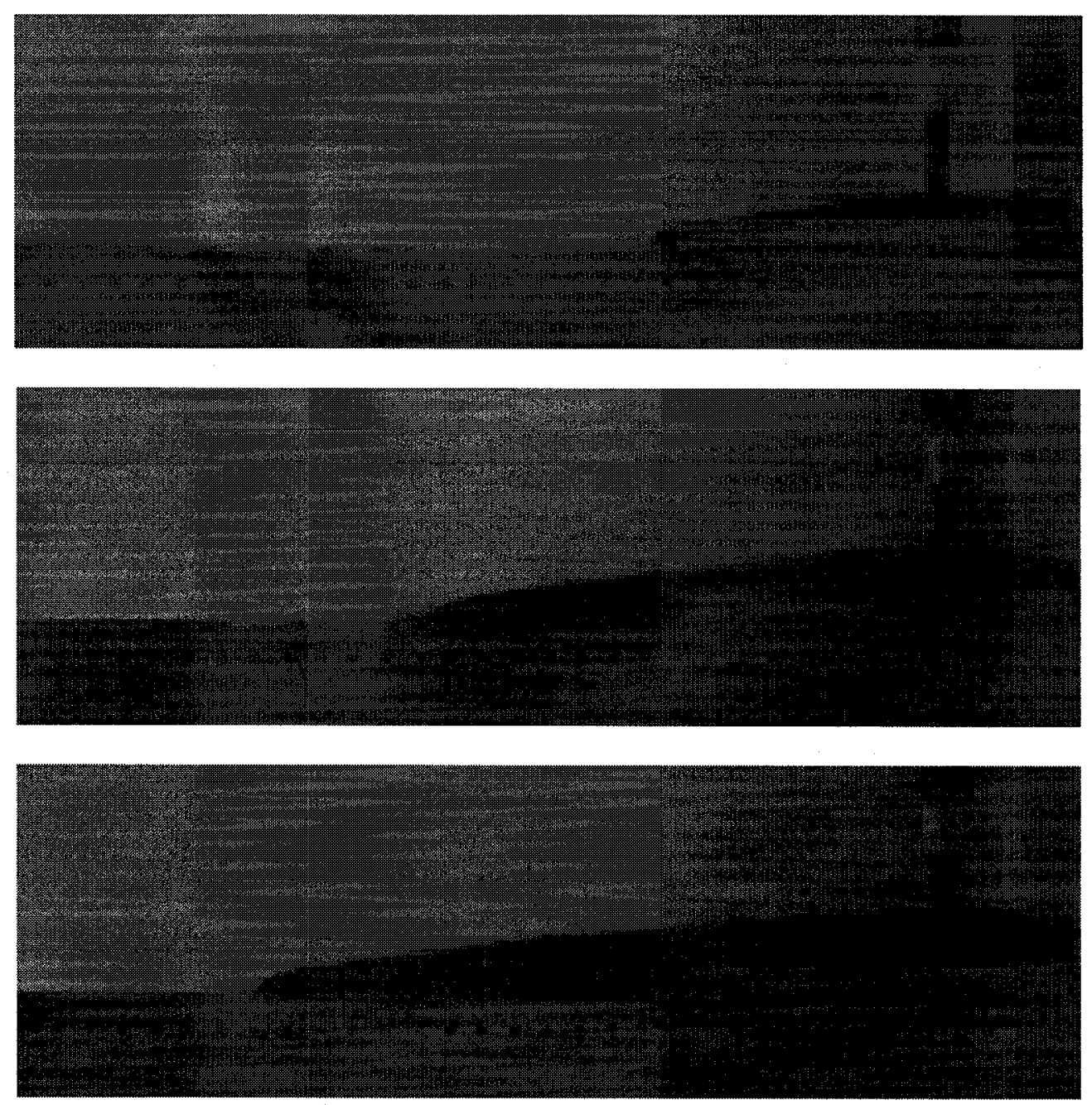

Figure IV. 17: Example of visualization of a flume test at $t=3-6-9$ sec. 


\subsubsection{Pouring test}

The pouring tests conducted on a horizontal plane created cone shapes with diameters and height of 21 and $2.2 \mathrm{~cm}$ respectively. A graphical representation of one of the resulted profile, as well as its visualization is presented in Figure IV.18 and Figure IV.19 as follows.

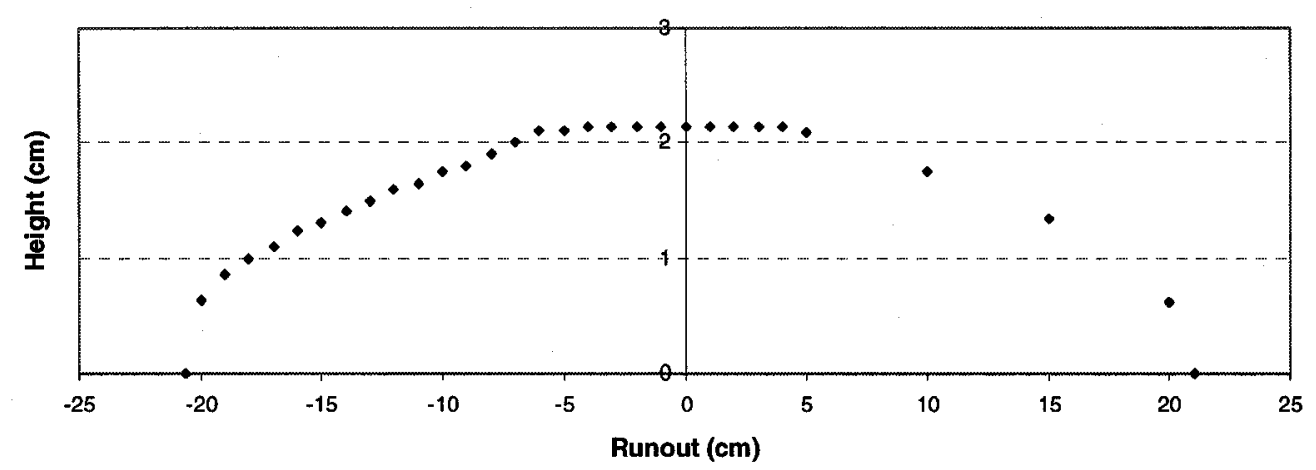

Figure IV. 18: Graphical representation of a pouring test on a horizontal plane. Sample at $40 \%$ gravimetric water content.
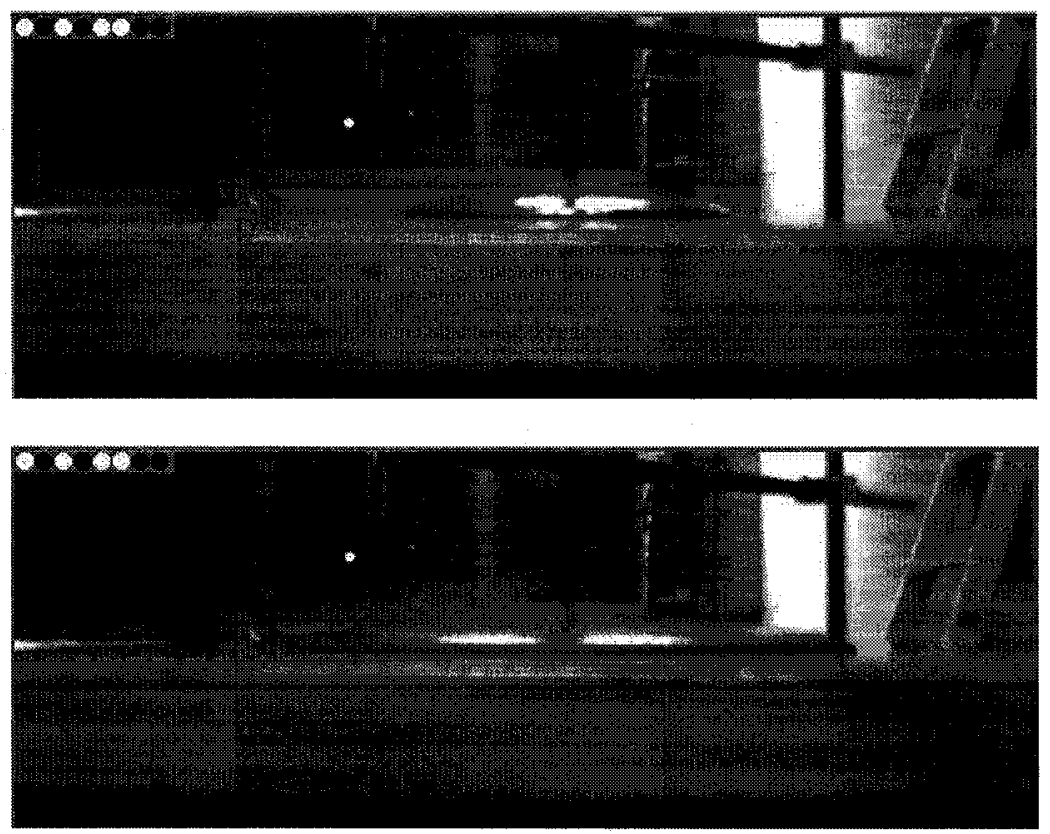

Figure IV. 19: Visualization of a pouring test at $t=3-9 \mathrm{sec}$. 


\subsubsection{Predicted flow prafiles}

\subsubsection{Steady state flow prediction on a flat bed}

The flow profiles obtained from the flume tests were compared with those predicted by using equation III.1 presented in Section 3.6.1. Figure IV.20, for example, presents a comparison between the resulted profiles of three flume tests and the associated prediction. It should be noted that the flume tests were performed at different volumes of material and same water content (40\%). The yield stress considered in the equation was $36 \mathrm{~Pa}$.

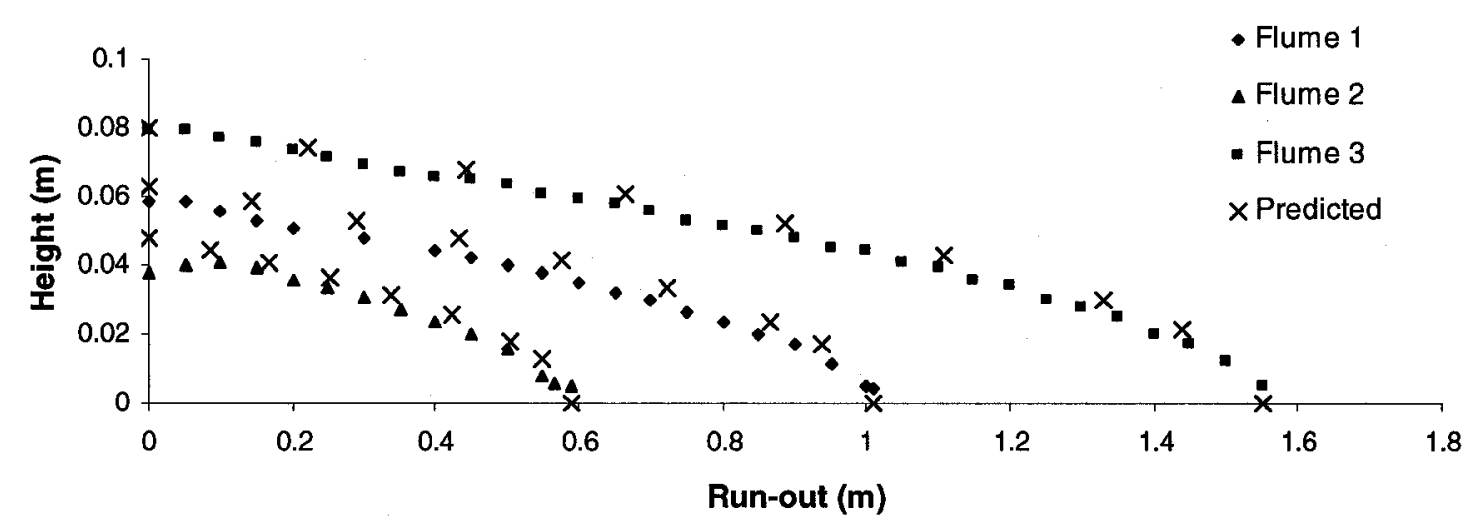

Figure IV. 20: Measured and predicted flow profiles for different volumes of material.

As observed from Figure IV.20, the results show a good agreement between the measured and predicted profiles.

Similarly, the flow profiles for the pouring test presented in Figure IV.21 on the next page shows a good agreement with the experimental data.

HENRIQUEZ, J.A. 2008. DYNAMIC IMAGING AND MODELLING OF GOLD PASTE TAILINGS FLOWS 


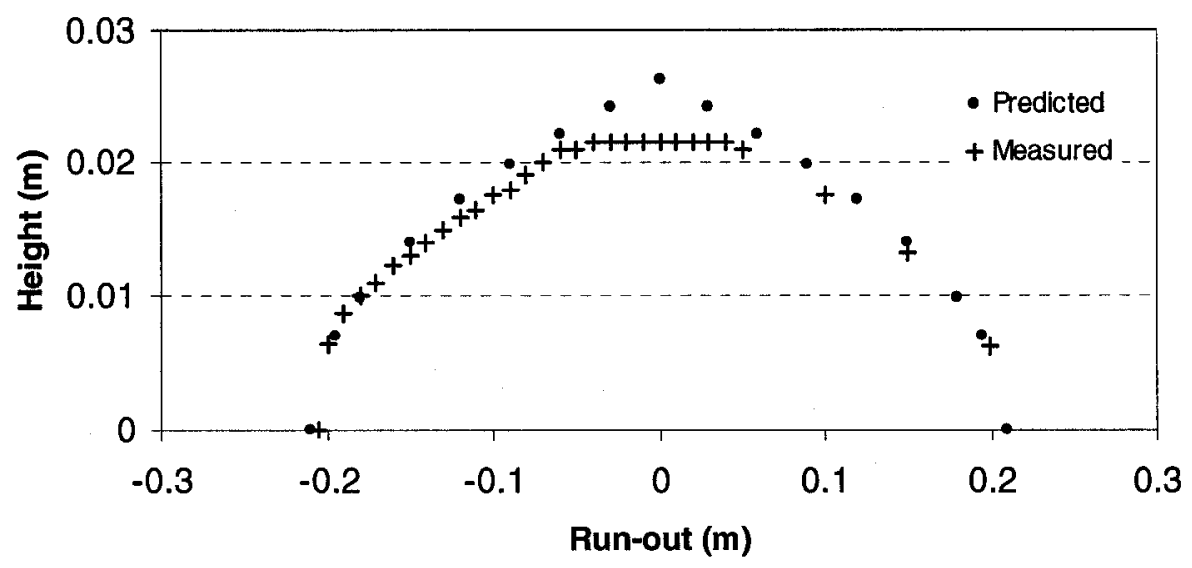

Figure IV. 21: Measured and predicted flow profiles of a pouring test.

\subsubsection{Steady state flow prediction on an inclined bed}

Flow profiles obtained from flume tests performed at different slopes were compared with profiles predicted using equation III.2 presented in Section 3.6.1. Figure IV.22 and IV.23 as follows present the measured and predicted profiles, considering a slope of 0.57 and 1.14 degrees respectively. Note that the gravimetric water content and yield stress were $40 \%$ and $36 \mathrm{~Pa}$.

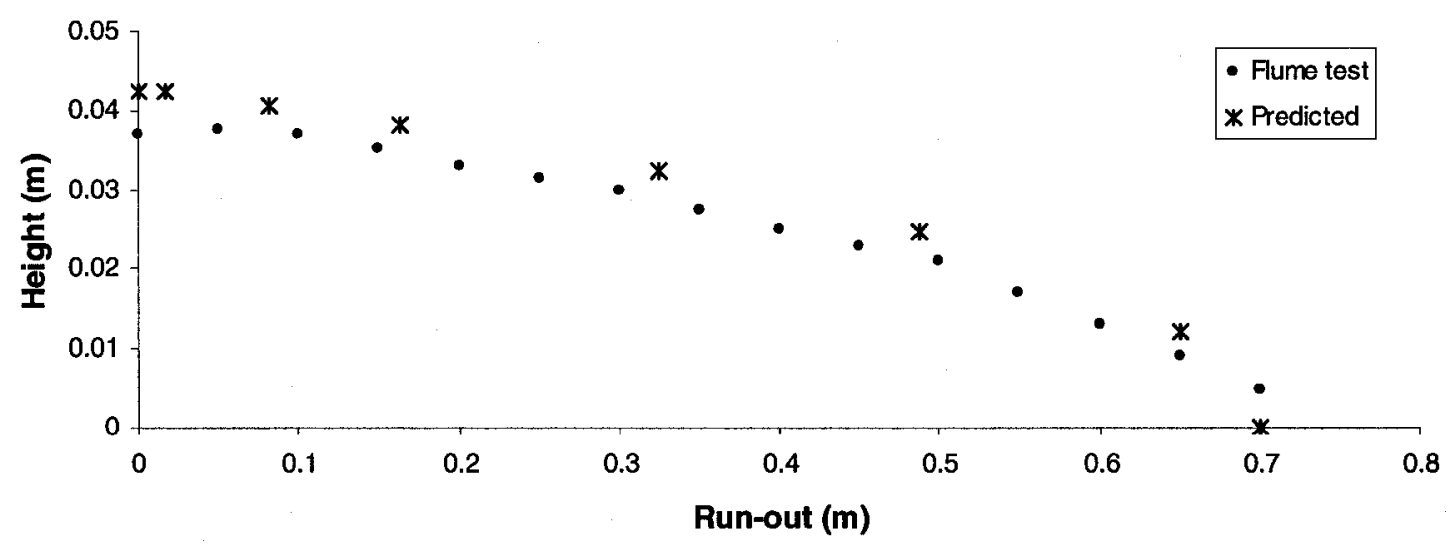

Figure IV. 22: Measured and predicted flow profiles at a slope of 0.57 degrees. 


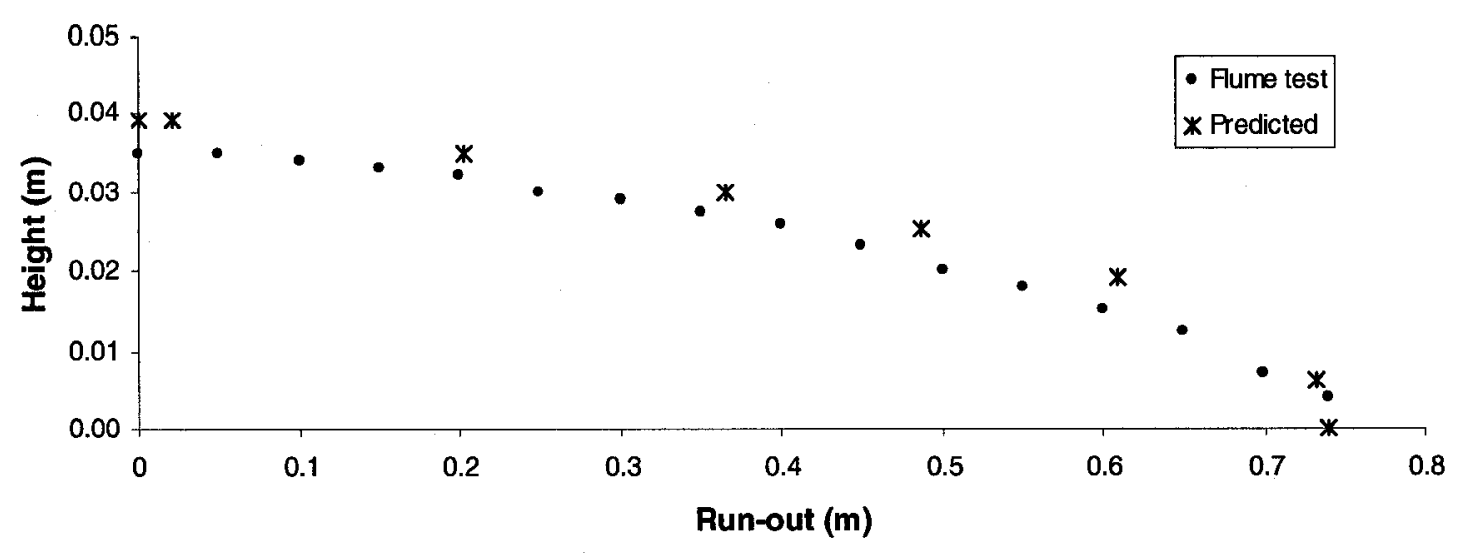

Figure IV. 23: Measured and predicted flow profiles at a slope of 1.14 degrees.

Similar to the previous scenario (flat surface), the results show a good agreement between the measured and predicted profiles.

\subsubsection{Transient flow prediction}

\section{* Transient flow prediction on a single layer}

Flow profiles obtained from flume tests performed on a single layer were compared with profiles predicted using equation III.4 presented in Section 3.6.2. An example is illustrated in Figure IV.24, which shows the resulted profiles of two tests performed at different volumes of tailings together with the predicted profiles. Note that the gravimetric water content, yield stress, and viscosity were $40 \%, 36 \mathrm{~Pa}$, and $0.65 \mathrm{~Pa} \cdot \mathrm{s}$ respectively.

HENRIQUEZ, J.A. 2008. DYNAMIC IMAGING AND MODELLING OF GOLD PASTE TAILINGS FLOWS 

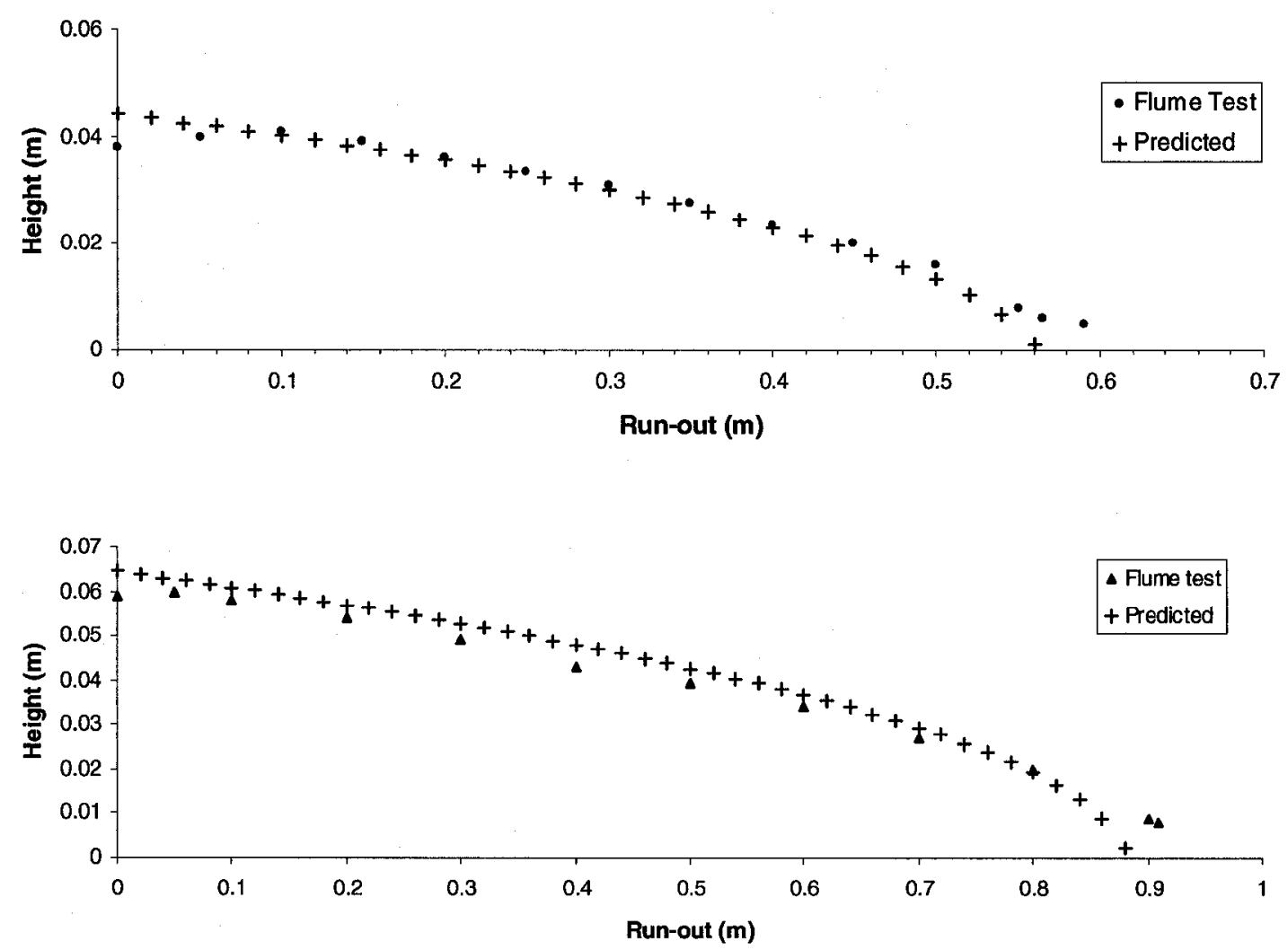

Figure IV. 24: Measured and predicted flow profiles using the transient solution. Note that profiles for different volumes of material are presented.

As observed from the previous figure, the predicted profiles have acceptable fit to the measured ones.

Similarly, predicted profiles for the same tests presented above but at different times steps were evaluated. Figures IV.25 and IV.26 on the next page show the measured and predicted flow profiles at $3-6-9 \mathrm{sec}$ after the material was poured through the funnel. 


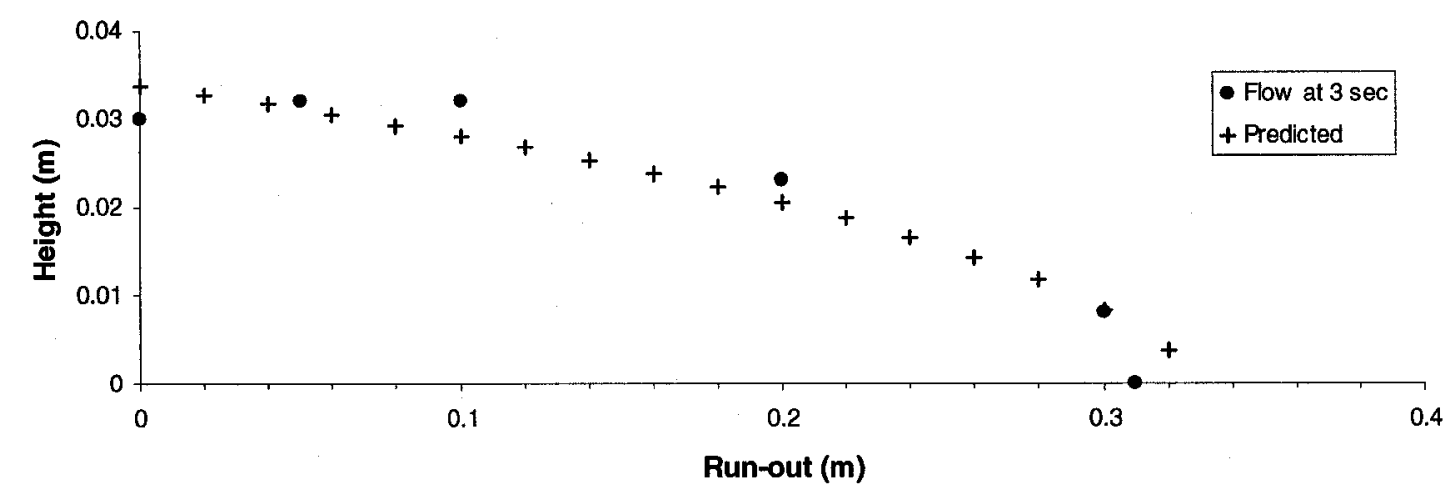

Figure IV. 25: Measured and predicted flume profiles at $t=3 \mathrm{sec}$. Yield stress and viscosity equal to $36 \mathrm{~Pa}$ and $0.65 \mathrm{~Pa} \cdot \mathrm{s}$ respectively.

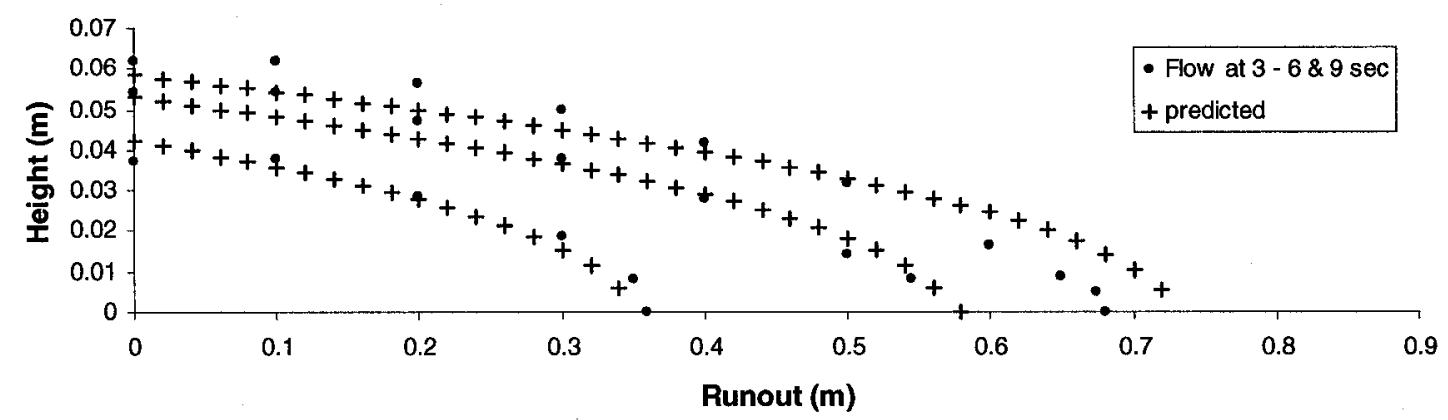

Figure IV. 26: Measured and predicted flume profiles at $\mathrm{t}=3-6-9 \mathrm{sec}$. Yield stress and viscosity equal to $36 \mathrm{~Pa}$ and $0.65 \mathrm{~Pa} \cdot \mathrm{s}$ respectively.

As can be observed from the previous two figures, the simulated flows appear to move slightly faster than the recorded ones, with maximum differences in the order of $5.5 \%$ (run-out) and $5.2 \%$ (height) respectively.

\section{Transient flow prediction for a second layer}

As mentioned earlier, flume tests were also performed on successive layers. The flow profiles obtained from a second layer that was poured on top of an existing one were compared with profiles predicted using the transient equation presented previously (eqn. 
III.4). It should be noted that in this case the channel bottom height $(\mathrm{H})$ is determined by the geometry of the first layer deposited in the flume.

Figure IV.27 as follows presents the predicted and measured flow profiles for two different tests.
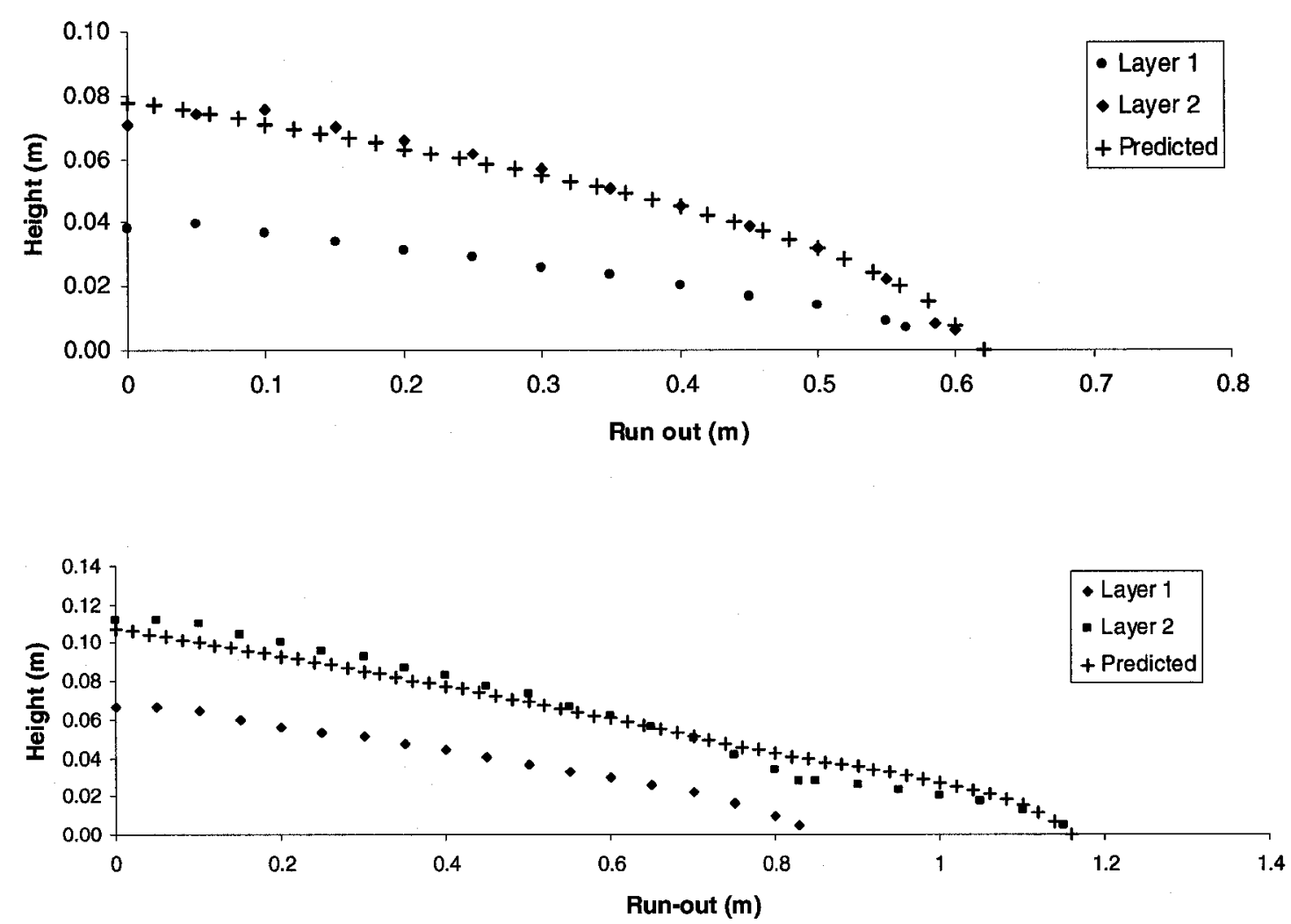

Figure IV. 27: Measured and predicted flow profile for a second layer. Tailings at 40\% gravimetric water content. Yield stress and viscosity equal to $36 \mathrm{~Pa}$ and $0.65 \mathrm{~Pa} \cdot \mathrm{s}$ respectively.

Predicted profiles for the same test presented in Figure IV.27 above but at different times steps (at 3 and $6 \mathrm{sec}$ ) are presented in Figures IV.28 on the next page. 

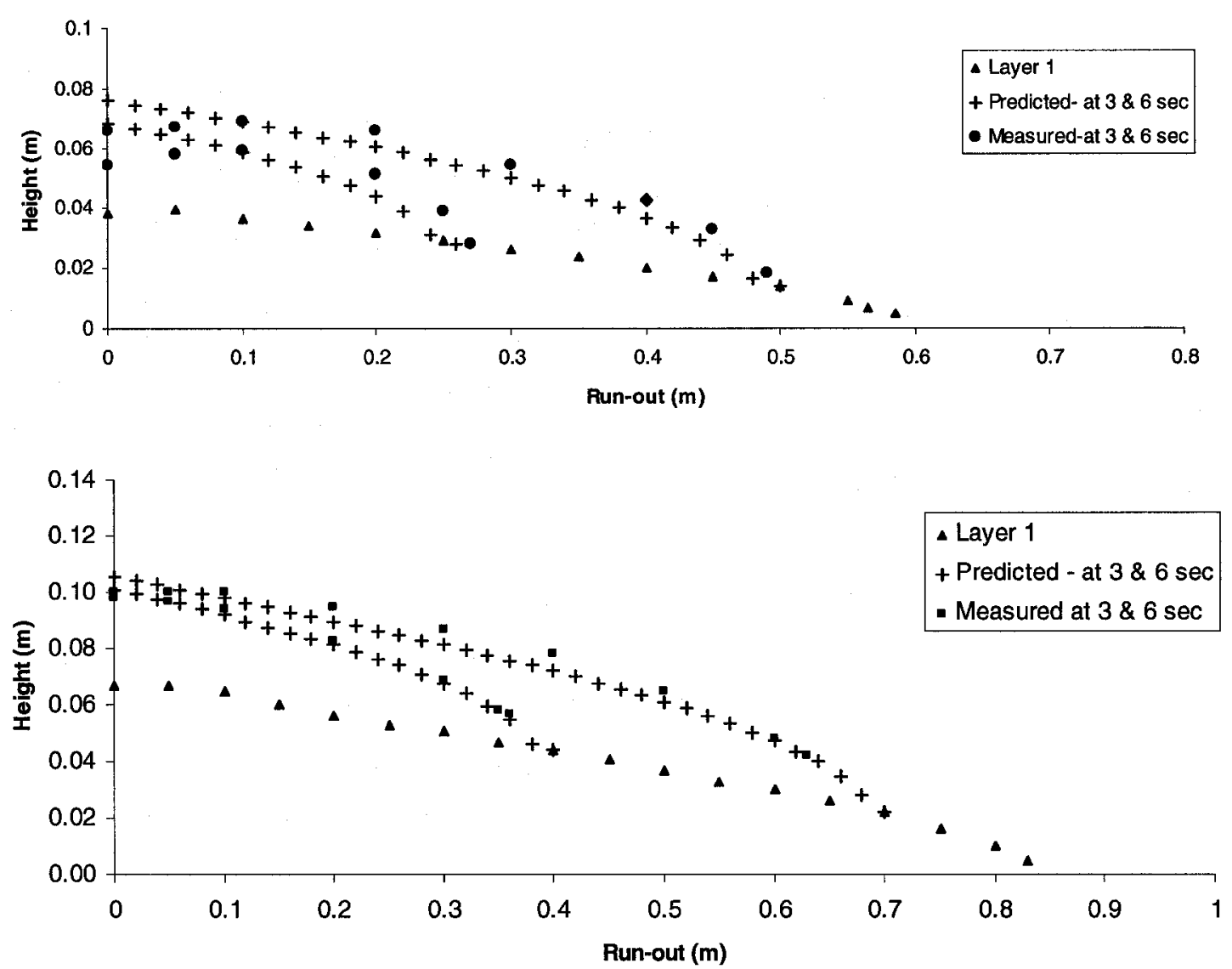

Figure IV. 28: Measured and predicted flow profile at 3 and $6 \mathrm{sec}$ for a second layer. Two different tests are shown. Tailings at $40 \%$ gravimetric water content. Yield stress and viscosity equal to $36 \mathrm{~Pa}$ and $0.65 \mathrm{~Pa}$ 's respectively.

Similar to the prediction for a single layer, the simulated flows for the second layer appear to move slightly faster than the recorded ones (see second graph of Figure IV.28), with maximum differences in the order of $10 \%$ (run-out) and $5 \%$ (height) respectively. 


\section{* Comparison between the steady state and transient solution}

Flow profile predictions using the steady state equation (eqn. III.2) were compared with the ones predicted by the transient solution (eqn. III.4). For this particular situation, a constant slope and flow discharge were assumed. The results are presented in Figure IV.29 as follows.
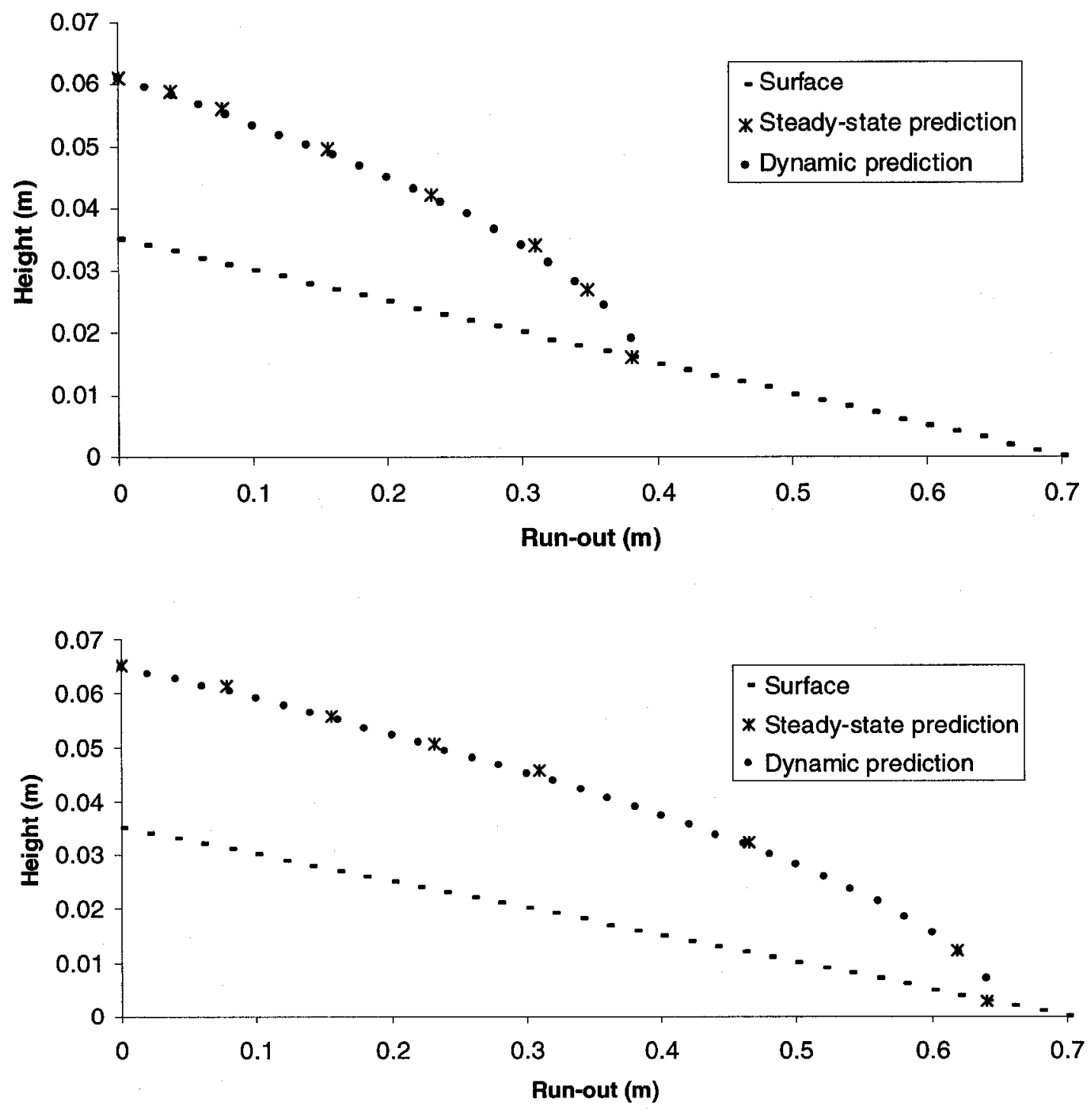

Figure IV. 29: Graphical representation of flow profiles predicted using the steady state and transient solution. Yield stress and viscosity equal to $36 \mathrm{~Pa}$ and $0.65 \mathrm{~Pa} \cdot \mathrm{s}$. 


\subsection{DISCUSSION}

\subsubsection{Particle size distribution}

As mentioned earlier, the particle size of tailings varies significantly depending on the mineral being processed as well as on the mineralogical composition of the ore body. However, all high-density tailings should contain sufficient fine particles to avoid segregation when being transported and deposited, thus obtaining a homogeneous material across the tailings facility.

The particle size distribution analysis performed in this study revealed that the gold tailings sample has an average grain size $\left(\mathrm{d}_{50}\right)$ of around $35 \mu \mathrm{m}$ and that approximately $40 \%$ by weight corresponds to particles finer that $20 \mu \mathrm{m}$.

Similar results were reported by Kwak et al. (2005), who performed a particle size distribution on a similar gold paste tailings sample (from the Bulyanhulu gold mine). Their results showed that $50 \%$ by weight correspond to particles finer that $20 \mu \mathrm{m}$.

These results are consistent with the requirement that paste tailings must contain at least $15 \%$ by mass of particles smaller than 20 microns. 


\subsubsection{Rheological Characterization (yield stress)}

Yield stress values of the gold mineral tailings sample at different water content were determined using the slump technique. The results presented in Figure IV.2 previously showed that the dimension of the cylinder slightly affected the slump height and, consequently, the yield stress. For example, when comparing the cylinders that were used to perform the tests, the largest one exhibited higher dimensionless slump than the small ones at the same water content, which resulted in higher yield stress values. Figure IV.30 below clearly indicates this situation.

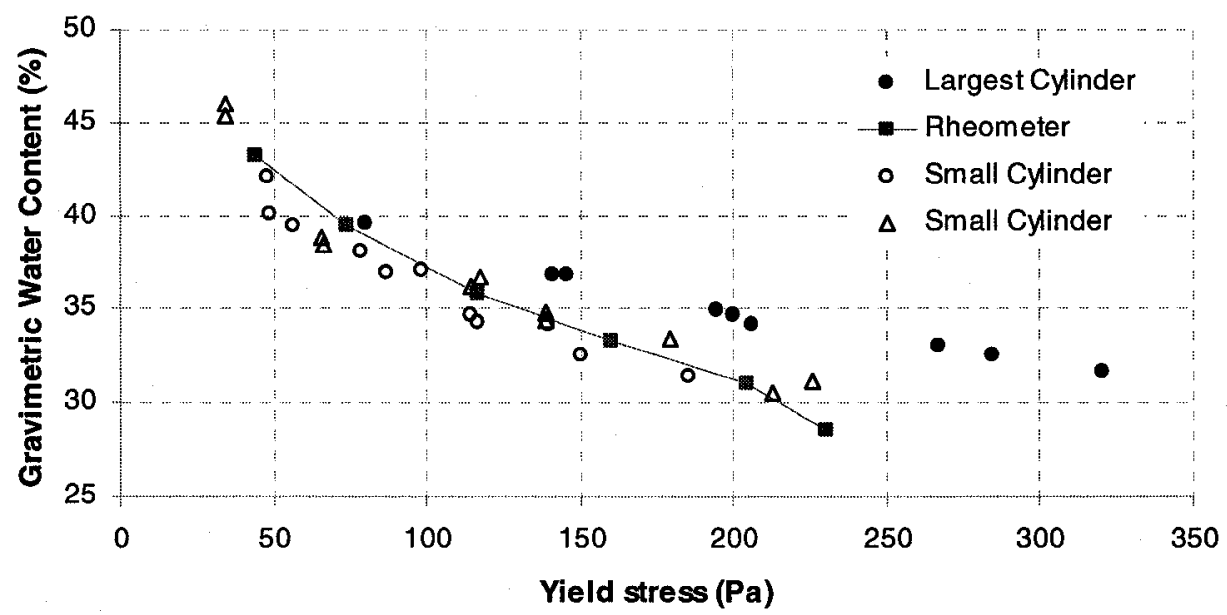

Figure IV. 30: Comparison of yield stress results for different cylinders heights with results obtained using the rheometer. Cylinder dimensions are presented in Section 3.3.

The solids content of paste tailings normally varies from 70 to $80 \%$ depending on the dewatering process being used. As illustrated in Figure IV.31 on the next page, at this range the yield stress becomes very sensitive to any change in solids concentration. A small variation in the solid content, for example, can lead to a high change in the yield stress.

HENRIQUEZ, J.A. 2008. DYNAMIC IMAGING AND MODELLING OF GOLD PASTE TAILINGS FLOWS 


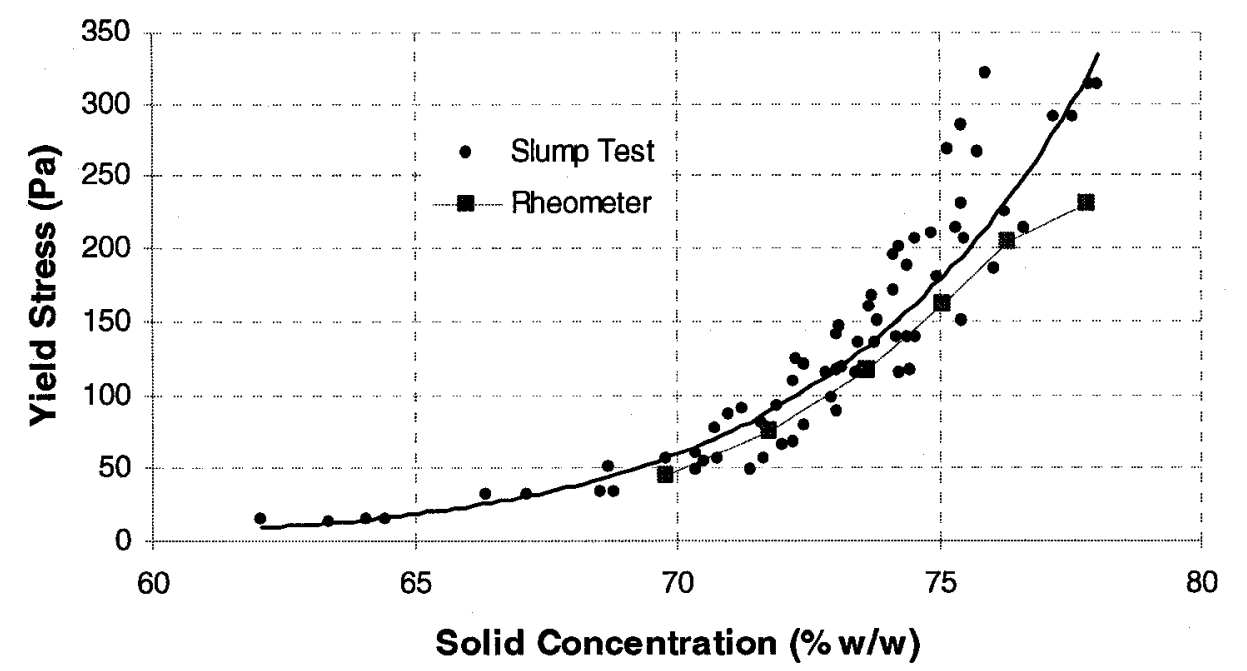

Figure IV. 31: Yield stress vs. solids concentration (slump and rheometry results are presented).

It should be also noted from the previous figure that the results from the slump tests show good agreement with those obtained by the rheometer, especially for yield stress values lower than $150 \mathrm{~Pa}$. A similar situation was observed by Pashias et al. (1996) and Gawu and Fourie (2004), who stated that the slump test can predict accurate yield stress values up to $200 \mathrm{~Pa}$, beyond which the results deviates when compared with values obtained from conventional rheometers. However, as presented in the next paragraph, yield stress values obtained from the slump tests and by fitting the Bingham model to a flow curve may overestimate the true yield stress that is related to the flow deposition of the tailings, that is, the yield stress at which the tailings will stop flowing.

The flow curve (shear rate vs. shear stress) presented in Figure IV.6 showed that by fitting the Bingham model to the entire data the yield stress resulted to be higher than the one obtained when considering only the lower shear rate values $\left(<90 \mathrm{sec}^{-1}\right)$ of the 
same rheogram, being around $52 \mathrm{~Pa}$ for the first case and $36 \mathrm{~Pa}$ for the second one (for a material with a gravimetric water content of $40 \%$ respectively).

As presented in the results section, flow profile predictions of single and multi layers were better described using a yield stress of $36 \mathrm{~Pa}$, corresponding to the yield stress estimated from the flow curve at the low shear rate range.

It is known that shear stress values at low shear rates are not reliable due to the discrepancy than can be found in the results obtained at such range (Liddell and Boger, 1996). In this context, fitting the Bingham model only to the low shear rate range from the flow curve may not give a representative or true yield stress value. However, as presented in the results section, the predicted flow profiles fit very well to the experimental data when using the yield stress obtained from the low shear rate range of the flow curve.

\subsubsection{Flume test}

The flume test results presented in Section 4.1.4.1 basically show how the water content of the sample affected the extent of the flows and, consequently, their angles of repose. A sample with a water content of $40 \%$, for example, resulted in a run-out of approximately $120 \%$ greater that the one with $30 \%$ for the same volume of material. As a result, the angle of repose augmented from 1.8 to 11.3 degrees respectively. 
Further observations of the results evidenced that tests performed with the gate resulted in a greater flow distance than the ones conducted with the funnel for a given water content and volume. This difference can be explained by the fact that the material in the reservoir experiences a greater pushing force caused by the hydrostatic head, which resulted in a greater run-out of the flow. When reducing the hydrostatic pressure, that is, reducing the height of the material in the reservoir to half of the initial one, no considerable difference was observed.

Now, when observing the average slope formed by the deposition of different volume of tailings another difference arises. As can be noted from Figure IV.32 below, as the volume of tailings increases the resulted deposition angle decreases. This finding indicates that the angle of repose is a function of the scale of the deposit, that is, smaller flows will exhibit steeper slopes than larger flows, at the same water content and density. This behaviour was perfectly characterized by equation III.1, as shown in Figure IV.20 previously.

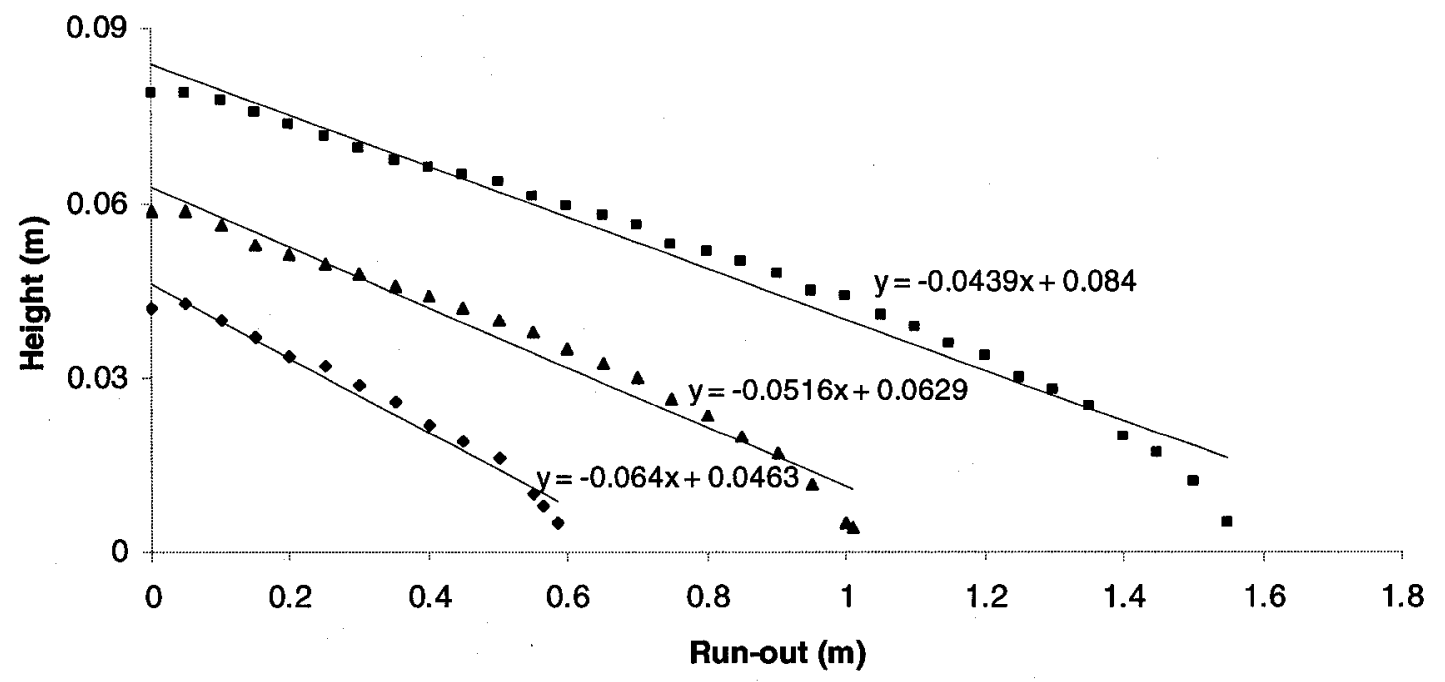

Figure IV. 32: Flow profiles for different volumes of tailings. 
Similar situation was found with flume tests performed at different initial slopes (0.57 and 1.14 degrees). As expected, when increasing the slope of the plane, the flow resulted in a greater extend and, therefore, in a lower angle of repose. For instance, for the same volume and water content of material, the angle of repose on the horizontal plane was around $3.4^{\circ}$, whereas for the inclined plane (0.57 - 1.14 degrees) was $2.3^{\circ}$ and $2^{\circ}$ respectively. This phenomenon is basically due to the material experiences a greater apparent force caused by gravity, which results in a greater extent of the flow. Again, this behaviour is well characterized by equation III.2, as shown in Figure IV.22 earlier.

Flume tests performed on successive layers exhibited the same trend indicated previously, that is, the slope of each flow gets steeper as a new layer is poured. For example, the first layer achieved angles of repose of around 3 degrees, whereas the third one exhibited an angle of repose of approximately 7 degrees.

\subsubsection{Flow profile predictions}

As presented in Section 4.1.6, flow profiles obtained from flume tests performed on a flat surface, on successive layers, at different initial slopes, and for different volumes of material were compared with profiles predicted using a steady state and transient solution.

In general, the predictions fit very well to the experimental data. However, when looking at the predicted profiles at different time steps, the simulated flows appeared to move slightly faster than the recorded ones. This situation may be explained by the fact 
that a constant viscosity was assumed (in reality the viscosity varies with shear stress) and also due to some differences in flow rate experienced when pouring the material through the funnel.

Another interesting observation arises when evaluating the sensitivity of the steady state and transient solution to yield stress (in the range of 36 and $52 \mathrm{~Pa}$ ). As presented in Figures IV.33, IV.34, and IV.35 below, both the steady state and transient solutions are somewhat sensitive to this change in yield stress. The graphs evidence that the run-out of the profiles slightly decreases as the yield stress increases, which is consistent with the fact that larger yield stresses will exhibit a more resistant to flow. For each case, for example, the maximum differences between the predictions for yield stresses of 36 and $52 \mathrm{~Pa}$ were: $12 \%$ in run-out and 10\% in height for the first case (Figure IV.33); 7\% in run-out and height for the second case (Figure IV.34); and 7\% in run out and $4.5 \%$ in height for the third case (Figure IV.35).

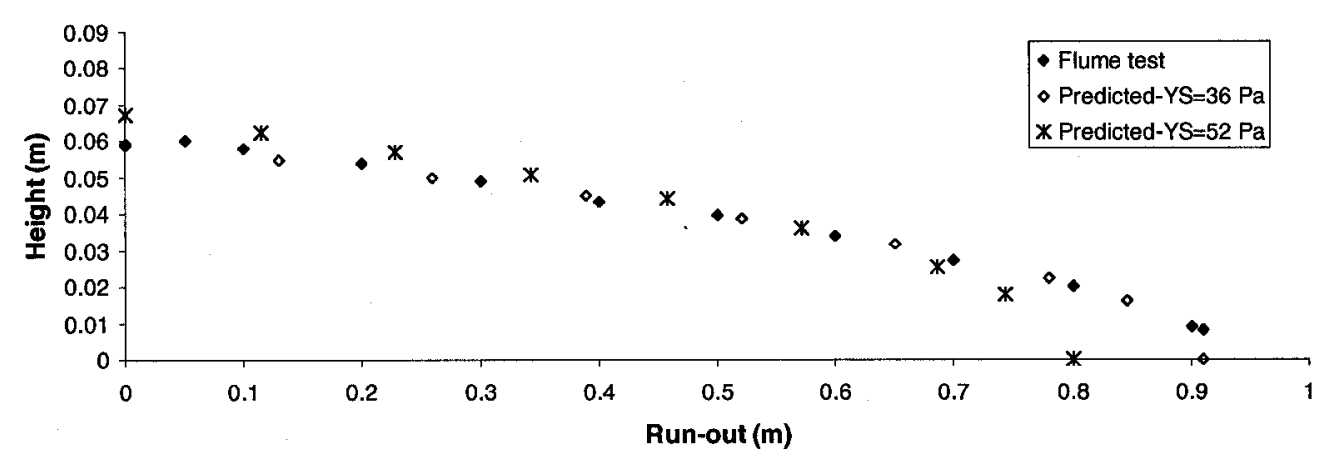

Figure IV. 33: Flow profiles prediction for a single layer using the steady state solution. Yield stress values of 36 and $52 \mathrm{~Pa}$. Note that "YS" refers to yield stress. 


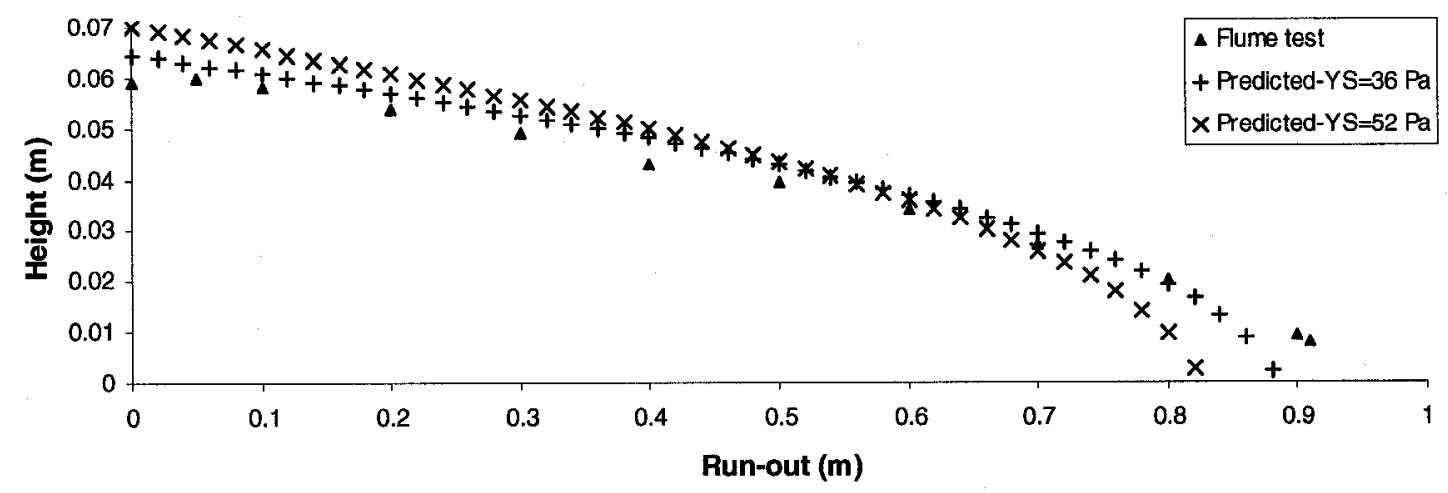

Figure IV. 34: Flow profiles prediction for a single layer using the transient solution. Yield stress values of 36 and $52 \mathrm{~Pa}$. Note that "YS" refers to yield stress.

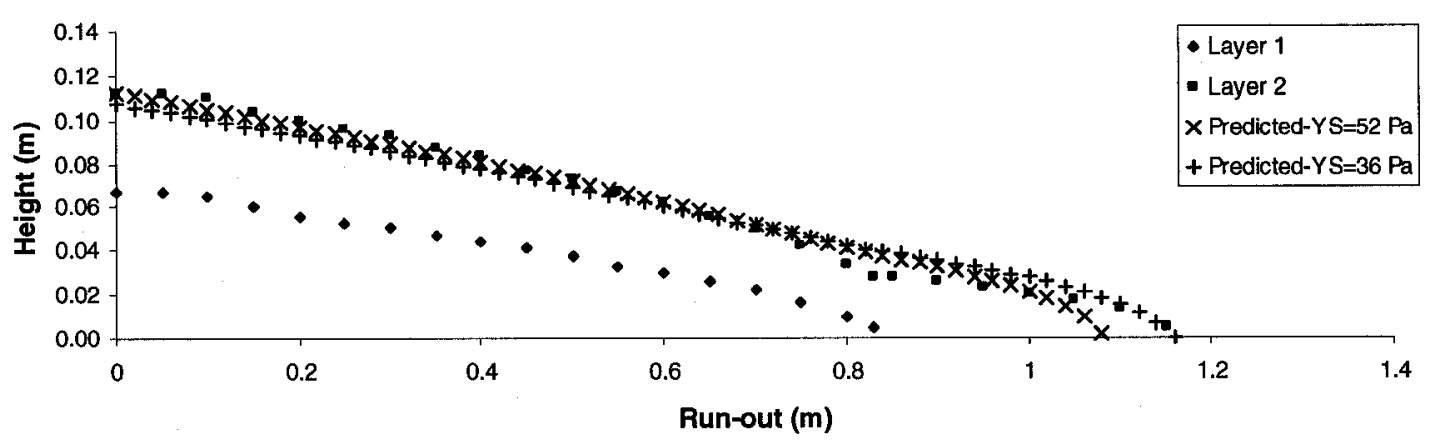

Figure IV. 35: Flow profiles prediction of a second layer using the transient equation. Yield stress values of 36 and $52 \mathrm{~Pa}$. Note that "YS" refers to yield stress.

\subsubsection{Extrapolation to the field}

As mentioned earlier, current practices have attempted to predict the deposition geometry of high-density tailings base on single angles obtained from laboratory flume tests. This study demonstrated that this is not the case since the average slope formed by the deposition of tailings is dependent on the scale of the deposit, that is, as the volume of tailings being deposited increases the resulted deposition angle decreases. 
To clarify the previous point, let's assume two scenarios: First, the tailings are discharged from one single deposition point, and second, they are discharged from multiple deposition points (only two points for this particular case). In both scenarios, the flow will be limited to a specific surface area and the same constant flow rate will be assumed. The resulted stacks are illustrated in Figure IV.36 below.
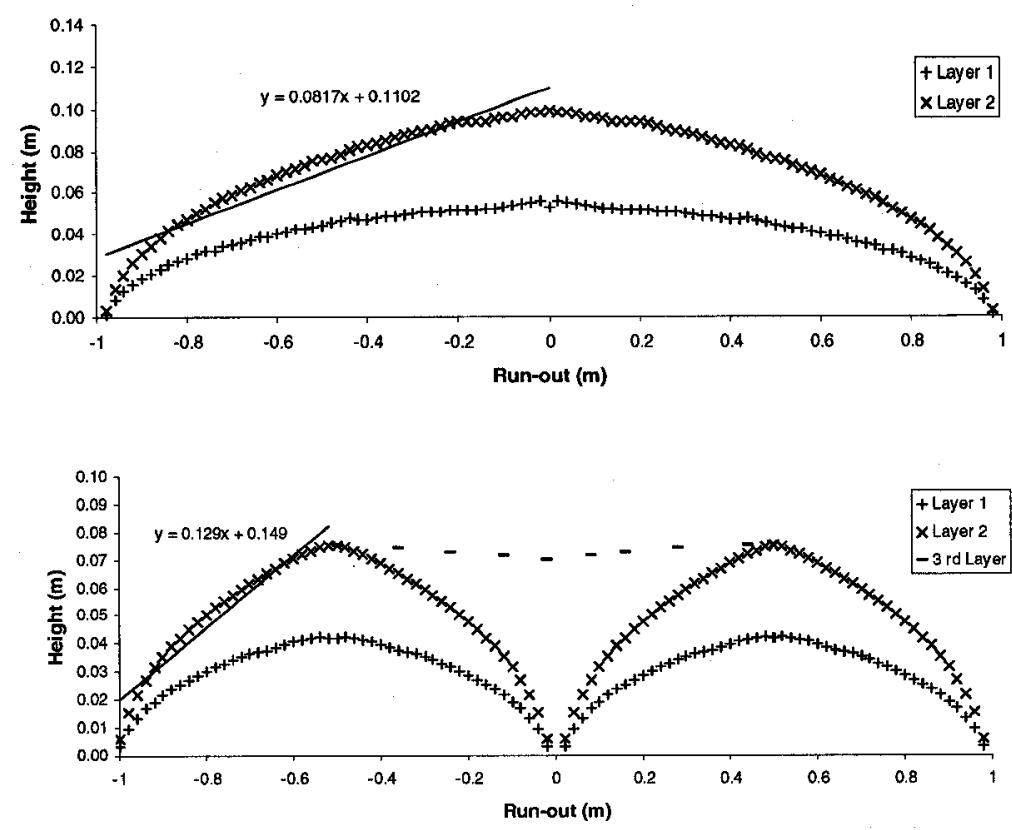

Figure IV. 36: Graphical representation of two case scenarios. First, the tailings are discharged from a single disposal point (first graph). Second, they are discharged from multiple deposition points (second graph). Same flow rate was assumed for both cases.

As observed from Figure IV.36 above, cycling deposition points (second scenario) will generate thinner layer. Thinner layers, as discussed previously, will form steeper average slopes (see linear equations in Figure IV.36). An increase in the slope of the deposit will, therefore, allow for stacking larger volume of material, making more efficient the use of the disposal area. In addition, deposition of thicker layers will take 
longer to dry, whereas thinner layers will facilitate evaporation, allowing the tailings to dry and gain strength faster.

Similarly, if the same volume of tailings stored in the first graph of Figure IV.36 were discharged all at once (without letting the material self consolidate to be able to place a second layer on top), the size of the tailings facility would have to be enlarged, as presented in Figure IV.37 below.
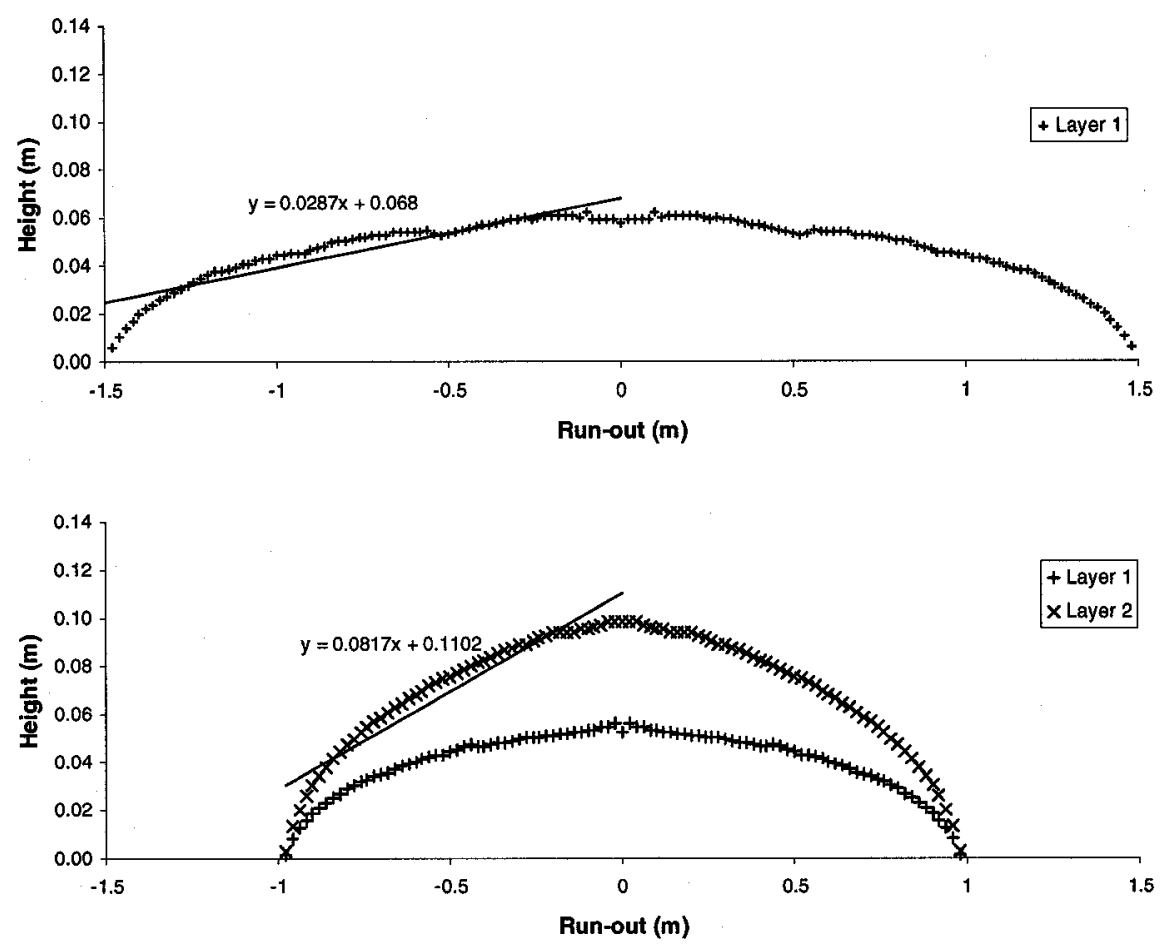

Figure IV. 37: Graphical representation of the profiles obtained when considering the deposition of a volume of tailings in one and two layers.

Another scenario is presented in Figure IV.38 on the next page. In this particular case, several layers (of same volume) were discharged one on top of each other. As observed, the slope of the deposit increases as a new layer is poured. However, when evaluating the rate of increment it can be found that each time that a new layer is poured 
the slope increases in a low proportion with respect to the previous one. For example, the slope of the second layer increased about $42 \%$ with respect to the slope of the first layer and the fifth layer increased only $0.8 \%$ with respect to the fourth one.

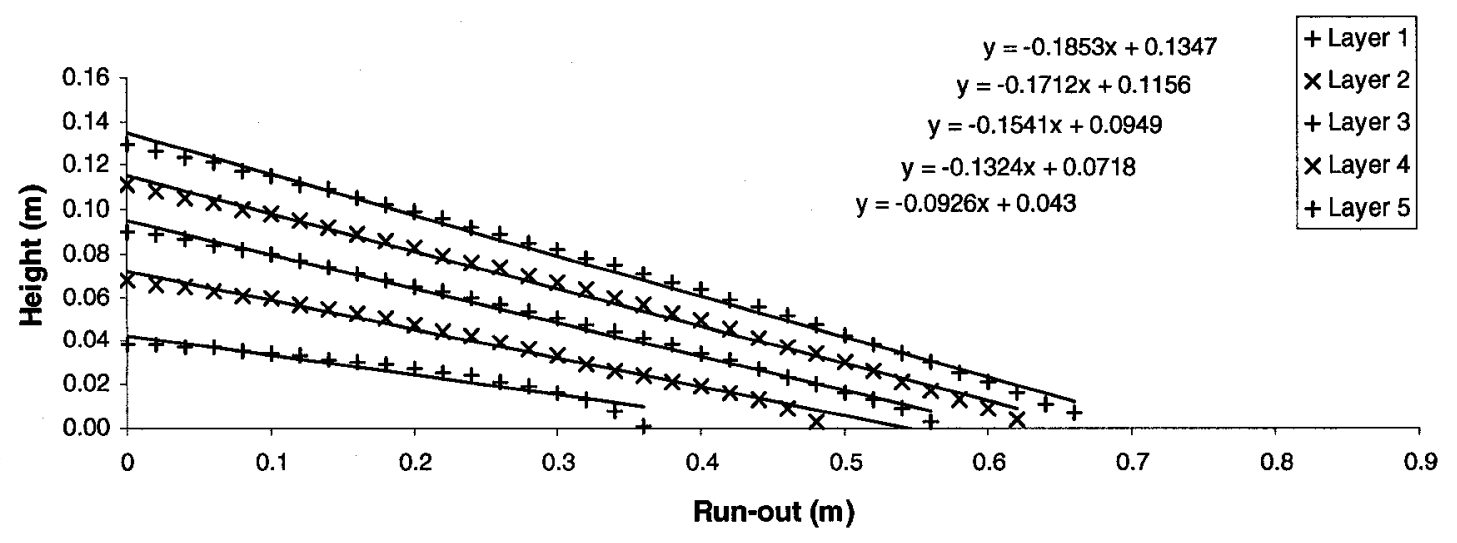

Figure IV. 38: Representation of deposition of five different layers, one of top of each other.

The theory presented along this research assumes the slow flow of a homogeneous fluid, where the inertia is negligible and the thickness-to length ratio is very small. In this context, if we assume that the flow spreading of paste tailings obeys these assumptions, and based on the results obtained; this theory may be applicable to the field. 


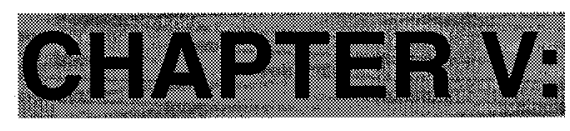

\section{CONCLUSIONS}




\section{$5.1 \quad$ CONCLUSIONS}

This research focused on studying the flow and depositional behaviour of gold paste tailings. To this end, several flow tests were performed at a laboratory scale and the flows were recorded using a high-speed camera. The visualizations of the flows were then compared with predictions of steady-state and transient equilibrium profiles obtained using a static and dynamic computer code written by the author.

The rheological parameters of the tailings (yield stress and viscosity) were determined from slump tests and flow curves obtained using a Rheometer, model R/SCPS.

The rheological characterization revealed that the yield stress is very sensitive to changes in solids concentration, particularly in the range of $70-80 \%$ (corresponding to the solids content of paste tailings). In addition, the flow curves evidenced that by fitting the Bingham model only to the low range of shear rates the yield stress was lower than the one obtained when considering the entire data. Given the fact that shear stress values at low shear rates are difficult to measure accurately, fitting the Bingham model only to the low shear rate range may not give a representative or true yield stress value. However, the flume tests themselves may be used to evaluate the critical yield stress by fitting with the steady state solution.

Flume tests results showed how the water content of the sample affected the extent of the flows and, consequently, their angles of repose. Similarly, it was observed 
that as the volume of tailings being deposited increases the resulted deposition angle decreases. This indicates that the average slope formed by the deposition of tailings is dependent on the scale of the deposit, that is, smaller flows will exhibit steeper slopes than larger flows, at the same water content and density. This may explain the inconsistency found between slopes measured at a laboratory scale with those obtained in the field.

Flow profiles predicted using the steady state and transient solution resulted to have an acceptable fit to the experimental data.

The results obtained from this work reveal that the theory presented along this study (slow flow of a homogeneous fluid, where the inertia is negligible and the thickness-to length ratio is very small) has the potential to be applicable to the field. 


\subsection{RECOMMENDATIONS}

$\checkmark$ The same discharge scenario was employed in all of the tests presented in this study. In this context, the sensitivity of the flows to variation in discharge should be evaluated.

$\checkmark$ It was observed that the overall angle formed by the deposition of tailings is a function of the scale of the deposit. Therefore, it is recommended to perform flume tests at larger scales and compare the results with predictions obtained using the numerical and analytical techniques presented in this study.

The lubrication theory was applied to develop a numerical and analytical solution for simulating the deposition geometry of a gold paste tailing, and the flow behaviour of this material was described using the Bingham model. This theory should be extended to predict the three-dimensional flow over complex topography and tested against experiments with more complex geometry.

Multilayer deposition tests were performed on tailings where the underlying layer was prevented from desiccating. In arid climates, the underlying layer will desiccate and may remove water from the fresh layers being deposited. This may influence the flow behaviour and should be investigated. 


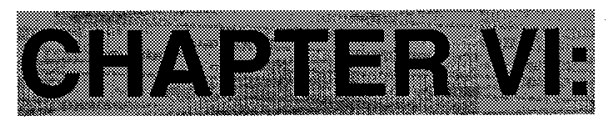

REFERENCES 


\section{REFERENCES}

ASTM. 1990. Standard test method for particle-size analysis of soils. Designation: D 422 -63, Philadelphia, PA.

ASTM. 1998. Standard test method for slump of hydraulic-cement concrete. Designation: C 143/C 143 M-97, Philadelphia, PA.

Cincilla, W.A., Landriault, D.A., and Verburg, R. 1997. Application of paste technology to surface disposal of mineral wastes. Proceedings of the $4^{\text {th }}$ International Conference on Tailings and Mine Waste '97. Fort Collins, Colorado, USA, 343 - 356.

Clayton, S., Grice, T.G., and Boger, D.V. 2003. Analysis of the slump test for on-site yield stress measurement of mineral suspensions. International Journal of Mineral Processing, 70(1-4), 3-21.

COCHILCO. 2006. Anuario de estadísticas del cobre y otros minerales 1986 - 2005 . Vigésima Quinta Edición. Retrieved from the Comisión Chilena del Cobre Web site: http://www.cochilco.cl/anm/articlefiles/456-ANUARIO2005-PDF(11-AGO-06).pdf.

Coussot, P. and Proust, S. 1996. Slow, unconfined spreading of a mudflow. Journal of Geophysical Research, 101(B11), $217-229$.

Davies, M.P. and Martin, T.E. 2000. Upstream constructed tailings dams - a review of the basics. Proceedings of the 7th International Conference on Tailings and Mine Waste '00, Fort Collins, Colorado, USA, 3 - 15.

Davies, M. P. 2002. Tailings impoundment failures: Are geotechnical engineers listening? Waste Geotechnics, Geotechnical News, 22(3), 31 - 36. 
DIN (Deutsches Institut für Normung) 53019-2. 2001. Viskosimetrie - Messung von Viskositäten und Fließkurven mit Rotationsviskosimetern - Teil 2: Viskosimeterkalibrierung und Ermittlung der Messunsicherheit. Beuth Verlag GmbH, Berlin.

Engman, M., Sellgren, A., Sundqvist, A., Wennberg, T., and Goldkuhl, I. 2004. Users perspective on the design of high density base metal tailings handling systems. Proceedings of the Eleventh Tailings and Mine Waste Conference, Vail Colorado, USA, $45-54$.

Feasby, D.G., Blanchette, M., Tremblay, G., Sirois, L.L. 1991. The mine environment neutral drainage program. Proceedings of the 2nd International Conference on the Abatement of Acidic Drainage, Montreal, PQ, 1-26.

Garcia, C., Ballester, A., Gonzalez, F., and Blazquez, M.L. 2005. Pyrite behaviour in a tailings pond. Hydrometallurgy, 76(1-2), $25-36$.

Gawu, S.K.Y. and Fourie, A.B. 2004. Assessment of the modified slump tests as a measure of the yield stress of high-density thickened tailings. Canadian Geotechnical Journal, 41(1), 39 - 47.

Grant-Stuart, D. 2004. Paste versus conventional tailings. Retrieved from Spintelligent LLC, Mining review web site: http://www.miningreview.com/terms.php.

Grimalt, J.O., Ferrer, M., and Macpherson, E. 1999. The mine tailings accident in Aznalcollar. The Science of the Total Environment, 242(1-3), 3 - 11.

Hallbom, D.J. and Norwood, W.J. 2007. Fuzzy rheology and smooth running paste systems. Proceedings of the Tenth International Seminar on Paste and Thickened Tailings, Australian Centre for Geomechanics, Perth, Australia, 199 - 210. 
Harris, J. 1977. Rheology and non-Newtonian Flow. Longman Inc., New York, USA.

Hunter, R.J. 1981. Zeta potential in colloid science, principles and applications. Academic Press, New York, USA.

ICOLD and UNEP. 2001. Bulletin 121: Tailings dams - Risk of dangerous occurrences, Lessons learnt from practical experiences. Paris, 144.

Jeyapalan, J.K., Duncan, M., and Seed, B. 1983. Analyses of flow failures of mine tailings dams. Journal of Geotechnical Engineering, 109(2), 150 - 171.

Kreith, F. 1999. Fluid Mechanics. Boca Raton, CRC Press LLC, Florida, USA.

Kwak, M., James, D.F., and Klein, K.A. 2005. Flow behaviour of tailings paste for Surface Disposal. Journal of Mineral Processing, 77(3), 139 - 153.

Lideell, P.V. and Boger, D.V. 1996. Yield stress measurement with the vane. Journal of Non-Newtonian Fluids Mechanics, 63(2-3), 235 - 261.

Lindvall, M. and Drielsma, J. 2006. Tailings management in Europe - An industry perspective. Paste 2006, Proceedings of the Ninth International Seminar on Paste and Thickened Tailings, Australian Centre for Geomechanics, Limerick, Ireland, 81 91.

Liu, K.F. and Mei, C.C. 1990. Approximate equations for the slow spreading of a thin sheet of Bingham plastic fluid. Physics of Fluids A (Fluid Dynamics), 2(1), 30 - 36.

MAC. 2005. Canadians view mining industry as sector of "strategic importance" to Canada. Retrieved from Newsroom, the Mining Association of Canada Web site: http://www.mining.ca/www/media_lib/MAC_News/English/surveyeng.pdf.

HENRIQUEZ, J.A. 2008. DYNAMIC IMAGING AND MODELLING OF GOLD PASTE TAILINGS FLOWS 
Mainali, G. 2006. Monitoring of tailings dams with geophysical methods. Licentiate Thesis, Lulea University of Technology, Sweden.

Martin, T.E., Davies, M.P., Rice, S., Higgs, T., and Lighthall, P.C. 2002. Stewardship of tailings facilities. Report commissioned by Mining Minerals and Sustainable Development (MMSD) a project of International Institute for Environment and Development (IIED), N 2.

Mei, C.C. and Yuhi, M. 2000. Slow flow of a Bingham fluid in a shallow channel of finite width. Journal of Fluid Mechanics, 431, 135 - 159.

Meggyes, T. and Debreczeni, A. 2006. Paste technology for tailings management. Land Contamination and Reclamation, 14(4), 815 - 827.

Mpofu, P., Addai-Mensah, J., and Ralston, J. 2003. Investigation of the effect of polymer structure type on flocculation, rheology and dewatering behaviour of kaolinite dispersions. International Journal of Mineral Processing, 71(1-4), 247 268.

Newman, P., Landriault, D. 1997. The use of paste technology in the surface disposal of mineral waste. Waste Minimisation and Recycle, Birmingham.

Nguyen, Q.D. and Boger, D.V. 1992. Measuring the flow properties of yield stress fluids. Annual Reviews of Fluid Mechanics, 24, 47 - 88.

Norman, D. K. and Raforth, R. L. 1998. Innovations and trends in reclamation of metal-mine tailings in Washington. Washington Geology, 26(2-3), $29-42$.

Oxenford, J. and Lord, E.R. 2006. Canadian experience in the application of paste and thickened tailings for surface disposal. Proceedings of the Ninth International Seminar on Paste and Thickened Tailings, Australian Centre for Geomechanics, Limerick, Ireland, 93 - 105. 
Pashias, N., Boger, D.V., Summers, J., and Glenister, D.J. 1996. A fifty cent rheometer for yield stress measurements. Journal of Rheology, 40(6), 1179 - 1189.

Paterson, A.J.C. 2006. Rheology control of thickened tailing and paste pumping systems. Proceedings of the $9^{\text {th }}$ International Seminar on Paste and Thickened Tailings, Australian Centre for Geomechanics, Limerick, Ireland, 47 - 56.

Pinto, M. and Barrera, S. 2002 Tailings beach slope forecasting - Copper tailings, Proceedings of the 9th International Conference on Tailings and Mine Waste, Fort Collins, Colorado, USA, 87 - 91.

Pirouz, B. and Williams, M.P.A. 2007. Prediction of non-segregating thickened tailings beach slopes - A new method. Proceedings of the $10^{\text {th }}$ International Seminar on Paste and Thickened Tailings, Australian Centre for Geomechanics, Perth, Australia, $315-327$.

Ritcey, G. M. 2005. Tailings management in gold plants. Hydrometallurgy, 78(1-2), 3 20.

Rodriguez-Paz, M.X. and Bonet, J. 2004. A corrected smooth particle hydrodynamics method for the simulation of debris flows. Numerical Methods for Partial Differential Equations, 20(1), 140 - 163.

Scola, J.C. and Landriault, D. 2007. An evaluation of high dewatered tailings disposal applications in large scale mining operations in Chile's Atacama Desert. Proceedings of the $10^{\text {th }}$ International Seminar on Paste and Thickened Tailings, Australian Centre for Geomechanics, Perth, Australia, 329 - 335.

Shih, W.H., Kisailus, D., and Shih, W.Y. 1996. Rheology and consolidation of colloidal alumina-coated silicon nitride suspensions. Journal of the American Ceramic Society, $79(5), 1155-1162$.

HENRIQUEZ, J.A. 2008. DYNAMIC IMAGING AND MODELLING OF GOLD PASTE TAILINGS FLOWS 
Shuttleworth, J.A., Thomson, B.J., and Wates, J.A. 2005. Surface paste disposal at Bulyanhulu - Practical lessons learned. Proceedings of the $6^{\text {th }}$ International Conference on Paste and Thickened Tailings, Mining Engineering Department of the University of Chile, Santiago, Chile.

Simms, P. 2007. On the relation between laboratory flume tests and deposition angles of high density tailings. Proceedings of the $10^{\text {th }}$ International Seminar on Paste and Thickened Tailings, Australian Centre for Geomechanics, Perth, Australia, 329 - 335.

Simms, P. and Bryan, R. 2007. Surface disposal of paste tailings - Insights from the laboratory and from the Bulyanhulu mine. $60^{\text {th }}$ Canadian Geotechnical Conference and $8^{\text {th }}$ Joint CGS/IAH-CNC Groundwater Conference, Ottawa, Canada, 1462 1469.

Simms, P., Grabinsky, M, and Zhan, G. 2007. Modelling evaporation of paste tailings from the Bulyanhulu mine. Canadian Geotechnical Journal, 44(12), 1417 - 1432.

Sofra, F. 2006. Rheological assessment - A road map for plant designers and operators. Paste 2006, Proceedings of the $9^{\text {th }}$ International Seminar on Paste and Thickened Tailings, Australian Centre for Geomechanics, Limerick, Ireland, 13 - 24.

Sofra, F. and Boger, D.V. 2001. Slope prediction for thickened tailings and pastes. Proceedings of the $8^{\text {th }}$ International Conference on Tailings and Mine Waste' 01, Fort Collins, Colorado, USA, 75 - 83.

Tanner, R. 2000. Engineering Rheology, Second Edition. Oxford University Press Inc., New York, USA.

Theriault, J., Frostiak, J., and Welch, D. 2003. Surface disposal of paste tailings at the Bulyanhulu Gold Mine, Tanzania. Mining \& the Environment III Conference: Sudbury 2003 - Mining and the Environment, Sudbury, Ontario, Canada.

HENRIQUEZ, J.A. 2008. DYNAMIC IMAGING AND MODELLING OF GOLD PASTE TAILINGS FLOWS 
Tome, M.F. and McKee, S. 1994. GENSMAC: A computational marker and cell method for free surface flows in general domains. Journal of Computational Physics, $110,171-186$.

Vick, S. G. 1990. Planning, design, and analysis of tailings dams, Second edition. John Wiley \& Sons, Inc. USA.

Will, B.A. 1988. Mineral Processing Technology, Fourth edition. Pergamon Press, England, UK.

Wright, P.G. 1977. The variation of viscosity with temperature. Physics Education, $12(5), 323-325$.

Yuhi, M. and Mei, C.C. 2004. Slow spreading of fluid mud over a conical surface. Journal of Fluid Mechanics, 519(25), 337 - 358.

Zhu, L., Papadopoulos, K., and De Kee, D. 2002. Yield stress measurement of silicon nitride suspensions. The Canadian Journal of Chemical Engineering, 80(6), 1175 1180 . 


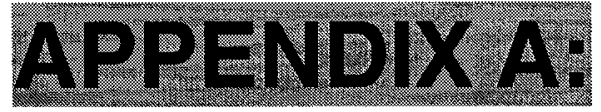

\section{CHEMICAL COMPOSITION}

\section{OF THE TAILINGS}




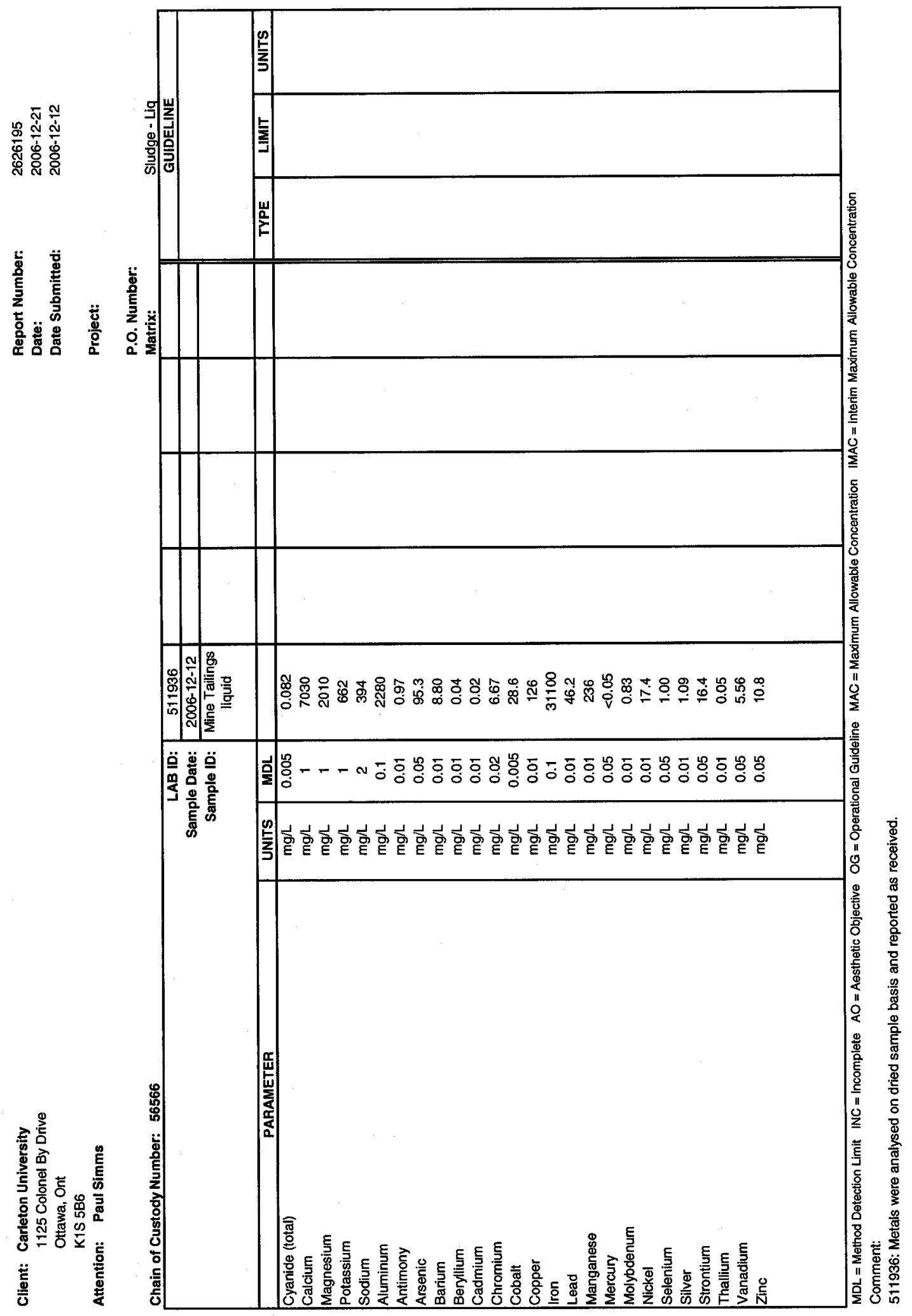




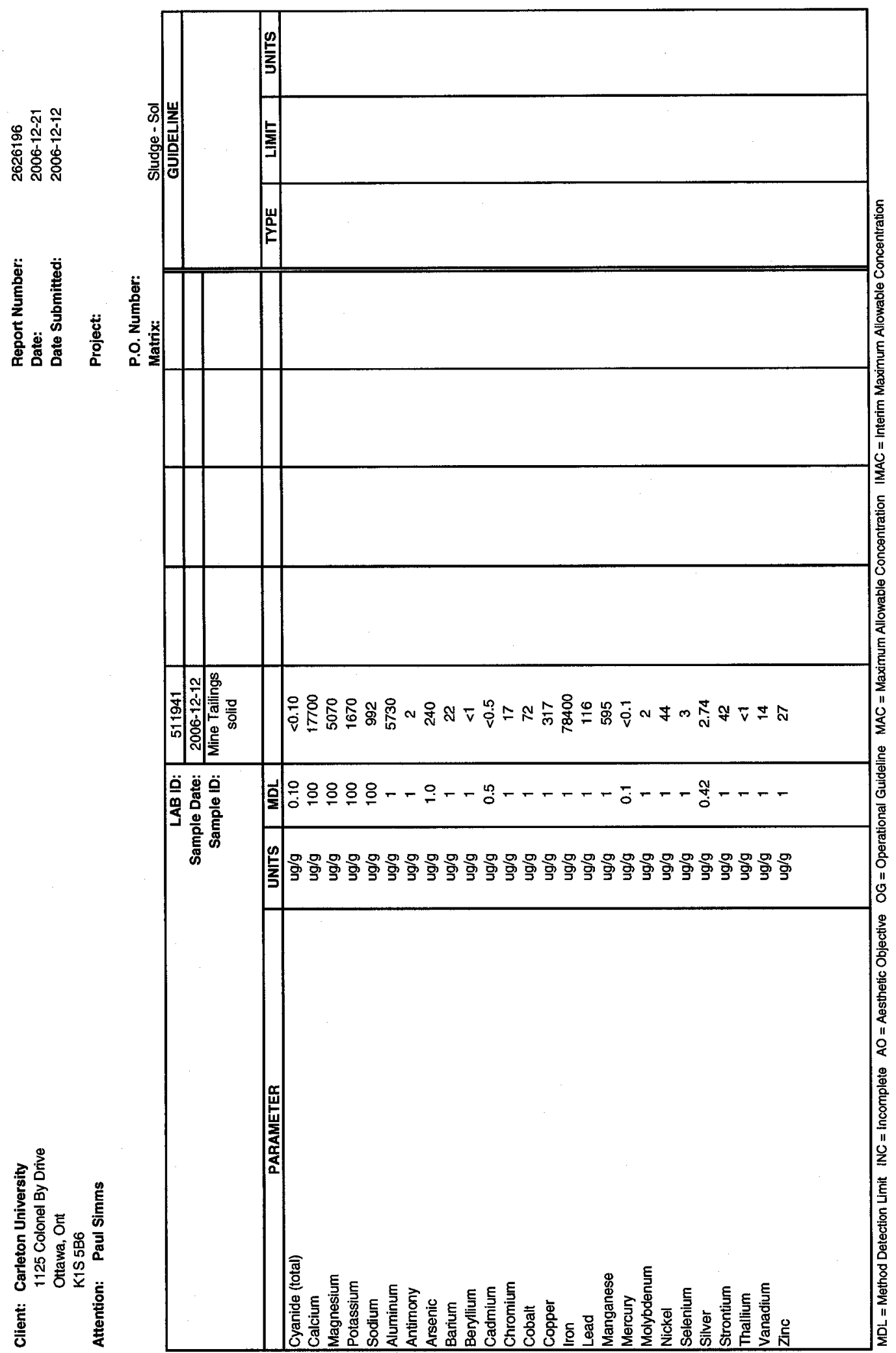

HENRIQUEZ, J.A. 2008. DYNAMIC IMAGING AND MODELLING OF GOLD PASTE TAILINGS FLOWS 


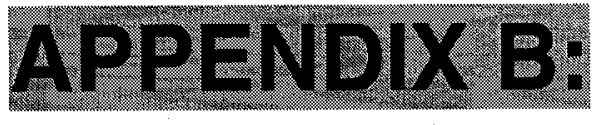

\section{PAPER SUBMITTED TO}

\section{MINERALS ENGINEERING}

Note: At the time of printing the present thesis, this paper was under review by Minerals Engineering. 


\title{
DYNAMIC IMAGING AND MODELLING OF MULTILAYER DEPOSITION OF GOLD PASTE TAILINGS
}

Henríquez, Julio and Simms, Paul ${ }^{1}$

Department of Civil and Environmental Engineering

Carleton University

Ottawa, Canada

\begin{abstract}
Surface disposal of paste or thickened tailings is contemplated as an alternative to conventional slurry deposition. One important challenge in managing paste is to predict the evolving geometry of the tailings stack. This study dynamically images multilayer and axisymmetric flows deposition of paste at a laboratory scale. It is found that both the steady-state and the dynamic flows can be modelled as a Bingham fluid using equations developed from lubrication theory. Yield stress and viscosity were determined from flow curves and slump tests. It is shown that the yield stress obtained from the slump test may overestimate the yield stress of significance to flow deposition; that is, the yield stress that characterizes when the tailings stop flowing. The lubrication theory equations show that the overall angle of a tailings deposit is dependant on the scale of the flow, which may explain the discrepancy between laboratory flume angles and field angles noted in practice.
\end{abstract}

Keywords: Tailings disposal, computational fluid dynamics, environmental, reclamation.

1 Corresponding Author: Paul Simms, Assistant Professor, Department of Civil and Environmental Engineering, Carleton University, Ottawa, Canada, K1S 5B6. Email:paul_simms@carleton.ca

HENRIQUEZ, J.A. 2008. DYNAMIC IMAGING AND MODELLING OF GOLD PASTE TAILINGS FLOWS 


\section{INTRODUCTION}

Surface disposal of thickened or paste tailings is an attractive option as it eliminates or reduces some of the risks associated with conventional tailings disposal, most notably, obviating the need for dams and eliminating the risk of catastrophic failure associated with conventional impoundments (ICOLD, 2001). Thickened or paste tailings offers other comparative advantages, such as: increased water recycling within the mining operation, and reduced groundwater seepage out of the tailings impoundment. Recent advances in technology have permitted economic dewatering and pumping of thicker tailings to the point where they behave as a non-Newtonian fluid, and form gently sloping stacks during deposition, thus reducing reliance on confinement by dams. Tailings thickened to the extent that no segregation of particle size occurs during transport and relatively small amount of settling occurs post-deposition are often called "paste" (Cincilla et al., 1997). Paste deposition has been employed at a full-scale at the Bulyanhulu Gold Mine in Tanzania (Simms et al., 2007, Suttleworth et al., 2005; Theriault et al., 2003). It has been shown at Bulyanhulu, that if the deposition is cycled between a number of points in the impoundment and the geometry of the flow is properly controlled (Shuttleworth et al., 2005), the tailings will densify and gain significant strength through desiccation, allowing the development of stable stacks with up to a 6 degree slope.

While the behaviour of thickened or paste tailings in the pipeline have been studied to a significant degree (Nyugen and Boger, 1998; Pullam et al., 2007; Sofra, 2007), the 
relation between rheology and deposition geometry has received less attention. Most studies have focused on charactering the geometry using a single angle at the laboratory scale (Kwak et al., 2005; Sofra and Boger, 2003). However, it has widely been observed in practice that the overall angles of deposits in the field are typically less than angles measured in the laboratory (Oxenford and Lord, 2006; Engman et al., 2004). This was partially thought to be attributed to shear thinning occurring during transport (Houman $e t$ al., 2007). Based on non-Newtonian flow theory previously applied to mud and lava flows (Liu and Mei, 1989), Simms (2007) proposed that the equilibrium beach profile is not characterized by a unique angle, and that the overall angle of the deposit is a function the size of the flow. Other researchers have begun tackling this problem (Fitton et al., 2008; Pirouz and Williams, 2007) using a different approach based on the critical deposition velocity for turbulent overland flow. This paper pursues the method proposed in Simms (2007) and examines the applicability of "lubrication theory" for predicting both equilibrium beach profiles and the dynamic flow behaviour of gold paste tailings during multilayer deposition.

\section{THEORY}

\section{Equations for equilibrium profiles}

Equations for the equilibrium profiles of yield stress fluids may be derived using "Lubrication Theory", in which the continuity and momentum equations for fluids are simplified by assuming the slow spreading of a thin layer or film. The simplifying assumptions are:

HENRIQUEZ, J.A. 2008. DYNAMIC IMAGING AND MODELLING OF GOLD PASTE TAILINGS FLOWS 
1. The ratio of thickness to horizontal extent of the flow are small, and

2. The velocity of the material is slow, such that terms that include the ratio of inertial to viscous forces will vanish from the momentum equation. In other words, the Reynold's number is small, and hence the flow in laminar.

These simplified momentum and continuity equations have been solved analytically for yield stress fluids under special geometries and conditions by several researchers, for applications such as mud or lava flow (Yuhi and Mei, 2004; Liu and Mei, 1989; Balmforth et al., 2002; Coussot and Proust, 1996).

For example, after the above assumptions are applied, if one considers flow along an inclined plane, the momentum equation in the direction of flow would reduce to (Liu and Mei, 1989):

$$
\frac{\partial p}{\partial x}=\rho g \sin \theta+\frac{\partial \tau}{\partial z}
$$

Where $p$ is pressure, $p$ is the bulk density, $\theta$ is the angle of the inclined surface from the horizontal, $g$ is the acceleration due to gravity, $\tau$ is the shear stress, the $x$ axis is the direction of the inclined plane, and the $z$ axis is perpendicular to the inclined plane. If we assume the pressure distribution to be hydrostatic, then

$$
p=\rho g(h-z) \cos \theta
$$

Where $h$ is the height of the free surface or thickness of the flow at a particular $x, h$ is measured perpendicular to $x$. Then differentiating (2) to substitute it into the left-hand side of (1), and solving for $\tau$ one obtains an expression in terms of depth $\mathrm{z}$ : 


$$
\tau=(h-z)\left(\rho g \cos \theta\left(\tan \theta-\frac{\partial h}{\partial x}\right)\right)
$$

Now, setting $z=0$, one may obtain an expression for the steady state profile of a Bingham fluid, given the condition $\tau<\tau_{\mathrm{y}}$, the yield stress. To examine the equation for a flat bed, we can set $\theta=0$ and solve for $h$ to obtain:

$$
h^{2}-h_{0}{ }^{2}=\frac{2 \tau_{y}}{\rho g}\left(x-x_{0}\right)
$$

Where $\mathrm{h}_{0}$ is the height at $\mathrm{x}_{0}$. This formula has been used to describe lava flows as early as Hulme (1974).

In the same vein as the derivation of Equation 4, an equation for the steady-state profile of flow from the top of an inclined hill may be derived (Yuhi and Mei, 2004):

$$
h^{\prime}-h_{0}^{\prime}+\ln \left(1-h^{\prime}\right)=x^{\prime}-x_{0}{ }^{\prime}
$$

where $h^{\prime}$ and $x^{\prime}$ are normalized variables, such that $h=h^{\prime}\left[\tau_{y} /(\rho g \sin \theta)\right]$ and $x=x^{\prime} \cot \theta$ $\left[\tau_{\mathrm{y}} /(\rho g \sin \theta)\right]$.

\section{Equations for dynamic solutions}

A depth integrated transient solution to the Navier-Stokes equation based on lubrication theory may be similarly derived (Yuhi and Mei 2004). Equation 6 gives the depthintegrated flow for one-dimension for constant mass:

$$
\frac{\partial h}{\partial t}=\frac{g \rho}{\mu} \frac{d h}{d x} \frac{1}{6}\left(3 h-h_{y}-2 H\right)\left(h_{y}-H\right)^{2}
$$


where $\mu$ is the dynamic viscosity, $\mathrm{h}$ is the vertical height of flow, $\mathrm{h}_{\mathrm{y}}$ is the depth above which plug flow occurs, and $\mathrm{H}$ is the bed elevation. The term $\mathrm{h}_{\mathrm{y}}$ may be found from the yield stress (Yuhi and Mei 2004):

$$
\rho g\left(h_{y}-h\right) \frac{d h}{d x}=\tau_{y}
$$

We have used a one-dimensional finite volume solution scheme of Equation 6 with a spatial discretization of $0.02 \mathrm{~m}$ and a time step of $0.0001 \mathrm{~s}$. A source term is introduced into the cell at one side of the spatial mesh to allow for addition of mass. Our mesh was 2 $\mathrm{m}$ long, so chosen to be longer than any of our measured flows.

It is possible to use Eqn. 6 for any given relationship between viscosity and shear stress, but we have assumed that the material is a Bingham fluid and, hence, the viscosity was constant.

\section{EXPERIMENTAL METHODOLOGY}

\section{Material Characterization}

The gold tailings used in these experiments are from the Bulyanhulu mine in Tanzania. The particle size distribution is presented in Figure 1. The tailings have a specific gravity of 2.9, are non-plastic with an Atterberg plastic limit of $20 \%$ and a shrinkage limit of 18\%. After thickening, the tailings are pumped at a gravimetric water content (Geotechnical water content, mass of water over mass of solids, abbreviation GWC) of $40 \%$, corresponding to a solids concentration of $70 \%$. It has been observed in the field

HENRIQUEZ, J.A. 2008. DYNAMIC IMAGING AND MODELLING OF GOLD PASTE TAILINGS FLOWS 
and laboratory that the tailings do release some bleed water, settling down to a GWC of about 30\% (Simms et al., 2007) in the absence of evaporation and drainage. The mineralogical content of the tailings is given in Table 1.

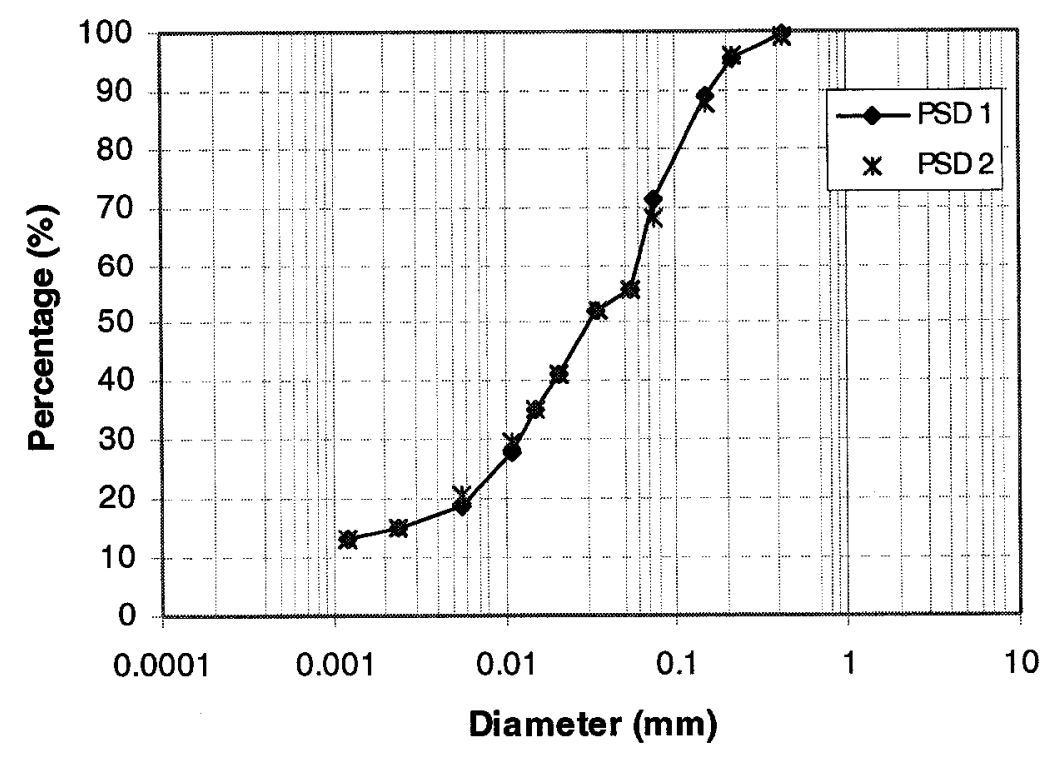

Figure 1 Particle size distribution of Bulyanhulu tailings from hydrometer

Table 1: Properties of Bulyanhulu tailings

\begin{tabular}{ll}
\hline PL, LL, SL (\%) & $20,23,18$ \\
\hline $\begin{array}{l}\text { Pumping water content } \\
\text { (gravimetric) }\end{array}$ & $40 \%$ \\
\hline Specific Gravity & 2.9 \\
\hline Mineralogy & Silicates (80\%), pyrite (6\%), \\
& calcite (5\%), Ankerite (4\%) \\
\hline
\end{tabular}

HENRIQUEZ, J.A. 2008. DYNAMIC IMAGING AND MODELLING OF GOLD PASTE TAILINGS FLOWS 
These tailings were shipped from the Bulyanhulu Mine late in 2006, and have slightly different properties than reported in other studies (Simms et al., 2007; Kwak et al., 2005). The tailings were shipped at the pumping water content, but settled during shipment, producing a layer of bleed water. This water was used for mixing, to bring the tailings to the desired water content. The main constituents of this water are Calcium (15 mmoles/L), magnesium (4 mmoles/L), and sulfate ( $25 \mathrm{mmoles} / \mathrm{L})$.

For all tests, the $\mathrm{pH}$ of the tailings and the temperature was monitored. The $\mathrm{pH}$ ranged between 6-7 while the temperature ranged from 21 to $24^{\circ} \mathrm{C}$.

\section{Rheological Characterization}

The rheology of the tailings was characterized at gravimetric water contents ranging from $30 \%$ to $60 \%$, using both slump test and by obtaining flow curves using a Brookfield Model RS-Plus rheometer with a plate on plate geometry. Slump tests have been advocated as a good index test to obtain the yield stress from thickened tailing (Clayton et al. 2003, Gawu and Fourie 2004). The slump test was performed using cylinders of varying height $(6 \mathrm{~cm}$ to $22 \mathrm{~cm})$ and diameter $(4 \mathrm{~cm}$ to $15 \mathrm{~cm})$. Prior to the tests, the tailings were mixed in buckets for 10 minutes using a mechanical stirrer. The slump tests were interpreted using the method of Pashias et al. (1996) to find the yield stress. 


\section{Flume and "pour" tests}

Flume tests have been extensively used to study the depositional behaviour of dewatered mine tailings (Sofra and Boger, 2002; Kwak et al., 2005; Engman et al., 2004). For this study, flume tests were performed on horizontal planes and successive layers. A high speed camera, Model IN250 from High Speed Imaging, was used to record the tests. For multilayer tests, each layer was left for about 24 hours before the next layer was added, allowing it to reach the post-bleed GWC of $30 \%$. This water content was confirmed by sampling. Pore-pressures using a tensiometer were monitored to ensure no significant suction developed. At this water content, the older layers remain saturated and no cracking develops. The flume tests were performed by using two methods: One, by filling up the flume reservoir and subsequently raising the reservoir gate, and two, by pouring the tailings through a funnel at one end of the flume. The funnel had an opening diameter of $2.4 \mathrm{~cm}$. Once prepared at the appropriate water content, the paste was placed in a bucket and mixed with a stirring machine for approximately 10 minutes prior to being deposited in the flume. The flume is made of see-through acrylic and is $30 \mathrm{~cm}$ tall, $15 \mathrm{~cm}$ wide, and $2.5 \mathrm{~m}$ long. The reservoir is $20 \mathrm{~cm}$ long and has a vertical gate.

Initial tests were performed to examine the effect of width of the flume and lubrication of the walls. A hydrophobic grease was used as a lubricant, and the walls were narrowed from 15 to $10 \mathrm{~cm}$. It was found that neither greasing nor changing the flume width had any significant effect on the final equilibrium profile of the flows (using the same volume of material per unit width). However, lubrication did have an effect on the dynamic 
profiles, in so much as it would prevent material from sticking to the walls, hence avoiding biasing the imaging of the tests from the side view. Therefore, the walls were lubricated during dynamic imaging tests.

A few "pour" tests were done using the funnel, where the material was deposited on a flat plane, spreading radially away from the deposition point to form axisymmetric deposits.

All the tests were performed on the sample in the "as-received" stated (no deflocculant was added) and at room temperature $\left(21-24^{\circ} \mathrm{C}\right)$.

\section{RESULTS}

\section{Rheological Characterization}

The yield stress determined from the slump tests are shown in Figure 2. While there is some variation in the slumps obtained using different size cylinders, there is a consistent relationship between gravimetric water content and yield stress for all the tests. 


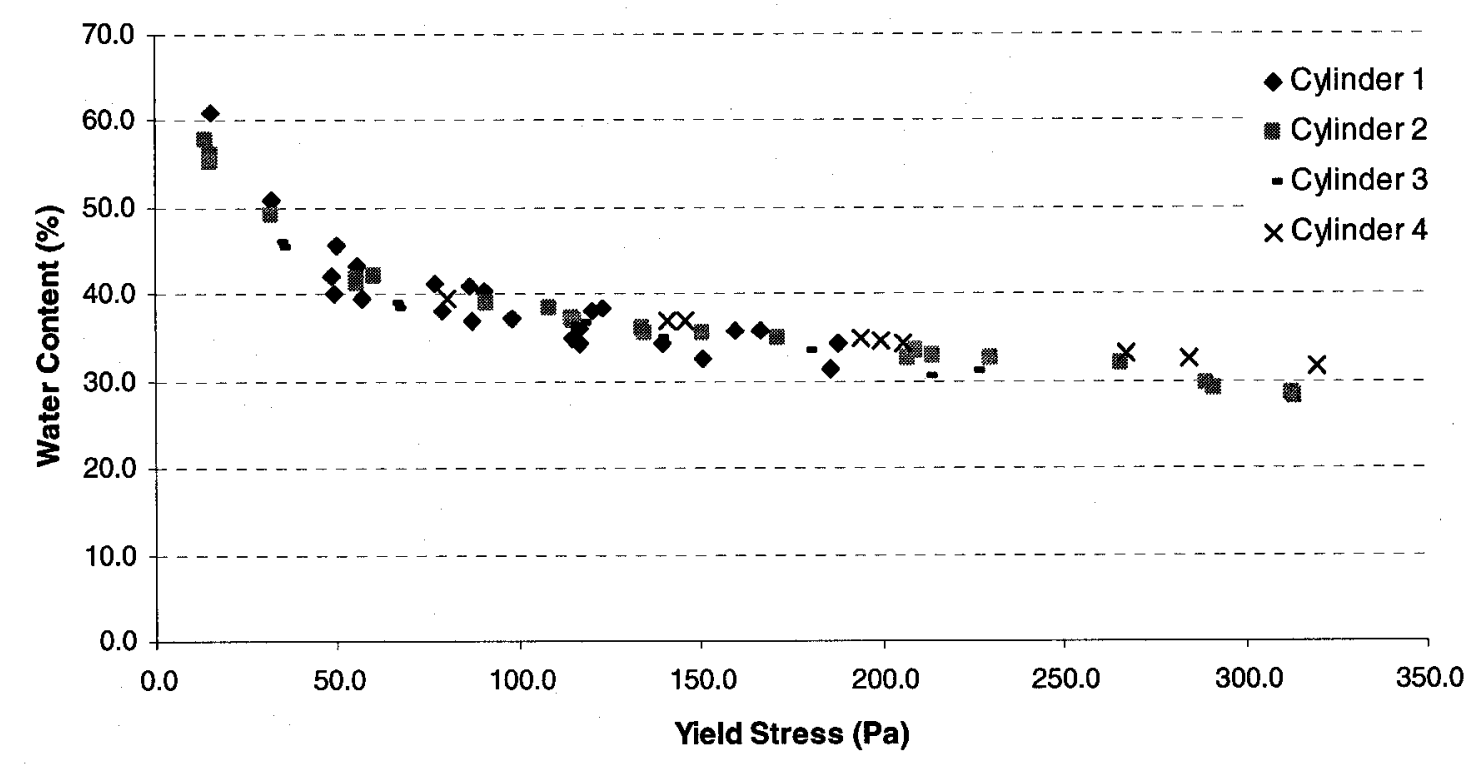

Figure 2 Yield stress from slump tests as a function of gravimetric water content using method of Palshias et al. (1996).

An example of a flow curve obtained using the rheometer is shown in Figure 3. It can be seen that there are different ways to interpret Bingham model parameters (yield stress and the viscosity) from this data, and that this material is not a perfect Bingham material. If the whole data set is used to fit the Bingham model, one will obtain a yield stress that is relatively high. If one only considers points at low shear rates, a higher viscosity and a lower yield stress is obtained. The significance of this difference is discussed towards the end of the paper: what is the most appropriate yield stress value to characterize our problem, namely at what point will the tailings stop flowing? 


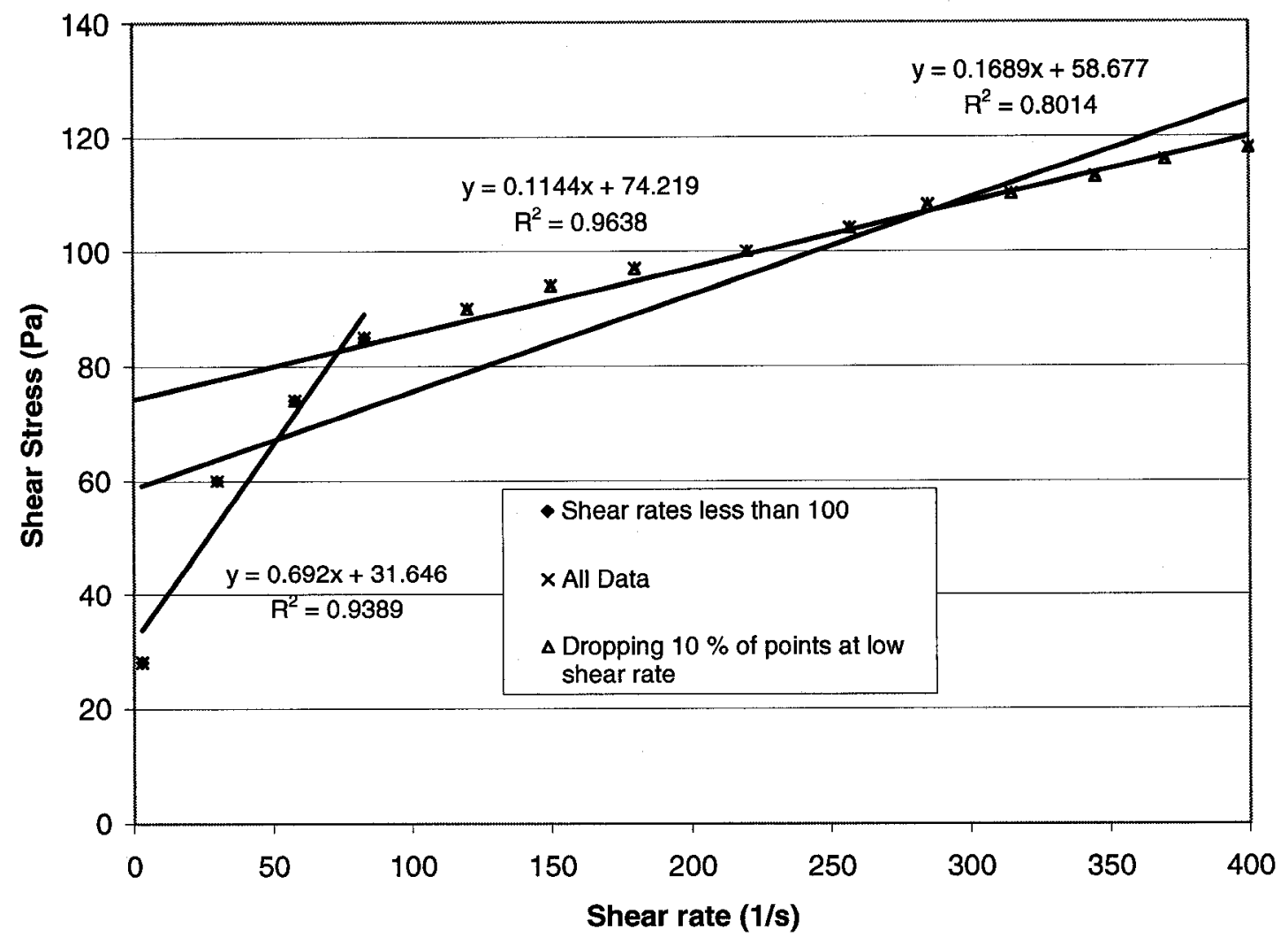

Figure 3 Flow curve for $39.5 \%$ gravimetric water content, showing 3 possible fits using Bingham model.

The yield stress obtained by considering only points with a shear rate lower than $100 \mathrm{~s}^{-1}$, considering all the data minus the initial $10 \%$ of the low shear rate data, and from the slump test are plotted in Figure 4. 


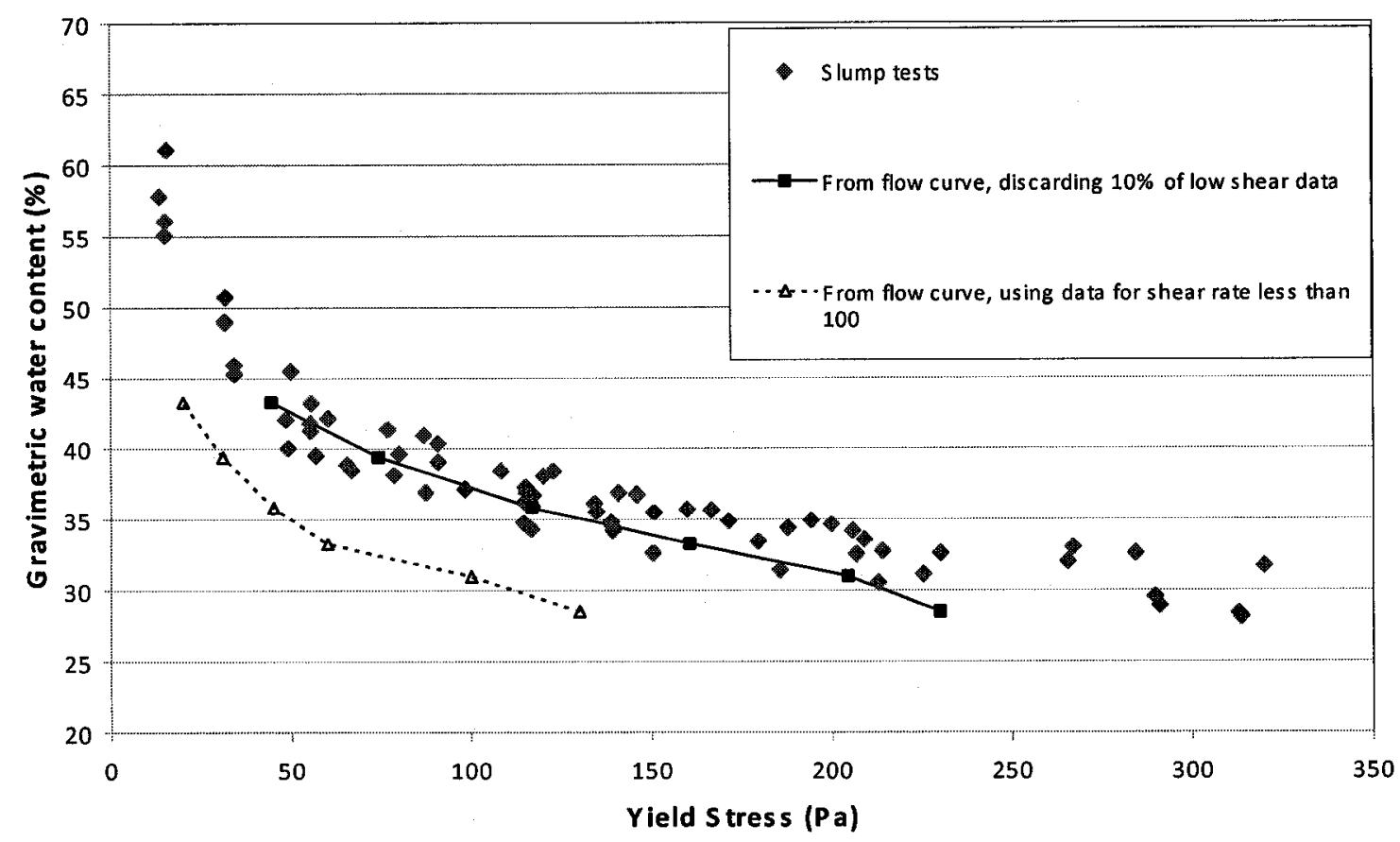

Figure 4 Yield stress from slump tests and rheometry.

The viscosity of the tailings, determined by the slope of the interpolated Bingham model to the flow curves, is given in Figure 5, where $10 \%$ of the data at the low shear end is discarded (DIN Standard 53019). Again, if the low end data is not discarded, and a fit is made to the data for shear rates less than $100 \mathrm{~s}^{-1}$, a considerably higher viscosity may be obtained. For example, at $39 \%$ gravimetric water content, the viscosity using the latter fit is $0.65 \mathrm{~Pa}$ s compared to $0.12 \mathrm{~Pa}$ s using the former fit. 


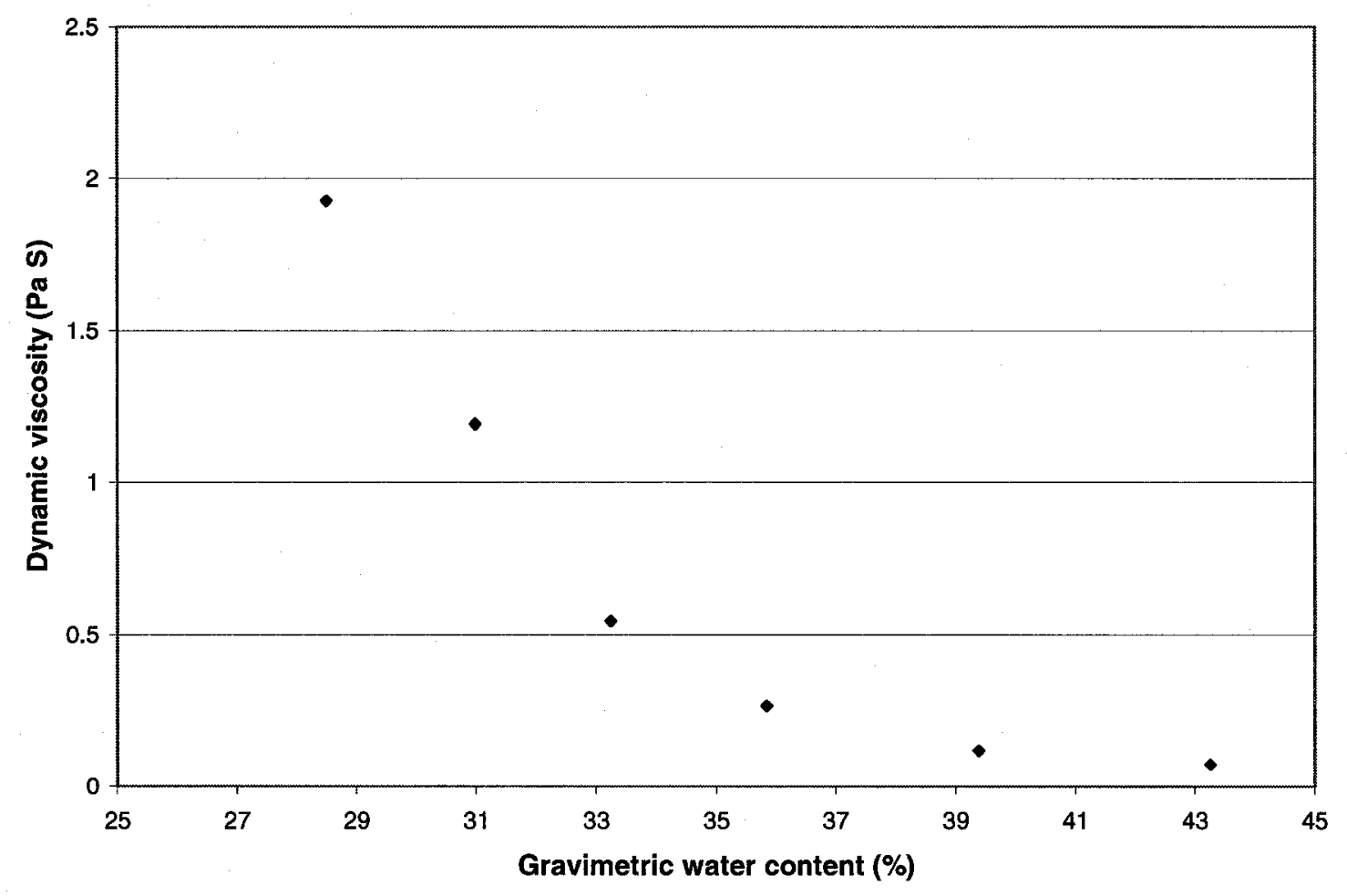

Figure 5 Dynamic viscosity from Bingham fit to flow curves, neglecting $10 \%$ data at the lowest shear rates.

\section{Flume tests - Equilibrium profiles}

It was found there was a significant difference between the shape of the flows between the two methods of deposition. The method using the gate resulted in thinner and longer steady-state profiles, especially when a larger volume of flow was used, as shown in Figure 6. In general, the theoretical prediction of steady-state geometry using Eqn. 4 gave much better fits with the second method (see Figure 7). For tailings at the pumping water content, the first method involves a significant release of potential energy, applying more of a push to the tailings - for large volumes of material in the reservoir. The inertia 
generated will be sufficient to violate the assumptions of lubrication theory. After these initial tests were performed, the rest of the flume tests were conducted using the funnel method.

Figure 7 shows fits of Eqn. 4 to tailings at $40 \%$ GWC and for three different volumes of flow. This figure illustrates two important points. The fits are all for yield stresses of 30 $\mathrm{Pa}$. This value corresponds to the yield stress obtained by fitting the Bingham model to the low shear range data of the flow curves, as described in the rheometry section. Figure 7 also shows that the overall scale of the deposit is a function of the scale of the flow each of the plots in Figure 7 is fit using Eqn. 4 employing the same parameters, the only difference is the total volume of the tailings.

Figure 8 shows profiles from duplicate pour tests. The deposits generated by these tests were quite symmetric, the run-out from the deposition point varied less than $1 \mathrm{~cm}$ in all directions. The fit using Eqn. 4 is good, except right at the top of the profile.

Multilayer deposition results are presented in Figures 9 and 10. Fresh deposits became thinner and the overall geometry appears to become increasingly linear as the simulated stack increases. It was discovered that the profile of the fresh layers can be calculated using Eqn. 3, calculating back from an assumed maximum run-out in discrete steps, by considering that $\theta=f(x)$ is given by the geometry of the underlying deposit. This calculation can be repeated for different assumed maximum run-outs, until the geometry with the correct volume is found. Examples are shown in Figures 11 and 12. The spatial step is $0.02 \mathrm{~m}$. 


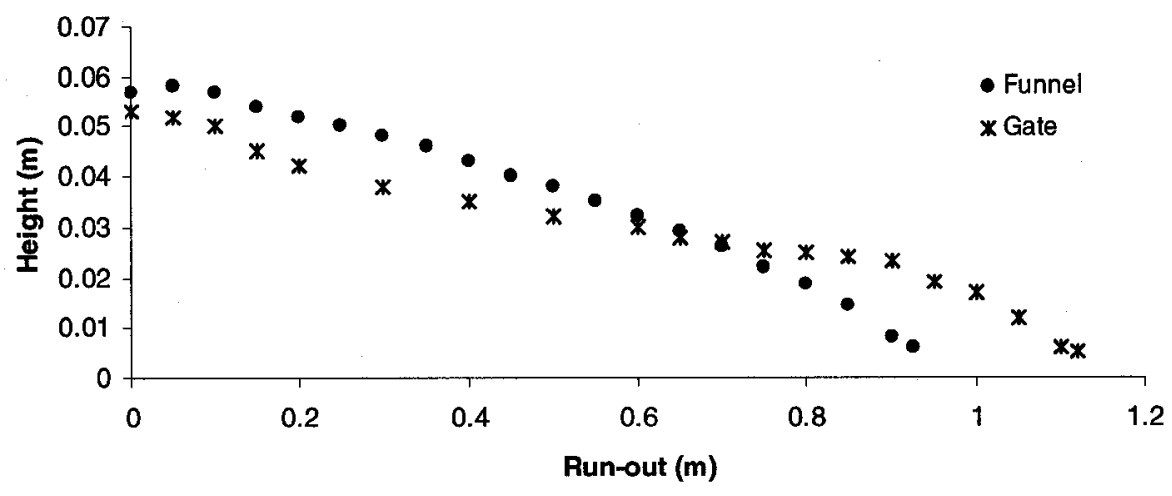

(a)

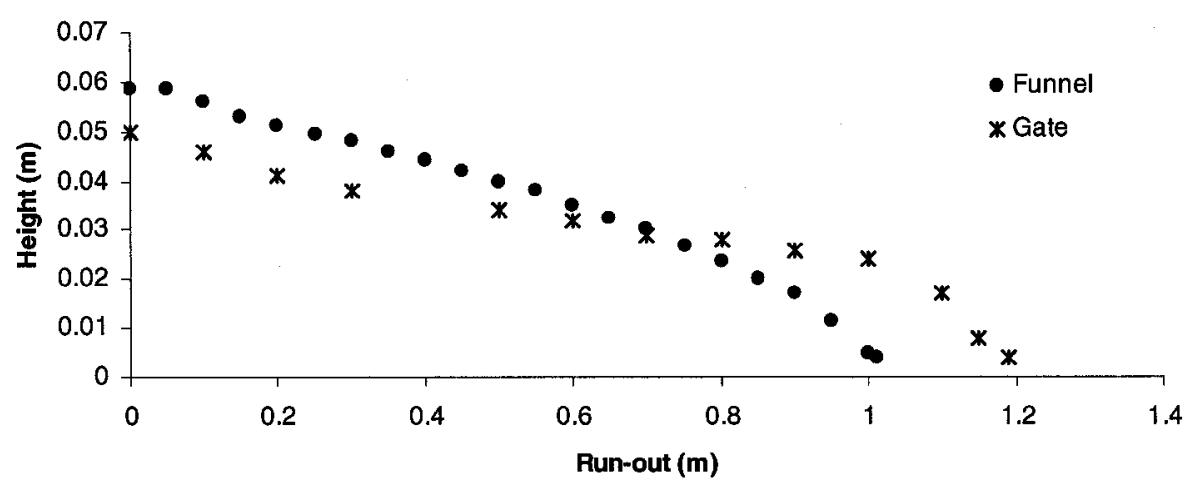

(b)

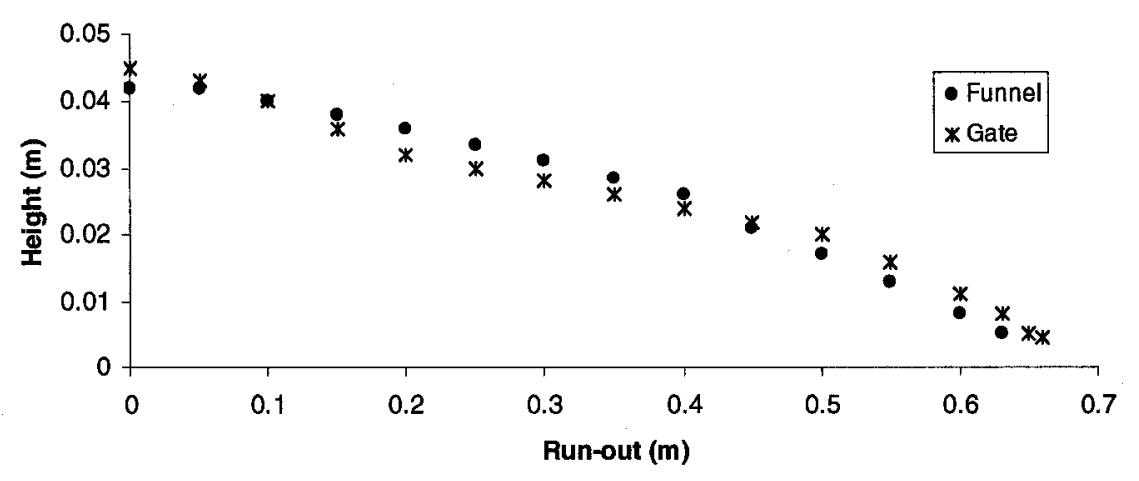

(c)

Figure 6 Equilibrium slope profiles for $40 \%$ GWC: for different deposition methods, repeated tests at larger volume ( $\mathrm{a}$ and $\mathrm{b}$ ) and for smaller volume $(\mathrm{c})$. 


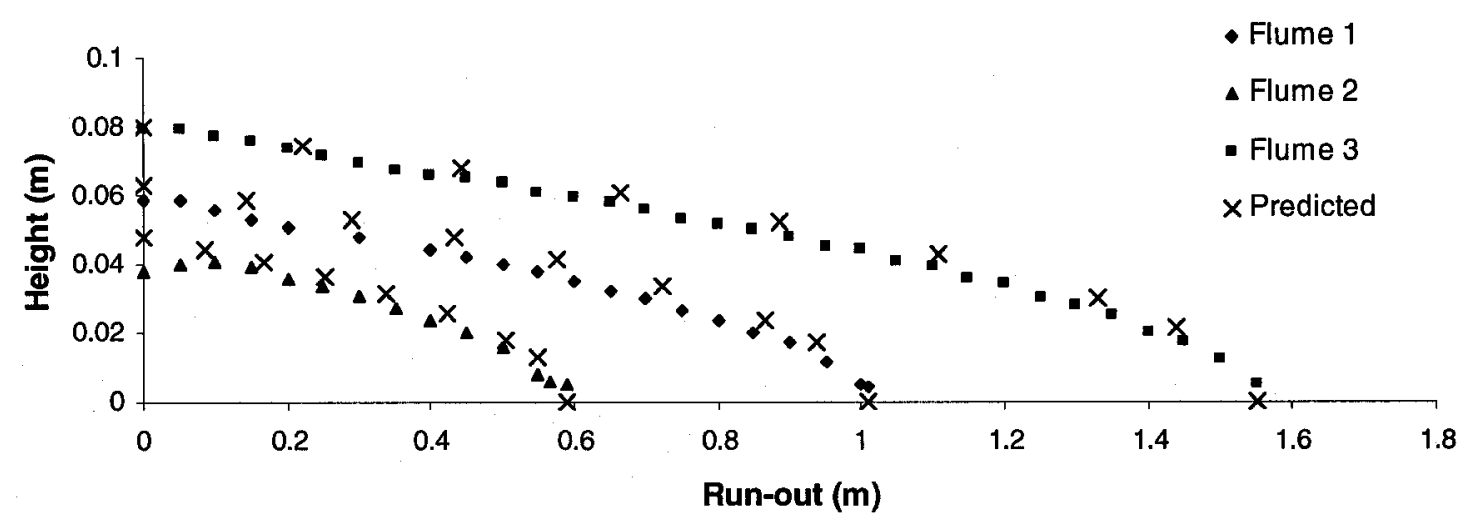

Figure 7 Three different single layer flows at $40 \%$ gravimetric water content at different volumes, all fitted with Eqn. 4 employing a $30 \mathrm{~Pa}$ yield stress.

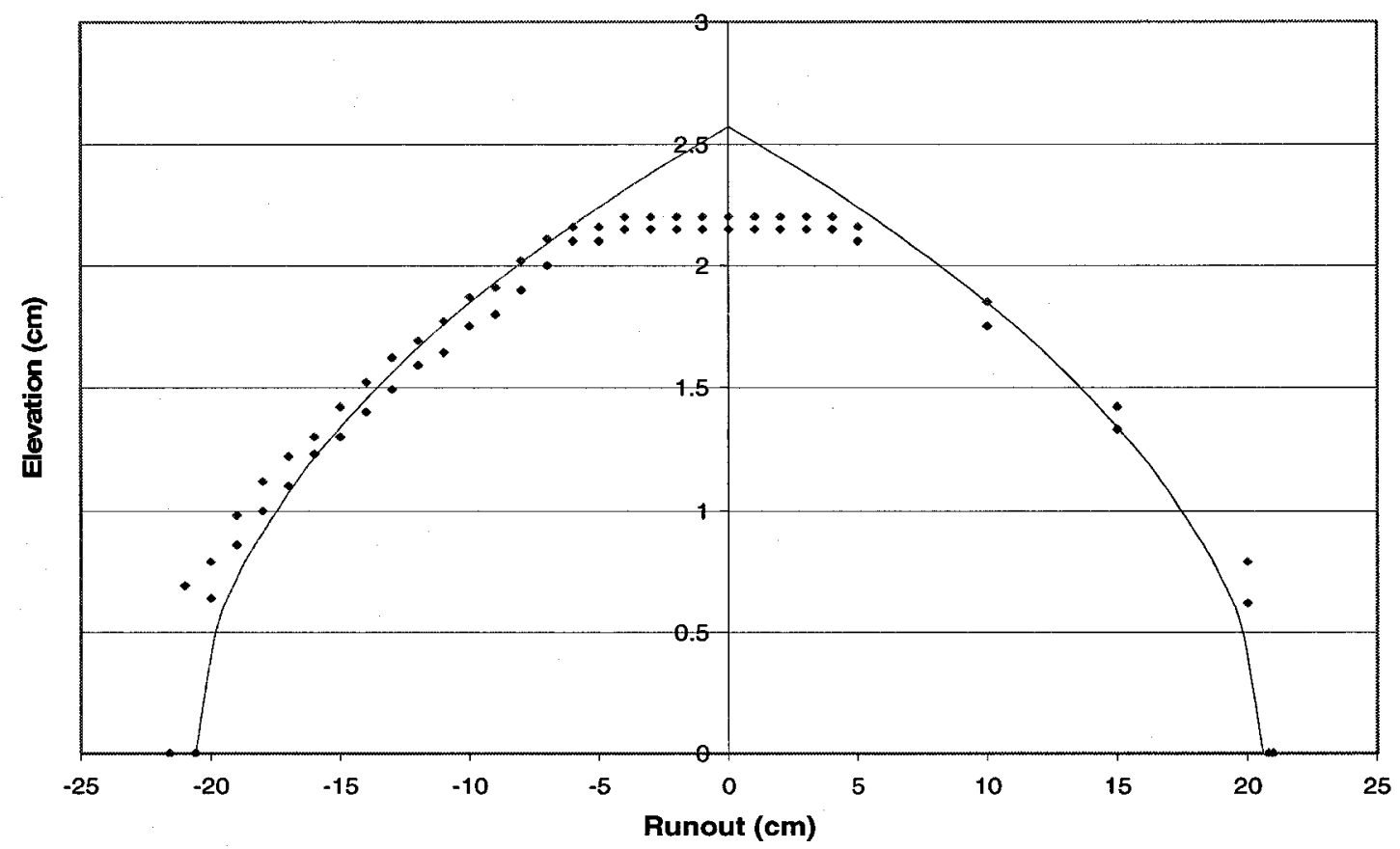

Figure 8 Replicate profiles of a pour test, and predicted slope from Eqn. 4 employing a $30 \mathrm{~Pa}$ yield stress. 


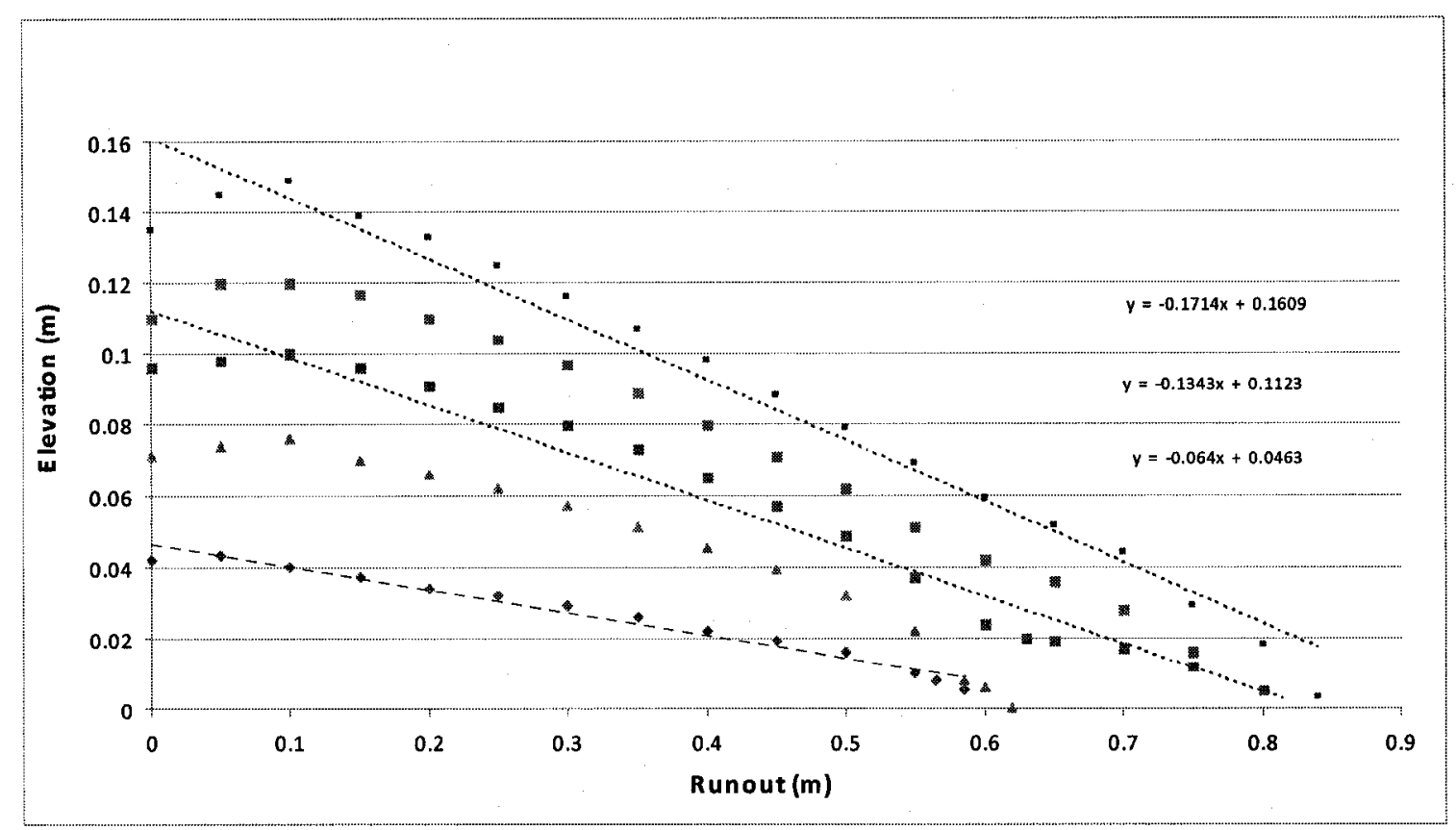

Figure 9 Sequential deposition of 5 layers of equal volumes, all $40 \%$, each layer left to settle to $30 \%$ GWC before the next layer is placed.

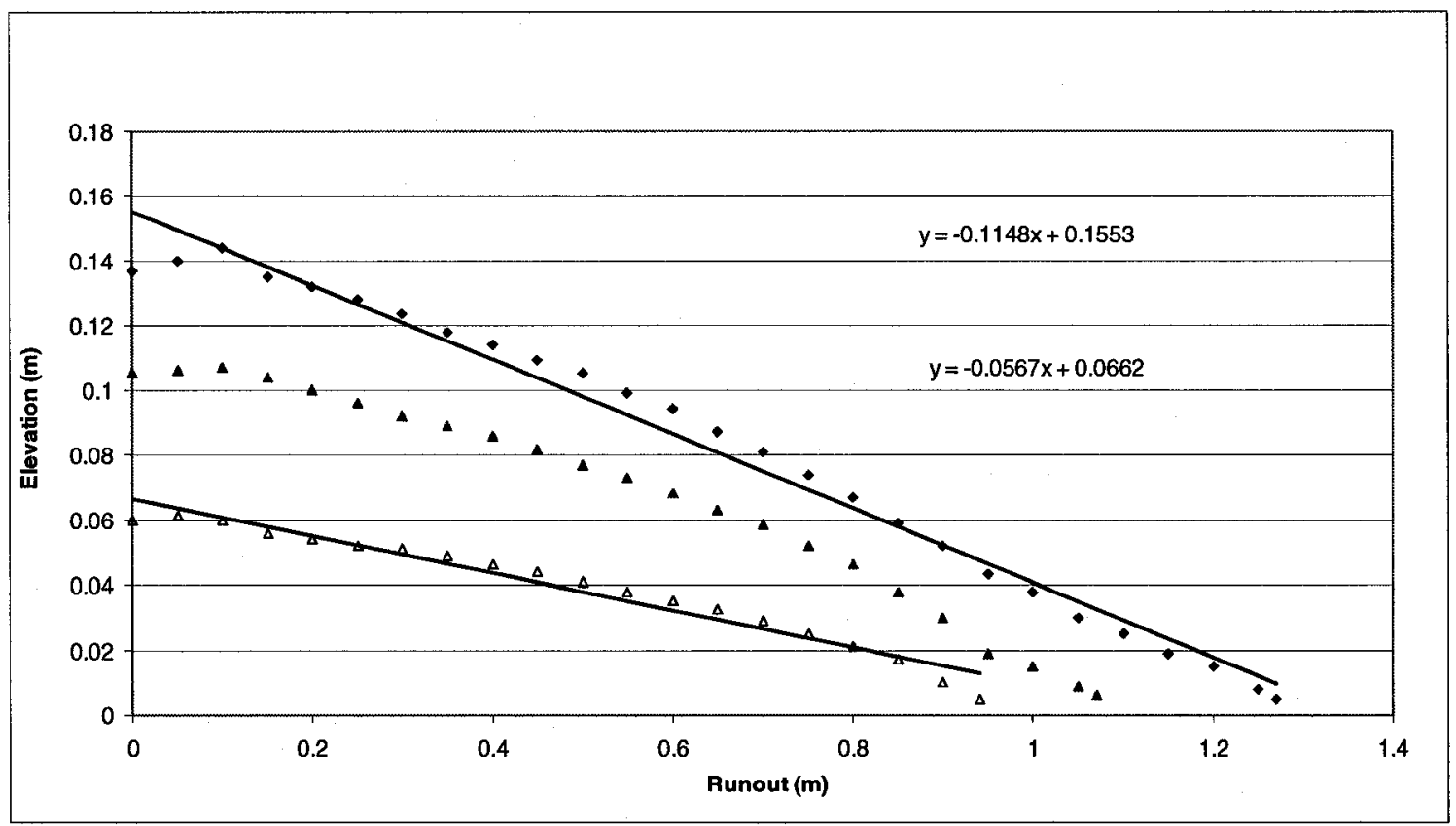

Figure 10 Sequential deposition of 3 layers of equal volumes (layer volume is twice that of layers in Figure 8), all 40\% GWC at deposition. 


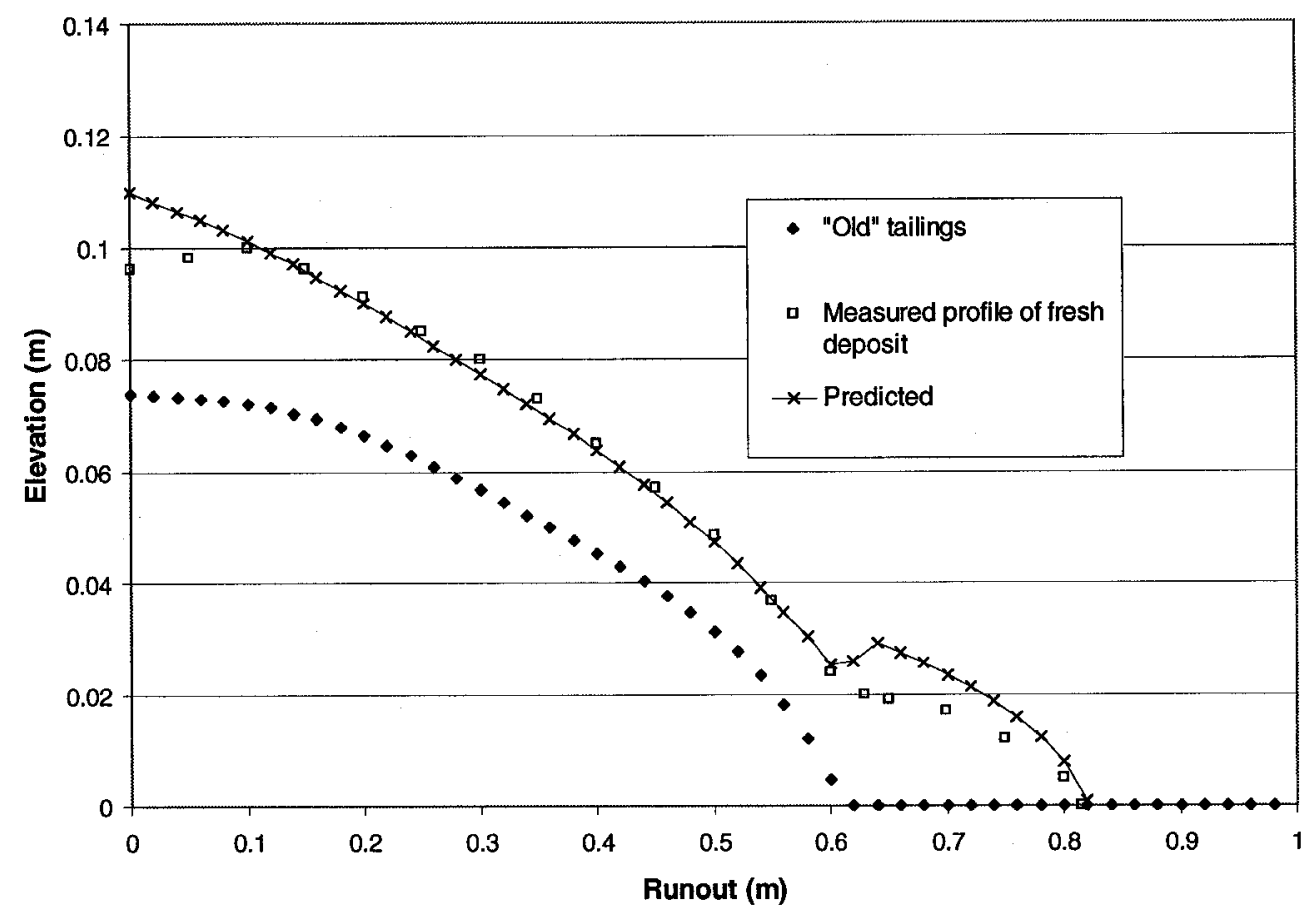

Figure 11 Steady-state equilibrium profile for tailings overlying a pre-existing deposit: Profiles are calculated using Eqn. 3.

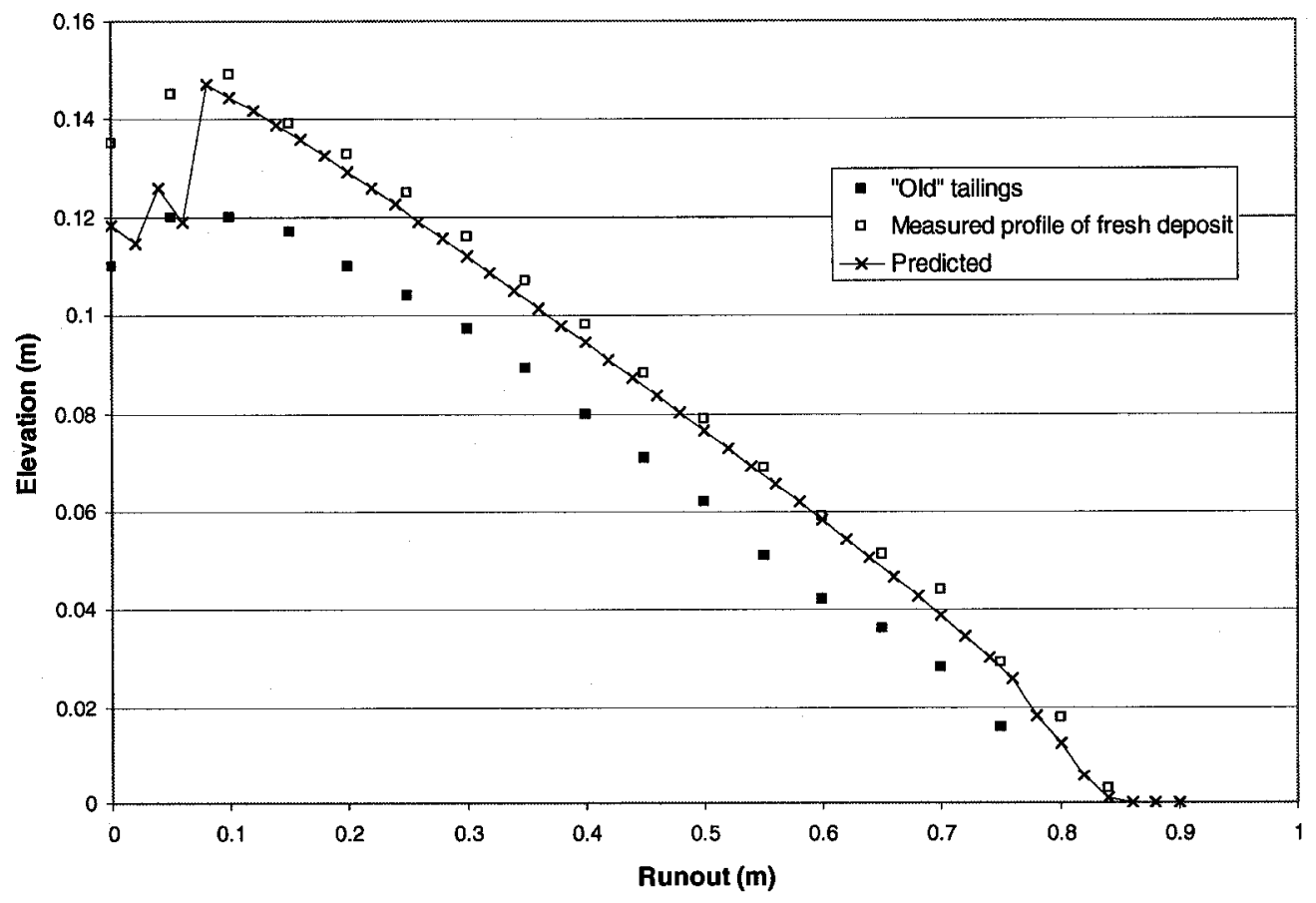

Figure 12 Steady-state equilibrium profile for tailings overlying a pre-existing deposit: Profile is calculated using Eqn. 3. 


\section{Flume tests - Dynamic imaging}

An example of the flow visualization in the flume is shown in Figure 13.
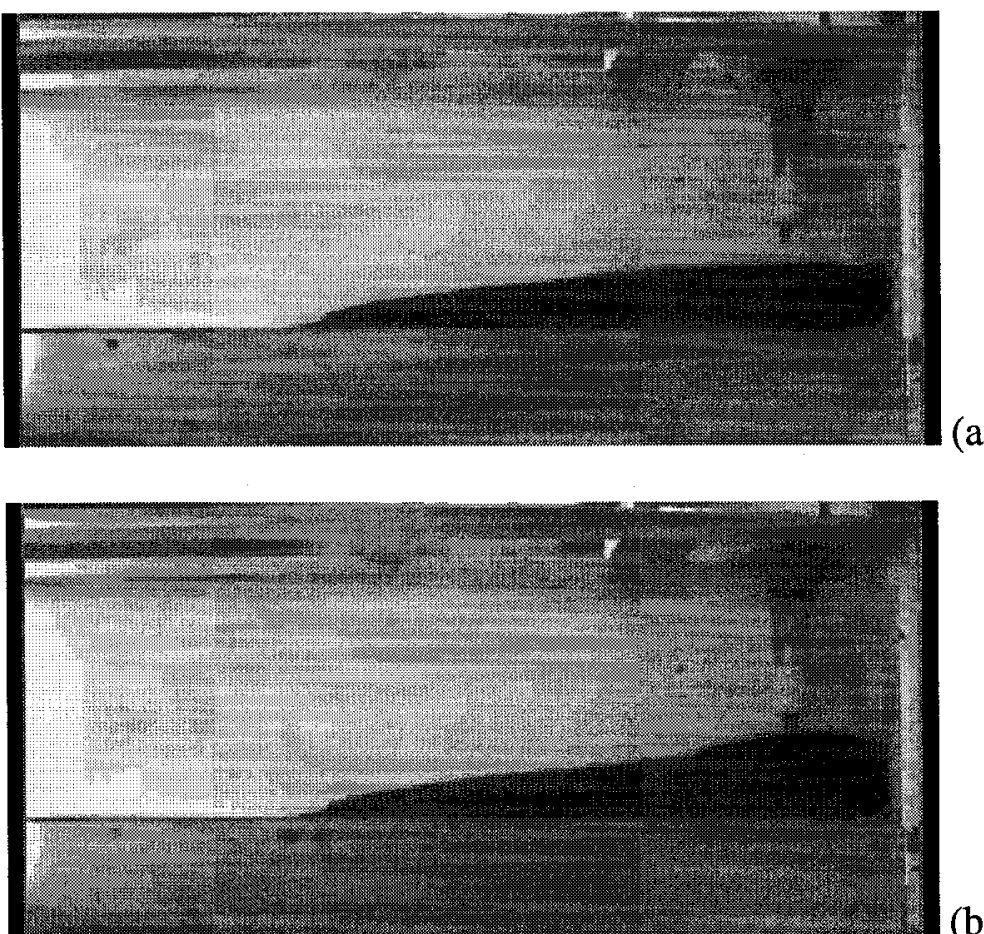

(a)

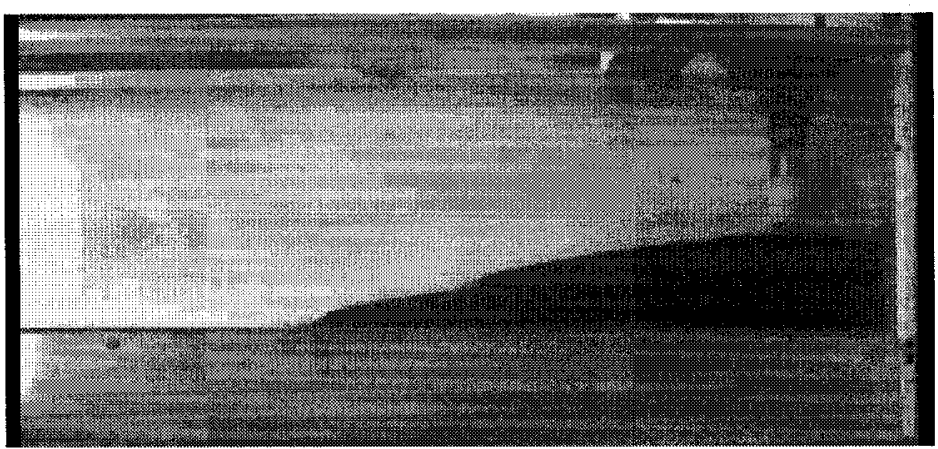

(b)

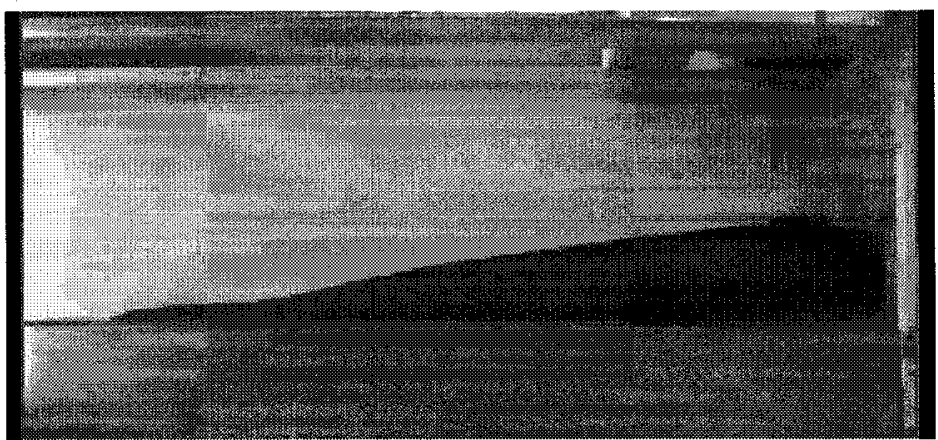

(c)

Figure 13 Example of visualization of paste flow (a) $0 \mathrm{~s}$ (b) $2 \mathrm{~s}$ (c) $4 \mathrm{~s}$ (d) stopped at $18 \mathrm{~s}$. 
For all the recorded tests, it was clear that the underlying layers were not remobilized when a fresh layer was added. Despite the imperfect boundary condition (using the funnel to introduce the tailings), the flow appears quite smooth and regular. Figure 14 shows an example of a fit of the dynamic model to flow in a single layer. We simulate mass addition in only the first cell of our mesh. The rate of mass addition is a step function based on the volume of the tailings observed at different times in the flume. We employed the viscosity obtained by fitting data from the flow curve for shear rates lower than $100 \mathrm{~s}^{-1}$, as discussed previously. The value of this viscosity was $0.65 \mathrm{~Pa}$ s.

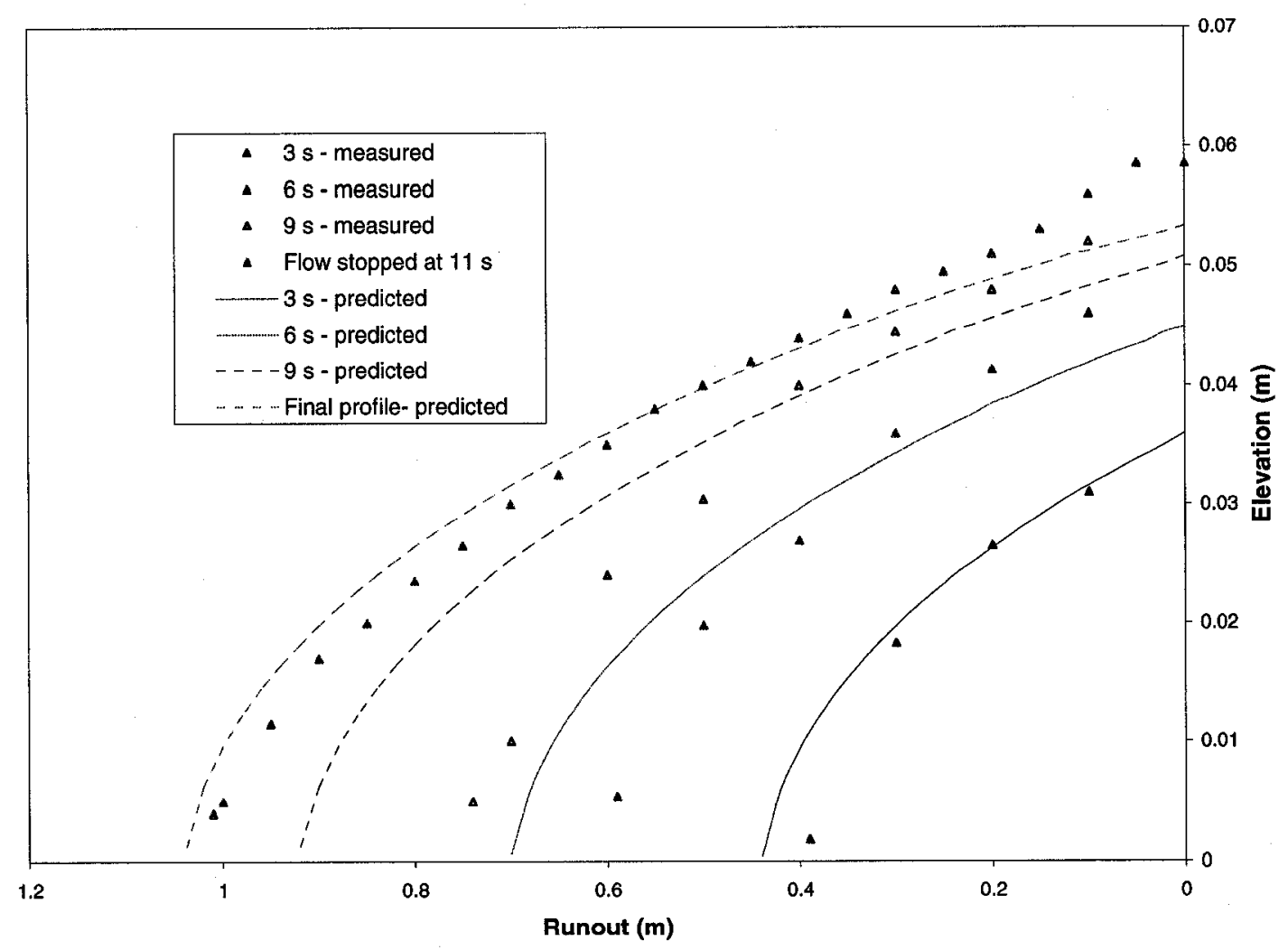

Figure 14 Simulation of transient flow in the flume for a single layer, tailings at $40 \%$ GWC, using a constant viscosity of $0.65 \mathrm{~Pa}$ s. 
It can be seen that while there is reasonable agreement at the early times, the simulated flow arrives at the equilibrium profile faster than the recorded flow. We suspected that this may be due to our assumption of constant viscosity. Nevertheless, the results are surprisingly accurate given the crude boundary condition. Two examples of predictions for multilayer flow are presented in Figure 15.

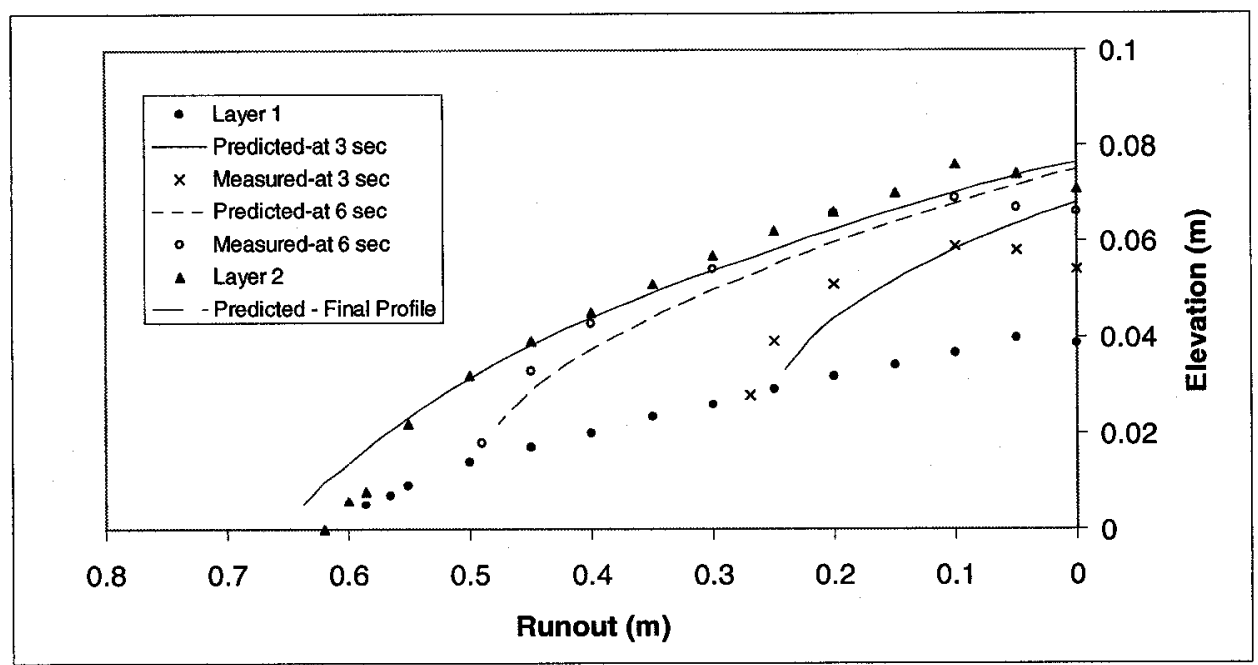

(a)

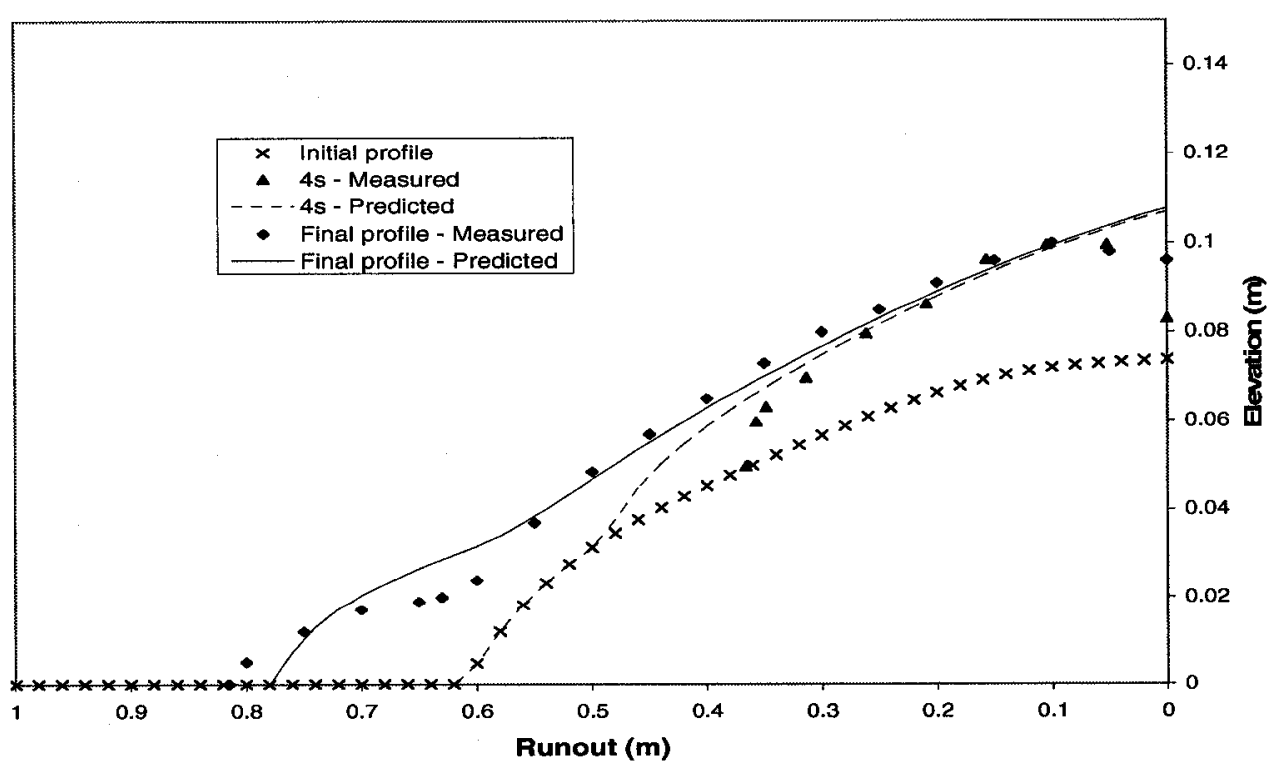

(b)

Figure 15 Two examples of a simulation of transient flow in the flume flowing over a) one previously deposited layers, and b) two previously deposited layers 


\section{DISCUSSION}

\section{What is the appropriate yield stress to characterize flow deposition?}

The best fit yield stresses for Eqn. 3 and 4. to our equilibrium profiles ranged between 30 and $45 \mathrm{~Pa}$ for tailings prepared at approximately $40 \% \mathrm{GWC}$. This number conforms much better to the yield stress obtained by fitting the low shear data with a Bingham model rather than using the whole flow curve or following DIN 53019. Unfortunately, shear stresses at low shear rates are the most sensitive to measurement error (DIN standard 53019). Therefore, fitting the low shear range from a flow curve with a Bingham model may not be an ideal alternative, due to uncertainty of torque measurements and the viscoelastic nature of the material. Rather, we would argue that our results suggest that a yield stress more characteristic of the behaviour during deposition may be obtained by fitting Eqn. 4 to small-scale flows, and that this is a useful utilization of small-scale flume tests.

\section{Application of theory to other results}

We present fits of Eqn. 4 to flume profiles of kaolinite tailings measured by Kwak et al. (2005), shown in Figure 16. This is not a best fit, the yield stresses used in the equation were measured independently using a Brookfield viscometer. These yield stresses correspond to the end of the elastic behaviour of the material (Kwak et al., 2005). 


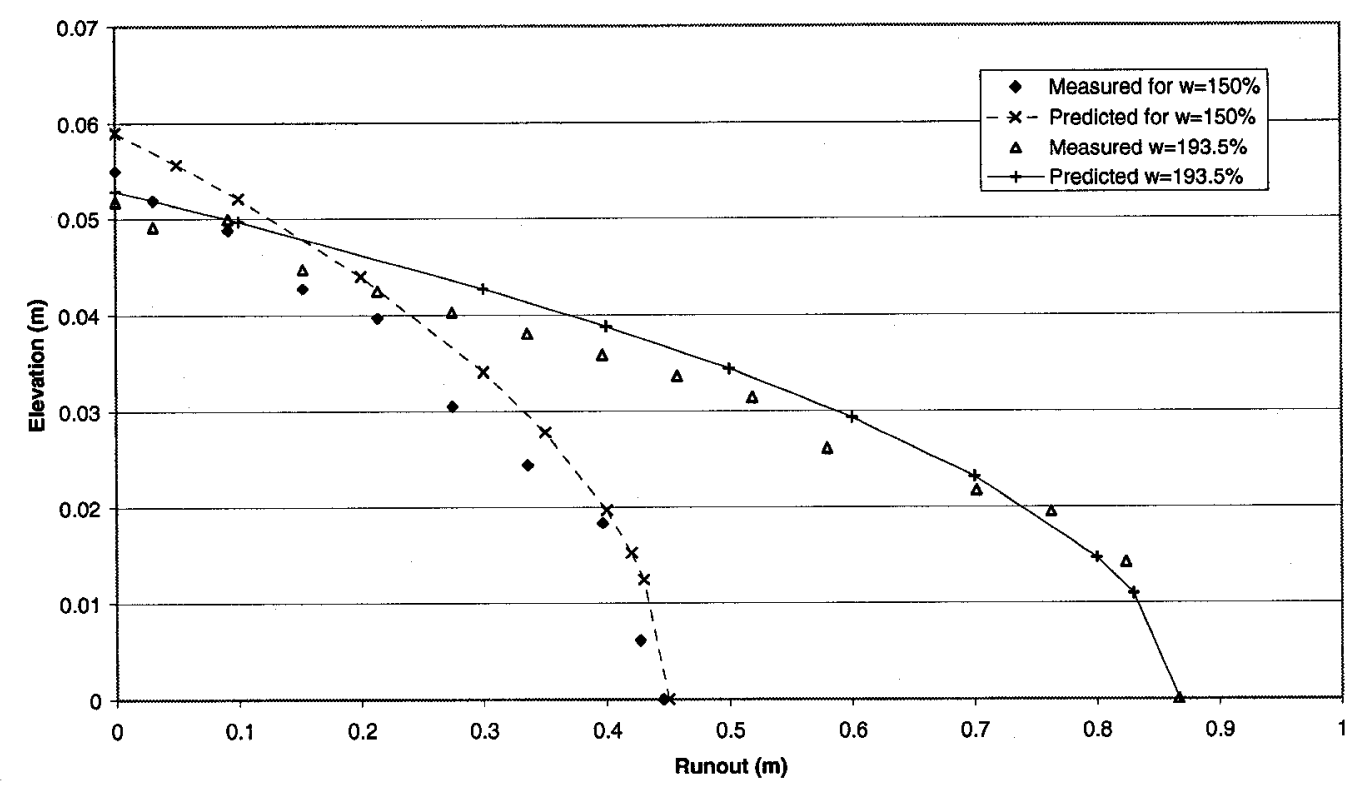

Figure 16 Flume profiles of kaolinite fitted with Eqn. 4 using independently measured yield stresses of 50 and $20 \mathrm{~Pa}$. Density was calculated using a specific gravity of 2.62 and assuming $\mathrm{S}=1$.

\section{Extrapolation to the field scale}

There are important differences between our experiments and how tailings are deposited in the field that are not studied in this paper, principally the effect of the deposition rate on final geometry. We believe, however, that theory demonstrated in the paper may be applicable to the field, as we believe that spreading flow distant from the deposition point will obey the assumptions of lubrication theory, namely slow velocity and thin layer flow.

The Bulyanhulu mine in Tanzania is the first to employ full-scale surface deposition. Deposition is cycled between a number of towers to facilitate desiccation. During early deposition, where the separate deposits centered around the different towers were not yet 
interfering with each other, the deposits had fairly regular geometry, though asymmetric due to a slight East-West slope of the base topography. Figure 17 shows a best fit to a profile obtained for tailings deposited over a topography with an approximate 0.5 degree downward slope, using Eqn. 5. Though we do not have detailed information as to the underlying topography, this Figure shows the theoretical approach described in this paper has plausibility.

The next stage of this work is to examine larger geometries of flow with varied rates of deposition. We hope to develop a 3-D version of the static and dynamic simulation techniques that have been presented, against large flume tests $(\sim 10 \mathrm{~m}$ in length) and against field deposition data.

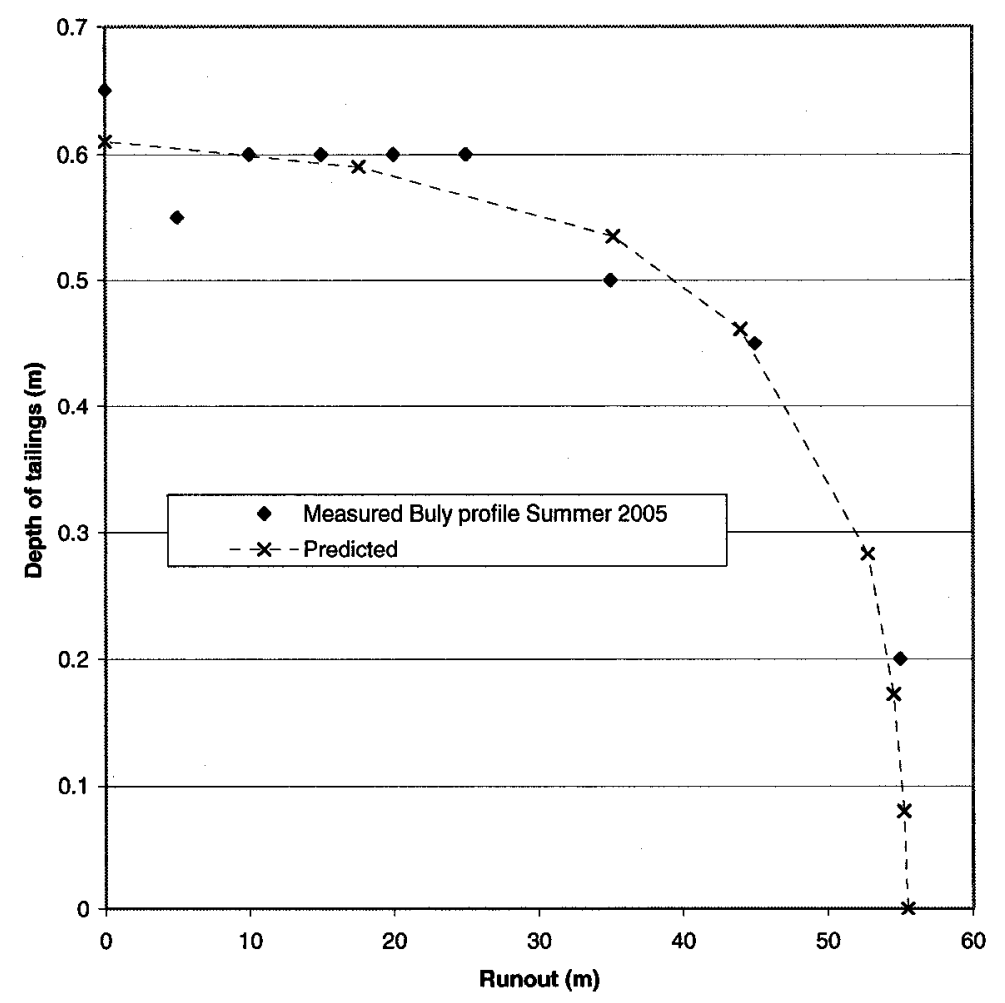

Figure 17 Profile of Bulyanhulu tailings in the field, fitted with Eqn. 5 for deposition from apex of a conical hill of 0.5 degree slope, $100 \mathrm{~Pa}$ yield stress, and bulk density of $1900 \mathrm{~kg} / \mathrm{m}^{3}$. 


\section{CONCLUSION}

Static profiles and dynamic flows of multilayer deposition of paste tailings are simulated in the laboratory, and compared to analytical and numerical predictions developed from lubrication theory of non-Newtonian flow. The results compare well and the theory shows promise for upscaling to the field. The theory shows that a single angle cannot be used to characterize the geometry of freshly deposited flow, and that the overall angle is scale dependant. This at least partially explains the discrepancy noticed between laboratory flume tests and field scale thickened tailings flows.

It is observed that the best fit yield stresses agree with rheometry results when a Bingham model is fit to data on a flow curve measured at low shear rates. This is a problem since these points are often discarded due to large measurement errors that occur at lower shear stresses. However, an alternative method to obtain the yield stress pertinent to deposition modelling is to fit flume tests using the theory outlined in the paper.

\section{ACKNOWLEDGEMENTS}

This research was primarily funded by the Ontario Centre of Excellence and Golder Associates. Barrick Gold provided the tailings, and the field profile from Bulyanhulu was obtained by undergraduate student Akber Pabani, who was employed by Barrick as a summer student, under the supervision of Bulyanhulu personnel. Golder Paste Tec provided technical support. We thank Professor John Goldak for an initial review of this paper.

HENRIQUEZ, J.A. 2008. DYNAMIC IMAGING AND MODELLING OF GOLD PASTE TAILINGS FLOWS 


\section{REFERENCES}

Balmforth,N.J., Craster, R.V., and Sassi, R. 2002. Shallow viscoplastic flow on an inclined plane. Journal of Fluid Mechanics, 470, 1-29.

Cincilla, W.A., Landriault, D.A., Verburg, R. 1997. Application of paste technology to surface disposal of mineral wastes. Proceedings of the Fourth International Conference on Tailings and Mine Waste '97, 343-356.

Clayton, S.; Grice, T.G.; Boger, D.V. 2003. Analysis of the slump test for on-site yield stress measurement of mineral suspensions. International Journal of Mineral Processing, 70(1-4), 3-21.

Coussot, P. and Proust, S. 1996. Slow, unconfined spreading of a mudflow. Journal of Geophysics Research, 101, 25217-25229.

Crowder, J.J. 2004. Deposition, consolidation, and strength of a non-plastic tailings paste for surface disposal. Ph.D. Thesis, Department of Civil Engineering, University of Toronto, Toronto, Ontario

DIN (Deutsches Institut für Normung) 53019-2. Viskosimetrie - Messung von Viskositäten und Fließkurven mit Rotationsviskosimetern - Teil 2: Viskosimeterkalibrierung und Ermittlung der Messunsicherheit. Beuth Verlag GmbH, Berlin, 2001.

Engman, M. ,Sellgren, A.,Sundquist, A., Wennberg, T. and Goldkuhl, I. 2004. Users perspectives on the design of high density base metal tailings handling systems. Proceedings of the eleventh tailings and mine waste conference, 10-13 October 2004, Vail, Colorado, USA, 45-54. 
Fitton, T.G., Bhattacharya, S.N. and Chryss, A.G. Three-dimensional modeling of tailings beach shape. Computer-aided Civil and Infrastructure engineering, 23, 31-44.

Gawu, S.K.Y. and Fourie, A.B. 2004. Assessment of the Modified Slump Tests as a Measure of the Yield Stress of High-Density Thickened Tailings. Canadian Geotechnical Journal, 41, 39 - 46.

Houman, J., Paterson, A.J.C., and van Sittert, F. 2007. Quantifying the effect of pump shear on slurry rheology. Proceedings of the tenth international seminar on paste and thickened tailings, Perth, Australia, March $13^{\text {th }}-15^{\text {th }} 2007,163-174$.

Hulme, G. 1974. The interpretation of lava flow morphology. Goephysics Journal of the Royal Astronomical Society, 39, 361-383.

Kwak, M. James, D. F., and Klein, K. A. 2005. Flow Behaviour of Tailings Paste Disposal. International Journal of Mineral Processing, 77(3), 139 - 153.

Liu, K.F., and Mei C.C. 1989. Slow spreading of a sheet of Bingham fluid on an inclined plane. Journal of fluid mechanics, 207, 505-529.

Nguyen, Q.D., and Boger, D.V. 1998. Application of rheology to solving tailings disposal problems. International Journal of Mineral Processing, 54 (3-4), 217-233.

Oxenford, J. and Lord, E.R. 2006. Canadian Experience in the Application of Paste and Thickened Tailings for Surface Disposal. Proceedings of the ninth international seminar on paste and thickened tailings, Limerick, Ireland, 3-7 April 2006, 93 - 105.

Pashias, N., Boger, D.V., Summers, J., and Glenister, D.J. 1996. A fifty cent rheometer for yield stress measurements. Journal of Rheology, 40(6), 1179-1189. 
Pirouz, B. and Williams, M.P.A. 2007. Prediction of Non-Segregating Thickened Tailings Beach Slopes - A New Method. Proceedings of the tenth international seminar on paste and thickened tailings, Perth, Australia, March $13^{\text {th }}-15^{\text {th }} 2007,315-$ 327.

Pullum, L., Graham. L, Rudman, M., Hamilton, R. 2006. High concentration suspension pumping. Minerals Engineering, 19, 471-477.

Shuttleworth, J.A.. Thomson, B.J., and Wates, J.A. 2005. Surface disposal at Bulyanhulu- practical lessons learned. $6^{\text {th }}$ International Conference on Paste and Thickened tailings, Santiago, Chile, April $20^{\text {th }}-22^{\text {nd }}$.

Simms P., Grabinsky M.W., and Zhan, G. 2007. Modelling evaporation of paste tailings from the Bulyanhulu mine. Canadian Geotechnical Journal, 44, 1417-1432.

Simms, P. 2007. On the Relation between Laboratory Flume Tests and Deposition Angles of High Density Tailings. Proceedings of the tenth international seminar on paste and thickened tailings, Perth, Australia, March $13^{\text {th }}-15^{\text {th }}, 329-335$.

Sofra, F. and Boger, D.V. 2002. Environmental rheology for waste minimisation in the minerals industry. Chemical Engineering Journal,86(3), 319-330.

Theriault, J., Frostiak, J., and Welch, D. 2003. Surface disposal of paste tailings at the Bulyanhulu gold mine, Tanzania. In Proceedings of Sudbury 2003, Mining and the Environment, Sudbury, Ontario, Canada, May $26^{\text {th }}-28^{\text {th }} 2003$. Editors G. Spiers, P. Beckett, H. Conroy, 265-269.

Yuhi, M. and Mei C.C. 2004. Slow spreading of fluid mud over a conical surface. Journal of Fluid Mechanics, 519, 337-358. 


\section{VISUALIZATION OF THE}

\section{FLOW TESTS (ENCLOSED DVD)}

